\title{
Baseline household survey: Upper Dir district
}

Pakistan Initiative for Mothers and Newborns (PAIMAN)

Follow this and additional works at: https://knowledgecommons.popcouncil.org/departments_sbsr-rh

Part of the Family, Life Course, and Society Commons, and the Maternal and Child Health Commons How does access to this work benefit you? Let us know!

\section{Recommended Citation}

Pakistan Initiative for Mothers and Newborns (PAIMAN). 2006. "Baseline household survey: Upper Dir district." Islamabad: Population Council. 


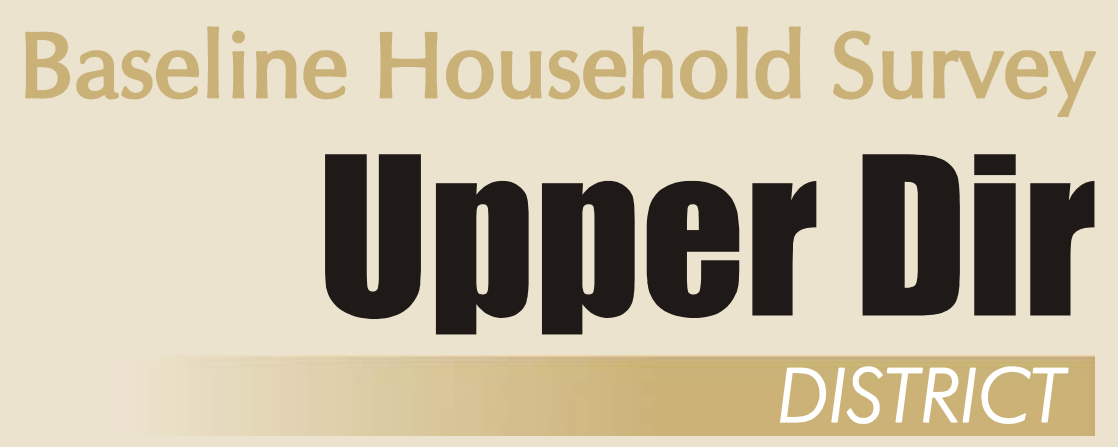





\section{Pakistan Initiative for Mothers and Newborns (PAIMAN)}

\section{Upper Dir Baseline Household Survey}




\section{(1) Population Council}

The Population Council, an international, non-profit, non-governmental organization established in 1952, seeks to improve the well-being and reproductive health of current and future generations around the world and to help achieve a humane, equitable, and sustainable balance between people and resources.

The Council analyzes population issues and trends; conducts research in the reproductive sciences; develops new contraceptives; works with public and private agencies to improve the quality and outreach of family planning and reproductive health services; helps governments design and implement effective population policies; communicates the results of research in the population field to diverse audiences; and helps strengthen professional resources in developing countries through collaborative research and programs, technical exchanges, awards, and fellowships.

\section{For inquiries, please contact:}

Population Council

\#7, Street 62, F-6/3, Islamabad, Pakistan

Tel: 92512277439

Fax: 92512821401

Email: info@pcpak.org

web: http://www.popcouncil.org

Layout \& Design : Ali Ammad

Printed by: Crystal Printers, Islamabad

Disclaimer:

"This study/report is made possible by the generous support of the American people through the United States Agency for International Development (USAID). The contents are the responsibility of JSI Research \& Training Institute, Inc. and do not necessarily reflect the views of USAID or the United States Government." 


\section{Contents}

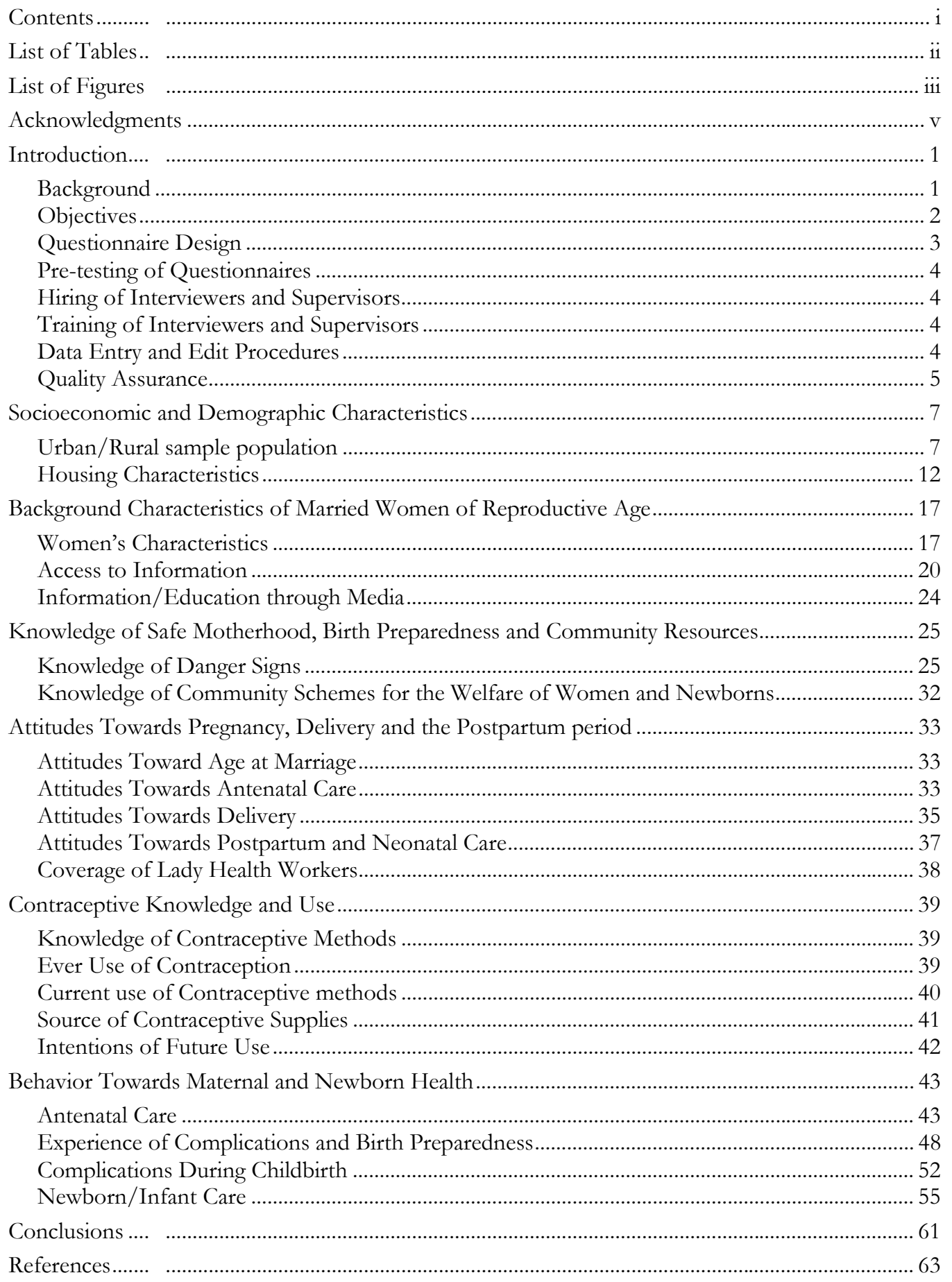




\section{List of Tables}

Table 1.1: Number of Blocks/Villages and Households selected for the sample population...... 2

Table 2.1:

Household results ............................................................................................. 7

Table 2.2:

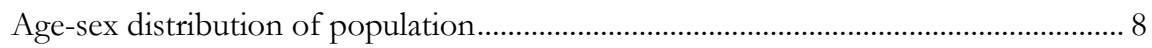

Table 2.3: $\quad$ Household population by age (15 years and above), sex and marital status ............... 9

Table 2.4: Household population by age (10 years and above), sex and educational level ........ 11

Table 2.5: $\quad$ Main source of drinking water ........................................................................................... 12

Table 2.6: $\quad$ Type of toilet facility used by household members...................................................... 13

Table 2.7: Ownership of household commodities/land ............................................................... 15

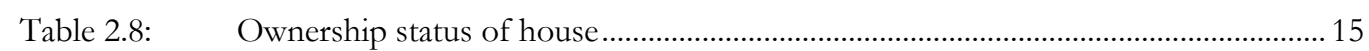

Table 3.1: $\quad$ Percentage distribution of women by age at marriage ................................................ 18

Table 3.2: $\quad$ Education level and literacy of married women and their husbands .......................... 19

Table 3.3: $\quad$ Percentage distribution of married women by number of children ever born, mean number of children ever born, living children and age group, compared to the 1998 Population census........................................................................................... 20

Table 3.4: $\quad$ Percentage distribution of married women by length of preceding birth interval... 20

Table 4.1: Knowledge of existence and importance of transport, blood and finances by the community at the time of delivery ................................................................................ 32

Table 5.1: Respondents who believe that women should receive delivery services from health professional/ percentage of respondents who believe women in their community obtain delivery services from SBAs.......................................................... 36

Table 7.1: $\quad$ Type of complications experienced during the last delivery …................................... 52

Table 7.2: $\quad$ Person who made decision to seek health care/mode of transport used to reach

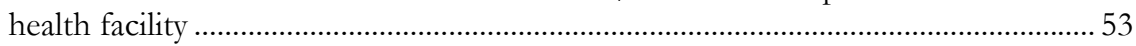

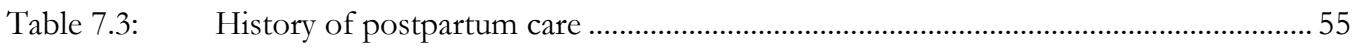

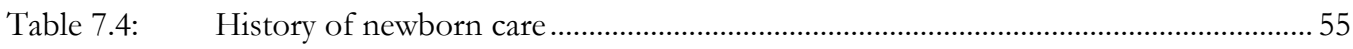




\section{List of Figures}

Figure 2.1: $\quad$ Percentage of males and females (10 years or more) by educational level................ 10

Figure 2.2: $\quad$ Proportion of males and females (10 years + ) who have ever been to school by

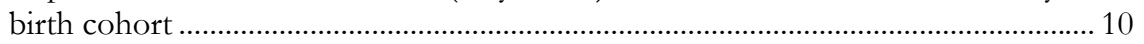

Figure 2.3: $\quad$ Main type of fuel used in the households for cooking ............................................... 13

Figure 2.4: $\quad$ Material used for construction of roof.......................................................................... 14

Figure 3.1: $\quad$ Percentage distribution of women by age group ...................................................... 17

Figure 3.2: $\quad$ Percentage of women who watch TV or listen to the radio by place of residence... 21

Figure 3.3: Influence of TV programs on health behaviors of people.......................................... 22

Figure 3.4: Influence of radio on health behaviors of people ...................................................... 22

Figure 3.5: Frequency of reading newspaper .......................................................................... 23

Figure 3.6: $\quad$ Access to mass media (radio, TV or newspaper) .......................................................... 23

Figure 3.7: Percentage of married women who had heard/read about maternal and newborn messages during the last 3 months ............................................................................ 24

Figure 4.1: Knowledge of danger signs during pregnancy, which require medical attention...... 25

Figure 4.2: Percentage distribution of women by knowledge of the number of danger signs of

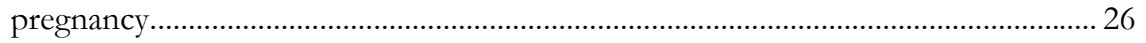

Figure 4.3: Distribution of respondents who had knowledge about complications during

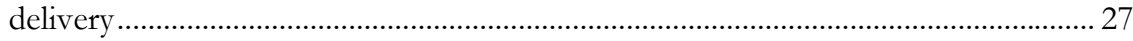

Figure 4.4: Percentage distribution of women by knowledge of number of danger signs of

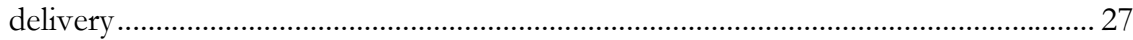

Figure 4.5: Percentage of married women who had knowledge about complications during

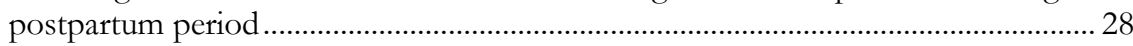

Figure 4.6: Percentage distribution of women by number of known danger signs of

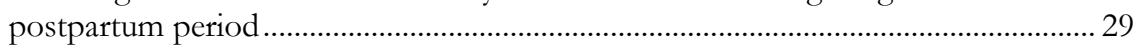

Figure 4.7: Percentage distribution of respondents who had knowledge about danger signs in

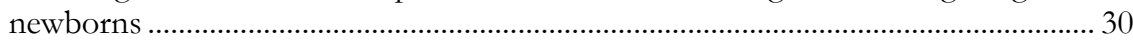

Figure 4.8: Percentage distribution of women by knowledge of number of danger signs

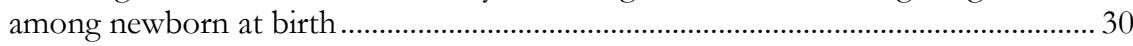

Figure 4.9: $\quad$ Source of information of danger signs during pregnancy ........................................ 31

Figure 5.1: Believe in necessity of antenatal check-ups/month of pregnancy when women

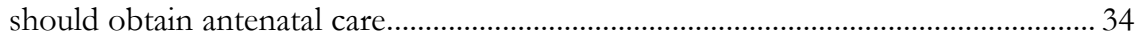

Figure 5.2: $\quad$ Month of pregnancy when antenatal care should be obtained .................................. 34

Figure 5.3: $\quad$ Place considered suitable for antenatal checkups ........................................................... 35

Figure 5.4: $\quad$ Percentage of married women who thought it necessary to receive TT shots and take iron/folate tablets during pregnancy ................................................................... 35

Figure 5.5:......Person who should make decisions regarding the health of a pregnant women ...... 37

Figure 5.6: Percentage of married women by mode of transport they would use to reach a

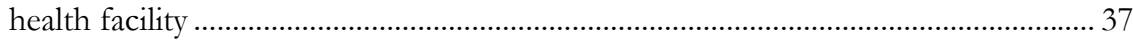

Figure 5.7: Belief in necessity of postnatal care by place of residence ......................................... 38

Figure 5.8: Presence of lady health worker in the community by place of residence................... 38

Figure 6.1: Percentage of married women by knowledge of specific contraceptive method...... 40

Figure 6.2: $\quad$ Ever/current use of family planning method by contraceptive ................................ 40

Figure 6.3: Distribution of current users of modern methods by source of supply.................... 41 
Figure 6.4: $\quad$ Percentage of married women by future intention to use contraceptives................. 42

Figure 7.1: Number of antenatal check-ups obtained ................................................................. 44

Figure 7.2: Gestational age at first antenatal check-up.............................................................. 44

Figure 7.3: $\quad$ Place from which antenatal care was obtained ............................................................. 45

Figure 7.4: Services performed/questions asked during antenatal check-up ............................ 45

Figure 7.5: $\quad$ Percentage of pregnant women by issues discussed during antenatal check-up ....... 46

Figure 7.6: $\quad$ Percentage of married women by status of 'TT injections received during the last

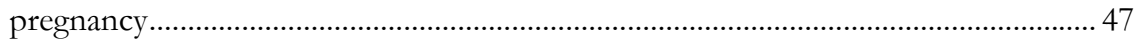

Figure 7.7: Place where TT shots were received ......................................................................... 47

Figure 7.8: Percentage of married women by status of iron/folate tablets taken during the last

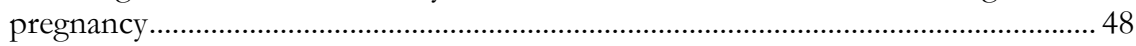

Figure 7.9: $\quad$ Percentage of married women who experienced complications during their last

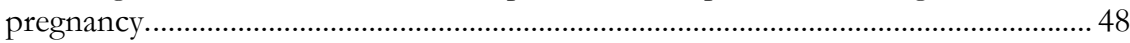

Figure 7.10: Percentage of married women who made arrangements for their last delivery ........ 49

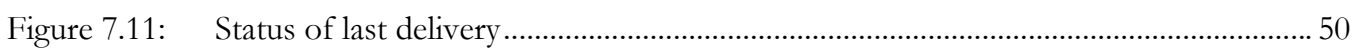

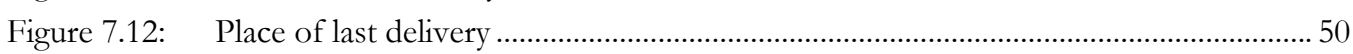

Figure 7.13: Distribution of births by type of attendant ................................................................. 51

Figure 7.14: Main reason for using a TBA/dai to assist with the last delivery.............................. 51

Figure 7.15: Percentage of delivery attendants who reportedly washed their hands before conducting the delivery/ type of thread used to tied the cord................................... 52

Figure: 7.16: Time taken to reach the health facility for childbirth................................................... 54

Figure 7.17: Average median time in minutes to get the transport, to reach the health facility and to obtain the treatment after reaching the facility................................................. 54

Figure 7.18: Percentage of newborns according to their size (small, normal and big) at birth ..... 56

Figure 7.19: Duration between the time of birth and the first bath given to a newborn...............56

Figure 7.20: Newborn feeding and health indicators..................................................................... 57

Figure 7.21: Percentage of newborns with danger signs/symptoms soon after deliver ................ 58

Figure 7.22: Percentage of newborns with danger signs within 7-days after delivery ................... 58

Figure 7.23: Place where treatment was sought for newborn complications ................................ 59

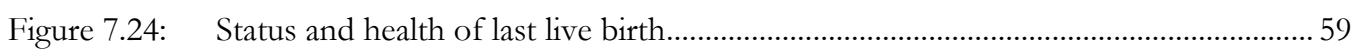




\section{Acknowledgments}

The PAIMAN Baseline Household Survey is a collaborative effort involving many partners, and will be the foundation of the PAIMAN project as a whole. Firstly, we would like to acknowledge our major partners. The United States Agency for International Development (USAID), in particular Mr. Chris McDermott, made funding available for this activity. Dr. Nabeela Ali, Chief of Party for PAIMAN, encouraged the study in general, and greatly facilitated the partnership between the Population Council and NIPS. The role of NIPS was supported under a separate agreement with PAIMAN. The comments, suggestions and feedback received from PAIMAN partners with regard to the design of this activity greatly contributed towards the success of the household survey.

The National Institute of Population Studies (NIPS)ably carried out the fieldwork for this study and were responsible for the completion of a clean dataset. We would like to appreciate the efforts of the Executive Director, Dr. Shafqat Saeed; and the Director Mr. Mahboob Sultan for the execution of the fieldwork; Computer Programmer, Mr. Fateh-ud-din, who managed the entry and cleaning of the data and the numerous NIPS staff members who carried out the study.

The Population Council was primarily responsible for designing the study, overseeing the data collection, analysis of data, and writing the reports. Dr. Arshad Mahmood, Director of Monitoring and Evaluation for PAIMAN, used his capable technical and managerial skills to oversee the entire study with enthusiasm and energy. Mr. Peter Miller, Deputy Country Director, contributed substantially in the design phase, and Dr. Zeba Sathar and Mr. Miller contributed towards the report preparation.

The essential work of the study was carried out by several Council staff members at all phases. During the design and pre-testing phases, we would particularly like to acknowledge Shagufta Naheed, Bushra Bano, Irfan Masood, Tayyaba Gul, and Saima Pervaiz for monitoring field work and ensuring quality data collection in the field. Saman Naz and Muhammad Ashraf assisted in preparing graphs and tables as well as with the writing process. Dr. Arshad Mahmood and Reem Khan jointly prepared the first draft of the baseline survey report, which served as the template for all ten district reports. Shafique Arif, Azeema Faizunisa and Nadia Abid also contributed to the report writing and reviewing process. Reem Khan completed the initial editing, Mehdi Ali Khan designed their layout, Ali Ammad formatted and Ms. Mary DeSouza proof read the district reports.

Finally, we must express our gratitude to the women of Upper Dir, who gave their time freely and cooperated with us in order to make this study possible. We hope to repay them by using the information obtained from them to improve maternal and neonatal health services in the district of Upper Dir. 



\section{Chapter}

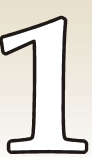

\section{Introduction}

\section{Background}

The Pakistan Initiative for Mothers and Newborns (PAIMAN) is a five-year project funded by the United States Agency for International Development (USAID). PAIMAN is committed to assisting the Government of Pakistan (GoP) in the implementation of the full spectrum of interventions necessary to address maternal and neonatal health $(\mathrm{MNH})$.

The consortium is led by John Snow Incorporated (JSI) with partners from Pakistani and international organizations including Aga Khan University, Contech, Greenstar Social Marketing, John Hopkins University Center for Communication Program (JHU), PAVHNA, Population Council and Save the Children USA.

USAID has provided a grant to implement PAIMAN in 10 districts of Pakistan's four provinces. These districts are: Upper Dir, Jhelum, Khanewal, and DG Khan in Punjab; Dadu and Sukkur in Sindh; Jafarabad and Lasbela in Balochistan; and Upper Dir and Bunner in North West Frontier Province. The goal of the project is to reduce maternal, newborn and child mortality in Pakistan. The project is based on the "Pathway to Care and Survival" framework. The five major strategic objectives are to:

1) Increase awareness and promote positive maternal and neonatal health behaviors

2) Increase access (including essential obstetric care) to and community involvement in maternal and child health services, while ensuring that services are successfully delivered through health and ancillary health services

3) Improve service quality in both the public and private sectors, particularly related to management of obstetrical complications

4) Increase the capacity of MNH managers and care providers

5) Improve the management and integration of services at all levels

The PAIMAN Project will promote skilled attendance as the long-term goal for all deliveries in Pakistan, while acknowledging that maternal and neonatal health outcomes are influenced by factors other than health care. The PAIMAN Project calls for a multi-pronged and integrated strategic approach, combining individual health care with public health and community-based interventions. 
To ensure that the success of PAIMAN is properly ascertained and that the appropriate lessons are learned, PAIMAN has developed a Monitoring and Evaluation Plan. Included in this plan is the establishment of baseline measures for a set of indicators which will be used to evaluate the success of the project. This baseline report explores the level of knowledge of, as well as the attitudes and behaviors towards, maternal and newborn health in Upper Dir district. The specific objectives of the baseline survey were as follows.

\section{Objectives}

- To measure the Intermediate Result 7 indicators necessary as part of PAIMAN's obligation to USAID.

- To measure PAIMAN indicators for which household survey data are appropriate for measurement, and for which sample sizes are feasible.

- To obtain information on maternal and neonatal health, along with related issues, which may be of use to district Departments of Health for health management purposes.

- To obtain information needed for the detailed design of the PAIMAN project, in particular behavior change communication, public/private partnerships, and health systems strengthening.

\section{Methodology}

\section{Study Population}

PAIMAN is primarily a district-level project, intended to improve the health of all pregnant and neonatal women, as well as all neonates of the district over the course of the project. To this end, the study covers community residents - notably mothers and prospective mothers - in order to understand and measure general knowledge and practice of issues in relation to pregnancy, delivery, obstetric and neonatal emergencies etc.

Hence, the study population for the baseline survey includes all married women of reproductive age (15-49 years) living in the selected districts. More specifically, it includes women who have experienced a pregnancy during the last three years.

\section{Sample Design}

The sampling design adopted for the survey is a stratified, systematic sample of households. The universe consists of all urban and rural areas of the district. The number of primary sampling units (PSUs) selected from urban and rural areas of Upper Dir is presented in table 1.1. The selection procedure is described below:

Table 1.1: Number of Blocks/Villages and Households selected for the sample population

\begin{tabular}{lrrr} 
& Area & $\begin{array}{c}\text { Number of Sample } \\
\text { Blocks/Villages }\end{array}$ & \multicolumn{2}{c}{$\begin{array}{c}\text { Number of Households } \\
\text { Selected }\end{array}$} \\
\hline Urban & & 2 & 48 \\
\hline Rural & 38 & 912 \\
Total & 40 & 960
\end{tabular}




\section{Urban Sample}

The "Enumeration Circle" was the smallest unit available in the 1998 Population District Census Reports as demarcated by the Population Census organizations. The maps of these circles were obtained from the Population Census Organization. The circles were already divided into blocks of approximately 250-300 households depending upon the number of households in each circle. The required numbers of enumeration blocks were selected with probability proportional to size (number of circles). Later, blocks were randomly selected with probability proportional to size from the list of total blocks in that circle. The listing of each block was then updated by the enumeration teams before selecting the sampled households. A fixed number of 24 households has been drawn from each sample enumeration block by using systematic random technique.

\section{Rural Sample}

The 1998 Population Census list of villages was used as the sampling frame for the selection of the rural sample. Villages in rural areas have been treated as primary sampling units (PSUs). Sample PSUs have been selected with probability proportional to size (number of households). Households within the sample PSUs have been considered as secondary sampling units (SSUs). The enumeration teams then updated the listing of each village before selection of households. A fixed number of 24 households has been drawn from each sample PSU by using the systematic random sampling technique.

\section{Questionnaire Design}

Three questionnaires have been developed by the Population Council, based on a combination of current general Demographic and Health Survey methodologies and the questionnaire developed by the Population Council for the Safe Motherhood Applied Research and Training (SMART) Project. The questionnaires contain data sufficient to estimate all PAIMAN indicators, which were collected by the household survey.

\section{Information on the following is included in the questionnaires:}

- Households Information

- Socio-economic status of women

- Fertility, pregnancy history and reproductive intentions

- Attitude towards, as well as knowledge and practice of contraceptive methods

- Attitude towards pregnancy, delivery and the postpartum period

- Current Birth Preparedness/Complications Readiness (BP/CR) and knowledge of newborn care

- Current birth practices

- Health seeking behaviors

- $\quad$ Future BP/CR intentions

- Personal beliefs regarding pregnancy, delivery and the postpartum period

- Common perceptions pertaining to women who are pregnant, delivering or in their postpartum period 
- Facilities regarding $\mathrm{BP} / \mathrm{CR}$ available in the community

- Factors that facilitate or hinder $\mathrm{BP} / \mathrm{CR}$

- Media habits

\section{Pre-testing of Questionnaires}

The questionnaires were reviewed by the PAIMAN's M\&E thematic group and other interested stakeholders, and were pre-tested in non-PAIMAN districts. The main objective of the pre-testing was to examine the suitability and effectiveness of questions in eliciting adequate responses, and to find out if there were any linguistic problems faced either by interviewers or by respondents.

Finally, the pre-testing also helped determine the approximate time required to complete a questionnaire. The pre-tests were carried out by the Population Council's female staff members, who recorded their experiences with regard to each question. These records were then used to revise and finalize the questionnaire.

\section{Hiring of Interviewers and Supervisors}

Since the respondents in the baseline household survey were to be married women of reproductive age (MWRA) and married men, it was decided that female interviewers would be used to interview women and male interviewers for male respondents. Based on the constitution of each team, the required number of Pushto speaking female interviewers were hired by the National Institute of Population Studies (NIPS) according to its own internal procedures.

\section{Training of Interviewers and Supervisors}

The quality of training received by interviewers is reflected in the quality of data they record. In order to ensure that the training provided for interviewers was of a high and uniform quality, and that interviewers understood the definitions and concepts behind the language of the questions, training was conducted by the Population Council in collaboration with NIPS. The training took place in Islamabad over a two week period, and interviewers were trained regarding survey procedures. During the training, interviewers visited 3-4 households to conduct practice interviews in order to prepare for the actual interview process.

It was very important for the interviewers to thoroughly understand the methodology and statistical importance of the sampled households. Training regarding the importance of the criterion for the selection of primary sampling units, mapping and listing procedure, sample selection, field operation procedures, as well as the selection of the particular households and respondents was also provided by experts.

\section{Data Entry and Edit Procedures}

Data processing was started from the field level with the checking of the questionnaires. Each team leader completed on-the-spot checks and preliminary editing of questionnaires during the enumeration period. Editing instructions were provided to the team leaders, and emphasis was laid on the importance of completing each questionnaire, correctly identifying each eligible respondent, and the completeness of household compositions. 


\section{Quality Assurance}

To ensure the quality of the data, Population Council staff monitored the fieldwork along with the field teams. While supervising the fieldwork, Population Council supervisory staff was also available to provide on-the-spot guidance to interviewers in the event that any part of the questionnaire was unclear to them. This ensured the completeness of each questionnaire. 



\section{Socioeconomic and Demographic Characteristics}

This chapter presents the socioeconomic and demographic characteristics of the survey population in the district of Upper Dir. Information was collected on some demographic and socioeconomic characteristics such as the condition of the households, including the source of drinking water, sanitation facilities, building materials, and possession of household durable goods. This information on the characteristics of the households is essential for the interpretation of survey findings. The definition of the household used for the baseline survey was "a person or a group of persons, related or unrelated, who live together in the same dwelling unit and share a common source of food".

\section{Urban/Rural sample population}

Table 2.1 shows the number of households selected in both urban and rural areas of Upper Dir, as well as the status upon completion of the interviews. A total sample of 960 households was selected from Upper Dir; this number included 912 households in rural Upper Dir and 48 households in urban Upper Dir. A total of six enumeration blocks/villages could not be completed due to the nonacceptance of survey teams in those villages.

Table 2.1: $\quad$ Household results

\begin{tabular}{lrrrrrr} 
& \multicolumn{2}{c}{ Rural } & \multicolumn{2}{c}{ Urban } & \multicolumn{2}{c}{ Total } \\
\cline { 2 - 7 } Result & Percent & Number & Percent & Number & Percent & Number \\
Completed & 73.1 & 667 & 100.0 & 48 & 74.5 & 715 \\
\hline Incomplete & 0.7 & 6 & & & 0.6 & 6 \\
\hline Refused & 24.4 & 223 & & & 23.2 & 223 \\
\hline Others & 1.8 & 16 & & & 1.7 & 16 \\
Total & 100.0 & 912 & 100.0 & 48 & 100.0 & 960
\end{tabular}

Table 2.1 indicates the completion rate of those interviews conducted in the blocks/villages of Upper Dir. Incomplete surveys may have been due to lack of knowledge on behalf of the respondents, or perhaps due to the fact that women were not willing or permitted to share sensitive information with interviewers. A total of 715 households (74.5 percent) in Upper Dir completed the survey, while 223 household (24.4 percent) refused to participate. Surprisingly none of the sampled household from urban area refused to participate, as all refusals came from rural Upper Dir. 


\section{Languages Spoken}

An overall picture of the ethnic and linguistic makeup of the district becomes clear by determining the languages spoken in the households. Baseline findings show that Pushto is spoken in all of the households in urban as well as rural areas of Upper Dir.

\section{Population Composition}

Table 2.2 shows the population of Upper Dir with regard to age and sex composition. Age and sex are important demographic variables, and are the primary basis of demographic analysis. They are also important variables in the study of reproductive health, mortality and fertility.

Distribution of population by age and sex in the district shows that there are more females (51 percent) than males ( 49 percent). Table 2.2 also shows almost half of the population of the district is less than 15 years of age, a trend which can be attributed to persistently high fertility rates in the recent past.

Table 2.2: $\quad$ Age-sex distribution of population

\begin{tabular}{lrrrrrr}
\multicolumn{1}{c}{ Age } & \multicolumn{2}{c}{ Males } & \multicolumn{2}{c}{ Females } & \multicolumn{2}{c}{ Both Sexes } \\
Group & Number & Percent & Number & Percent & Number & Percent \\
$<5$ & 577 & 17.5 & 546 & 15.7 & 1123 & 16.6 \\
\hline $5-9$ & 580 & 17.6 & 555 & 16.0 & 1135 & 16.8 \\
\hline $10-14$ & 519 & 15.7 & 531 & 15.3 & 1050 & 15.5 \\
\hline $15-19$ & 380 & 11.5 & 424 & 12.2 & 804 & 11.9 \\
\hline $20-24$ & 257 & 7.8 & 306 & 8.8 & 563 & 8.3 \\
\hline $25-29$ & 167 & 5.1 & 225 & 6.5 & 392 & 5.8 \\
\hline $30-34$ & 129 & 3.9 & 175 & 5.0 & 304 & 4.5 \\
\hline $35-39$ & 143 & 4.3 & 146 & 4.2 & 289 & 4.3 \\
\hline $40-44$ & 78 & 2.4 & 104 & 3.0 & 182 & 2.7 \\
\hline $45-49$ & 84 & 2.5 & 99 & 2.9 & 183 & 2.7 \\
\hline $50-54$ & 74 & 2.2 & 115 & 3.3 & 189 & 2.8 \\
\hline $55-59$ & 65 & 2.0 & 100 & 2.9 & 165 & 2.4 \\
\hline $60-64$ & 84 & 2.5 & 62 & 1.8 & 146 & 2.2 \\
\hline $65+$ & 160 & 4.9 & 83 & 2.4 & 243 & 3.6 \\
\hline Total & 3297 & 100.0 & 3471 & 100.0 & 6768 & 100.0 \\
\hline
\end{tabular}




\section{Marital Status}

This portion of the survey collected information on the marital status of all household members over 15 years of age. Table 2.3 compares the baseline household survey results with data from the 1998 Population Census. The data clearly shows that there has been a shift away from early marriages among both male and female populations in Upper Dir. Data presented in table 2.3 shows that about three quarters of the female population (15 years or older) was reported as currently married in the 1998 Population Census; however, at the time of PAIMAN household survey in the district, about 67 percent of women in the same age group were reported to be of the same status. Similarly, the percentage of males over 15 years of age who were reported as currently married at the time of the Census has dropped from 66 percent to 59 percent. Despite this decline, women still tend to get married earlier than men.

Table 2.3:

Household population by age (15 years and above), sex and marital status

\begin{tabular}{|c|c|c|c|c|c|c|}
\hline & \multicolumn{3}{|c|}{ Males } & \multicolumn{3}{|c|}{ Females } \\
\hline Age & Never & Currently & Widow/ & Never & Currently & Widow/ \\
\hline Group & Married & Married & Divorced & Married & Married & Divorced \\
\hline
\end{tabular}

PAIMAN Baseline 2005

\begin{tabular}{lrrrrrr}
\hline $15-19$ & 97.9 & 1.8 & 0.3 & 79.0 & 21.0 & 0 \\
\hline $20-24$ & 72.4 & 27.6 & 0 & 39.9 & 60.1 & 0 \\
\hline $25-29$ & 27.5 & 72.5 & 0 & 10.7 & 89.3 & 0 \\
\hline $30-34$ & 10.1 & 89.1 & 0.8 & 5.1 & 94.3 & 0.6 \\
\hline $35-39$ & 4.2 & 94.4 & 1.4 & 4.1 & 94.5 & 1.4 \\
\hline $40-44$ & 1.3 & 97.4 & 1.3 & 2.9 & 95.2 & 1.9 \\
\hline $45-49$ & 0 & 96.4 & 3.6 & 0 & 94.9 & 5.1 \\
\hline $50-54$ & 0 & 97.3 & 2.7 & 0 & 87 & 13 \\
\hline $55-59$ & 0 & 95.4 & 4.6 & 0 & 81 & 19 \\
\hline $60-64$ & 0 & 91.7 & 8.3 & 0 & 66.1 & 33.9 \\
\hline 65 and older & 1.3 & 91.9 & 6.9 & 3.6 & 54.2 & 42.2 \\
Total & 38.6 & 59.4 & 1.9 & 27.3 & 67.3 & 5.4
\end{tabular}

Population census 1998

\begin{tabular}{lrrrrrr}
\hline $15-19$ & 92.5 & 7.3 & 0.1 & 68.6 & 31.1 & 0.3 \\
\hline $20-24$ & 57.4 & 42.5 & 0.1 & 18.8 & 80.8 & 0.4 \\
\hline $25-29$ & 21.6 & 78.0 & 0.4 & 6.5 & 92.6 & 0.9 \\
\hline $30-34$ & 8.3 & 91.3 & 0.4 & 4.6 & 93.7 & 1.7 \\
\hline $35-39$ & 4.4 & 95.1 & 0.6 & 2.7 & 94.2 & 3.1 \\
\hline $40-44$ & 3.4 & 95.7 & 0.9 & 2.1 & 92.7 & 5.2 \\
\hline $45-49$ & 1.8 & 97.0 & 1.2 & 1.5 & 90.9 & 7.6 \\
\hline $50-54$ & 2.2 & 96.1 & 1.7 & 2.0 & 84.6 & 13.4 \\
\hline $55-59$ & 1.7 & 95.7 & 2.5 & 2.2 & 82.2 & 15.7 \\
\hline $60-64$ & 2.5 & 92.5 & 5.0 & 4.3 & 65.2 & 30.5 \\
\hline 65 and older & 3.6 & 85.3 & 11.1 & 5.8 & 51.0 & 43.1 \\
Total & 32.7 & 65.9 & 1.4 & 18.3 & 75.7 & 6.1
\end{tabular}




\section{Education Attainment}

Overall in Upper Dir, 30 percent of the male population (10 years and above) and 69 percent of the female population has never been to school (figure 2.1). About 30 percent of the male population studied up to primary level, while another 31 percent completed six to ten years of schooling. Onefifth of the females interviewed studied up to primary level and less than 10 percent have six to ten years of schooling.

Figure 2.1: $\quad$ Percentage of males and females (10 years or more) by educational level

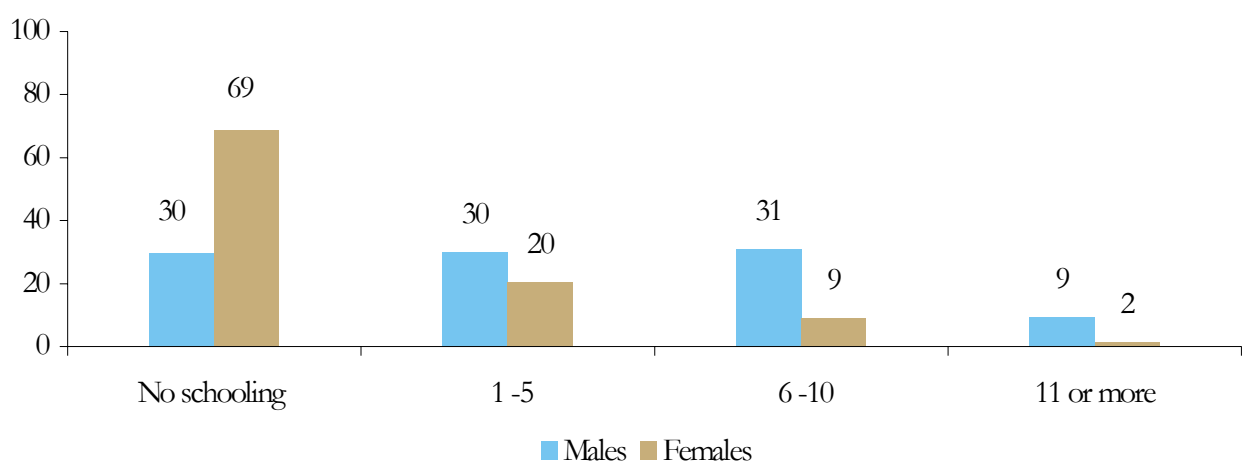

Data presented in figure 2.2 presents information on the proportion of males and females who have ever been to school by birth cohort. According to the data, the enrollment of the male population increases with age. Enrollment increased gradually from 17 percent among males born in the 1940s or earlier, to 55 percent among those who born in early 1960s. There was a sharp increase in school enrollment among males who were born between 1966 and 1970.

The situation was different for the female population of Upper Dir. According to the data, women born prior to 1965 received very little to no education. However, a sharp increase is noted in enrollment for women born between 1971 and 19 75, which continued to increase with each age cohort. Due to this rapid rise in women's education, the gap between enrollment rates of males and females has narrowed.

Figure 2.2: $\quad$ Proportion of males and females (10 years + ) who have ever been to school by birth cohort

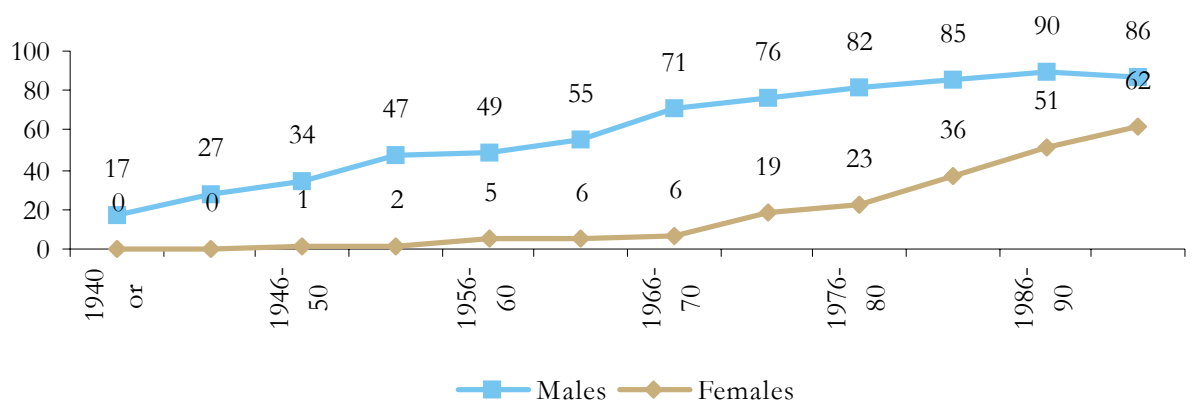


Comparison of trends in school enrollment among male and female populations shows that during the last 30 years, there has been a tremendous increase in the school enrollment of women in Upper Dir, increasing from 6 percent to 62 percent. Enrollment among the male population has increased from 71 percent to 86 percent.

Table 2.4: $\quad$ Household population by age (10 years and above), sex and educational level

\begin{tabular}{|c|c|c|c|c|c|}
\hline $\begin{array}{l}\text { Age } \\
\text { Group }\end{array}$ & $\begin{array}{c}\text { No } \\
\text { Schooling }\end{array}$ & $\begin{array}{c}1-5 \\
\text { Years }\end{array}$ & $\begin{array}{l}6-10 \\
\text { Years }\end{array}$ & $\begin{array}{c}11 \text { and } \\
\text { More years }\end{array}$ & Total \\
\hline \multicolumn{6}{|l|}{ Males } \\
\hline $10-14$ & 20.2 & 69.4 & 10.4 & 0 & 519 \\
\hline 15-19 & 10.3 & 29.7 & 56.6 & 3.4 & 380 \\
\hline $20-24$ & 14.8 & 18.7 & 47.1 & 19.5 & 257 \\
\hline $25-29$ & 18 & 17.4 & 46.1 & 18.6 & 167 \\
\hline $30-34$ & 24 & 18.6 & 29.5 & 27.9 & 129 \\
\hline $35-39$ & 28.7 & 7.7 & 39.9 & 23.8 & 143 \\
\hline $40-44$ & 44.9 & 7.7 & 30.8 & 16.7 & 78 \\
\hline $45-49$ & 51.2 & 11.9 & 27.4 & 9.5 & 84 \\
\hline $50-54$ & 52.7 & 14.9 & 27 & 5.4 & 74 \\
\hline $55-59$ & 66.2 & 6.2 & 18.5 & 9.2 & 65 \\
\hline $60-64$ & 72.6 & 15.5 & 9.5 & 2.4 & 84 \\
\hline $65+$ & 83.1 & 8.1 & 6.3 & 2.5 & 160 \\
\hline Total & 29.8 & 30.0 & 30.8 & 9.4 & 2140 \\
\hline \multicolumn{6}{|l|}{ Females } \\
\hline $10-14$ & 42.7 & 51.8 & 5.5 & 0 & 531 \\
\hline $15-19$ & 49.1 & 26.4 & 23.6 & 0.9 & 424 \\
\hline $20-24$ & 63.7 & 16.7 & 14.1 & 5.6 & 306 \\
\hline $25-29$ & 77.3 & 4.9 & 14.2 & 3.6 & 225 \\
\hline $30-34$ & 81.1 & 11.4 & 4 & 3.4 & 175 \\
\hline $35-39$ & 93.8 & 4.1 & 1.4 & 0.7 & 146 \\
\hline $40-44$ & 94.2 & 2.9 & 2.9 & 0 & 104 \\
\hline $45-49$ & 94.9 & 4 & 0 & 1 & 99 \\
\hline $50-54$ & 98.3 & 0.9 & 0.9 & 0 & 115 \\
\hline $55-59$ & 99 & 0 & 1 & 0 & 100 \\
\hline $60-64$ & 100 & 0 & 0 & 0 & 62 \\
\hline $65+$ & 100 & 0 & 0 & 0 & 83 \\
\hline Total & 68.9 & 20.4 & 9.2 & 1.6 & 2370 \\
\hline
\end{tabular}




\section{Housing Characteristics}

\section{Source of Drinking Water}

In order to obtain a clear understanding of the living conditions of the population, it was necessary to record the source of drinking water available to respondents and their families. Once the source of drinking water is identified, a conclusion in regards to the household's socio-economic status and hygiene levels can be drawn. Information regarding the main sources of drinking water in Upper Dir is presented in table 2.5. The results show that hand pumps (38 percent) followed by springs (36 percent) are the main sources of drinking water for rural households. Only about one-fifth of the households in rural Upper Dir have access to tap water. Households in urban areas of the district cited hand pumps (42 percent), government supply (35 percent) and springs ( 23 percent) as their main sources of drinking water.

With regards to pregnancy and neonatal care, the source of drinking water can indicate the level of hygiene and comfort available to an expectant mother or a newborn child. It also determines the socio-economic status of the household and, therefore to some extent, the educational background.

Table 2.5: $\quad$ Main source of drinking water

\begin{tabular}{lrrrrrr} 
& \multicolumn{2}{c}{ Rural } & \multicolumn{3}{c}{ Urban } & \multicolumn{2}{c}{ Total } \\
\cline { 2 - 7 } & Percent & Number & Percent & Number & Percent & Number \\
\hline Govt. supply (tap water inside) & 8.1 & 54 & 10.4 & 5 & 8.3 & 59 \\
\hline Govt. supply (communal) & 13.1 & 87 & 25.0 & 12 & 13.9 & 99 \\
\hline Motorized/hand pump & 38.1 & 254 & 41.7 & 20 & 38.4 & 274 \\
\hline Spring/stream & 36.1 & 240 & 22.9 & 11 & 35.2 & 251 \\
\hline Others & 4.7 & 29 & & & 4.4 & 29 \\
\hline Total & 100.0 & 666 & 100.0 & 48 & 100.0 & 714 \\
\hline
\end{tabular}

\section{Toilet Facilities}

Along with the source of drinking water, toilet facilities are a major indicator of a household's socioeconomic status and therefore the level of hygiene, sanitation and comfort available to an expectant or new mother, and her newborn children. The type of toilet facility a household has access to directly reflects the quality of sanitation, which has a more direct affect on mortality than does socioeconomic status (Martin, et al, 1983). Households lacking hygienic toilet facilities have a higher risk of disease and infection, which in turn endangers the health of newborns and their mothers.

Table 2.6 indicates that in rural Upper Dir, slightly more than a quarter of the households have access to a flush connected to the sewerage system or a septic tank; while in urban areas, 42 percent have access to this type of toilet facility. About 29 percent of rural households and 33 percent of urban household use pit latrines. However, 29 percent of rural households do not have access to any toilet facility and use open fields. 
Table 2.6:

Type of toilet facility used by household members

\begin{tabular}{lrrrrrrr}
\multirow{2}{*}{ Toilet facility } & \multicolumn{2}{c}{ Rural } & \multicolumn{2}{c}{ Urban } & \multicolumn{2}{c}{ Total } \\
\cline { 2 - 7 } & Percent & Number & Percent & Number & Percent & Number \\
Flush to sewerage & 6 & 40 & 16.7 & 8 & 6.7 & 48 \\
\hline Flush connected to septic tank & 20.7 & 138 & 25 & 12 & 21 & 150 \\
\hline Flush connected to open drain & 1.9 & 13 & 14.6 & 7 & 2.8 & 20 \\
\hline Raised latrine & 3.3 & 22 & 2.1 & 1 & 3.2 & 23 \\
\hline Pit latrine & 28.9 & 193 & 33.3 & 16 & 29.2 & 209 \\
\hline In fields & 28.9 & 193 & 4.2 & 2 & 27.3 & 195 \\
\hline Others & 10.2 & 68 & 4.2 & 2 & 9.8 & 70 \\
\hline Total & 100 & 667 & 100 & 48 & 100 & 715
\end{tabular}

\section{Fuel Used for Cooking}

A question regarding the type of fuel being used in household kitchens was also asked in the baseline survey. There are substantial urban-rural differentials indicated by type of cooking fuel. Figure 2.3 illustrates that in rural areas, 91 percent of the households use firewood, while about 8 percent use gas cylinders for cooking. In urban areas, two-thirds of the households surveyed use firewood while onethird use gas cylinders for cooking.

Figure 2.3: $\quad$ Main type of fuel used in the households for cooking

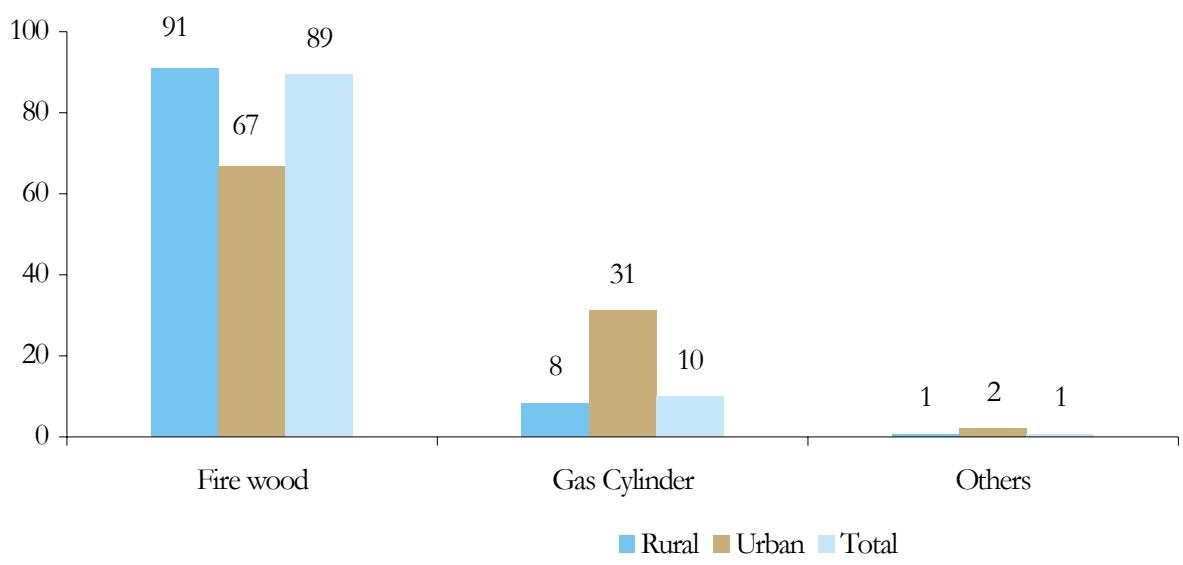

\section{Materials used for the Roof}

The materials used for the roof and walls of a household are major indicators of the socio-economic status of that household, as well as the living standards of the people residing there. The more secure the materials, the higher the level of comfort and living standard for residents, and the lower the risk of disease and infection.

According to figure 2.4, three-quarters of the households in urban areas and 84 percent in rural area have roofs made of wood and mud. Only six percent of rural households and 17 percent of urban households have roofs made of concrete. The results suggest that households in Upper Dir, regardless 
of their locality, experience not only a higher level of poverty, but also low hygiene, sanitation and living standards, when compared to other areas in Pakistan, thus making it an unsuitable environment for expectant and new mothers and newborn children alike.

Figure 2.4: $\quad$ Material used for construction of roof

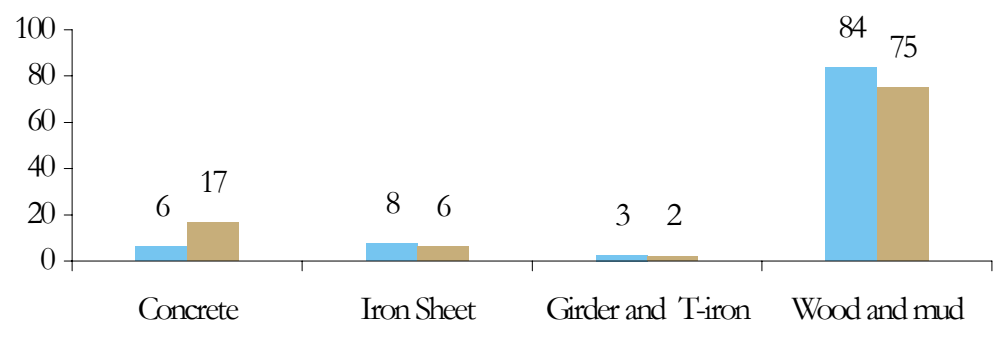

Rural $\square$ Urban

\section{Number of Rooms}

The number of separate rooms available for sleeping in each household is an important indicator of sanitation and hygiene levels. Overcrowding in households may lead to the spread of infections and diseases, which puts the lives of expectant/young mothers and their newborn children at risk. The results show that the mean number of rooms available for sleeping in both urban and rural areas in Upper Dir are approximately the same (2.7 rooms); however, the number of people in each household (household size) may differ greatly in urban and rural areas. On average, more than 4 people share one room in rural areas, whereas an average of 3.7 persons share one room in urban areas. This suggests that living conditions in rural areas are poorer than in urban areas.

\section{Household possessions}

Household possessions are perhaps one of the most effective ways of determining the socioeconomic level of a household. Often, it is easier to obtain information in regards to household possessions than to ask for details about the household income, which respondents may be less willing to provide for various reasons.

The list of household possessions in table 2.7 is setting-specific and will therefore be quite accurate in determining the socio-economic status of the households. The presence of durable goods in the household, such as a radio, television, telephone, refrigerator, motorcycle, and private car is another indicator of the household's socioeconomic status. Moreover, particular goods have specific benefits, for example, ownership of a radio or television is a measure of access to mass media and exposure to innovative ideas; telephone ownership measures access to an efficient means of communication; refrigerator ownership means the life of wholesome food is prolonged and ownership of private transport allows greater access to many services away from the local area.

While many urban and rural households own more common household possessions such as electric fans, irons and clocks etc., table 2.7 suggests that the possession of items such as electric goods (fans, irons etc), televisions, refrigerators, air conditioners, computers etc. is substantially higher in the urban areas compared to rural areas of Upper Dir. This may suggest that the urban population in Upper Dir has more spending power, a higher socio-economic status and a higher standard of living overall, which may have a positive effect on infant and maternal mortality. 
Table 2.7 also reveals that more than two-thirds the rural households own agricultural land, compared to about one-fourth of the urban households. According to the findings of the survey, agriculture is the main source of livelihood for 12 percent of the rural households in Upper Dir

Table 2.7: $\quad$ Ownership of household commodities/land

\begin{tabular}{lrrrr}
\multicolumn{1}{c}{ Household items } & Rural & Urban & \multicolumn{2}{c}{ Total } \\
& & & Percent & Number \\
Electric iron & 64.3 & 97.9 & 66.6 & 476 \\
\hline Electric fan & 60.0 & 89.6 & 62.0 & 443 \\
\hline Sewing machine & 55.8 & 75.0 & 57.1 & 408 \\
\hline Radio or cassette player & 57.4 & 60.4 & 57.6 & 412 \\
\hline Chair/table & 54.1 & 64.6 & 54.8 & 392 \\
\hline Television & 15.4 & 54.2 & 18.0 & 129 \\
\hline Telephone & 37.0 & 58.3 & 38.5 & 275 \\
\hline Watch/clock & 75.9 & 81.3 & 76.2 & 545 \\
\hline VCR/VCP/VCD/CD Player & 4.2 & 8.3 & 4.5 & 32 \\
\hline Refrigerator/deep freezer & 17.2 & 29.2 & 18.0 & 129 \\
\hline Air cooler & 2.4 & 2.1 & 2.4 & 17 \\
\hline Air conditioner & 1.2 & 4.2 & 1.4 & 10 \\
\hline Computer & 2.4 & 14.6 & 3.2 & 23 \\
\hline Bicycle & 1.2 & 2.1 & 1.3 & 9 \\
\hline Motorcycle & 1.0 & 2.1 & 1.1 & 8 \\
\hline Car/jeep & 6.4 & 6.3 & 6.4 & 46 \\
\hline Tractor/truck & 1.8 & 2.1 & 1.8 & 13 \\
\hline HH Owned any agriculture land & 67.9 & 22.9 & 64.9 & 464 \\
\hline Agriculture major source of livelihood & 12.3 & & 11.5 & 82 \\
\hline & & & & \\
\hline
\end{tabular}

\section{Ownership of the house}

Table 2.8 reflects the ownership of each of the households surveyed. About 92 percent of the respondents in both rural as well as urban areas live in houses that they own. In urban areas, 6 percent of the respondents live in rented houses compared to 1 percent in rural areas. Also, 6 percent of the rural respondents and 2 percent of urban respondents surveyed live in rent-free accommodations.

Table 2.8: $\quad$ Ownership status of house

\begin{tabular}{lrrrrrr}
\multirow{2}{*}{ Status } & \multicolumn{2}{c}{ Rural } & \multicolumn{2}{c}{ Urban } & \multicolumn{2}{c}{ Total } \\
& Percent & \multicolumn{1}{c}{ Number } & Percent & Number & Percent & Number \\
Owner occupied & 92.2 & 615 & 91.7 & 44 & 92.2 & 659 \\
\hline Rented & 1.2 & 8 & 6.3 & 3 & 1.5 & 11 \\
\hline Rent free & 6.3 & 42 & 2.1 & 1 & 6.0 & 43 \\
\hline Others & 0.3 & 2 & & & 0.3 & 2 \\
Total & 100.0 & 667 & 100.0 & 48 & 100.0 & 715
\end{tabular}





\section{Chapter \\ 3}

\section{Background Characteristics of Married Women of Reproductive Age}

Information regarding the basic background characteristics of respondents is essential for the interpretation of survey findings. This chapter describes the basic background characteristics including age, education level, and place of residence of the respondents. It also describes detailed information on the educational status of respondents and their husbands, literacy levels, and exposure to mass media. Only currently married women aged 15-49 were interviewed for this portion of the survey.

\section{Women's Characteristics}

\section{Age Distribution of Married Women}

The mean age of married women in Upper Dir is 30.5 years. Figure 3.1 indicates the number of married women of reproductive age in each age group for the households surveyed. In district Upper Dir, the most of the women interviewed were from the 25 to 29 year age group, whereas the fewest were from the 15 to 19 year age group. (Age distribution for urban women is not provided due to the small number of respondents). However, the mean age of women interviewed in urban areas is 33.2 years, whereas the mean age of women interviewed in rural areas is 30.3 years.

Mean age at marriage for women in Upper Dir is 16.7 years, while women in urban Upper Dir are married at an average age of 18.3 years. Table 3.1 presents data on age at marriage by residence, which indicates that 82 percent of the women in Upper Dir are married before reaching the age of 20. The proportion of women who marry at a young age (before 20 years of age) is much higher in rural areas (84 percent) as compared to urban areas (59 percent).

Figure 3.1:Percentage distribution of women by age group

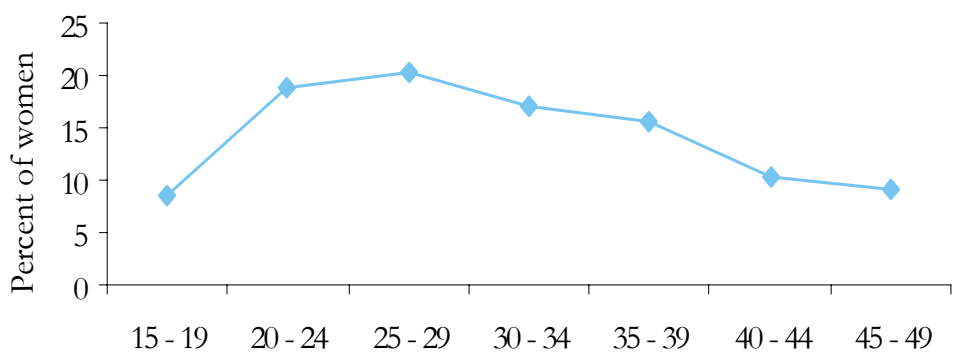

Age group 
Table 3.1:

Percentage distribution of women by age at marriage

\begin{tabular}{lrrrrrr}
\multirow{2}{*}{ Age at marriage } & \multicolumn{2}{c}{ Rural } & \multicolumn{2}{c}{ Urban } & \multicolumn{2}{c}{ Total } \\
\cline { 2 - 7 }$<15$ & Percent & Number & Percent & Number & Percent & Number \\
\hline $15-19$ & 18.4 & 145 & 10.9 & 5 & 18.0 & 150 \\
\hline $20-24$ & 65.3 & 515 & 47.8 & 22 & 64.3 & 537 \\
\hline $25+$ & 14.3 & 113 & 34.8 & 16 & 15.4 & 129 \\
\hline Total & 2.0 & 16 & 6.5 & 3 & 2.3 & 19 \\
Mean age at marriage & 100.0 & 789 & 100.0 & 46 & 100.0 & 835 \\
\hline
\end{tabular}

\section{Education/Literacy level}

The level of education obtained by a woman can be a good indicator of her status in society as well as the independent decision-making power available to her. It is presumed that the higher the level of education obtained by a woman, the more say she has in matters concerning her health and that of her children. With regard to maternal health, a higher literacy rate in women would result in an increased use of contraceptives, higher awareness of complications during and after pregnancy, a strong understanding of neonatal and newborn health, and finally a more complete understanding of safe birth practices.

It has also been shown that the mortality rates among children with mothers who have six or more years of education are considerably lower than the mortality rates among children with uneducated mothers (Martin, 1983). Educated women are more likely to recognize signs of illness in their children, actively seek assistance from a doctor, and finally administer the treatment in the manner required. Educated women are more also likely to return to a doctor in the event that the treatment administered failed to take effect. Therefore, the proactive nature of educated women in regards to the health of their children lowers the mortality rates of infants and young children.

The level of education of fathers also affects the mortality rates amongst children. This is partly an indication of socio-economic level, as typically the more education the father of a child has, the higher his socio-economic status and standard of living are likely to be. However, the effect an educated father has on the mortality rates of children is lower than the effect an educated mother has.

The ability to read is an important personal asset allowing women and their husbands increased access to various opportunities in their lives. By gathering information regarding the distribution of literacy among the respondents surveyed, maternal and newborn health communicators are better able to reach their target population with their messages. According to the table 3.2, overall 84 percent of married women in Upper Dir have never been to school. The situation in urban areas is slightly better than rural areas. Nearly 86 percent of the women surveyed in rural Upper Dir have never been to school, whereas the figure was 61 percent for urban areas. Table 3.2 also presents information on the literacy rate among married women of reproductive age. It shows that only 15 percent of the women interviewed in Upper Dir can read or write. Women in urban Upper Dir are three times more literate than their counterparts in rural areas (39 percent versus 13 percent respectively). 
Table 3.2:

Education level and literacy of married women and their husbands

\begin{tabular}{|c|c|c|c|c|c|c|c|}
\hline \multirow{2}{*}{\multicolumn{2}{|c|}{ Background profile }} & \multicolumn{2}{|c|}{ Rural } & \multicolumn{2}{|c|}{ Urban } & \multicolumn{2}{|c|}{ Total } \\
\hline & & Percent & Number & Percent & Number & Percent & Number \\
\hline \multirow{5}{*}{$\begin{array}{l}\text { Level of } \\
\text { education }\end{array}$} & No education & 85.7 & 676 & 60.9 & 28 & 84.3 & 704 \\
\hline & Up to primary & 6.7 & 53 & 10.9 & 5 & 6.9 & 58 \\
\hline & Up to middle & 3.2 & 25 & 6.5 & 3 & 3.4 & 28 \\
\hline & Up to secondary & 3.4 & 27 & 15.2 & 7 & 4.1 & 34 \\
\hline & Secondary + & 1.0 & 8 & 6.5 & 3 & 1.3 & 11 \\
\hline \multirow{2}{*}{$\begin{array}{l}\text { Respondent's } \\
\text { literacy }\end{array}$} & Literate & 13.4 & 106 & 39.1 & 18 & 14.9 & 124 \\
\hline & Illiterate & 86.6 & 683 & 60.9 & 28 & 85.1 & 711 \\
\hline \multirow{6}{*}{$\begin{array}{l}\text { Husband's } \\
\text { Level of } \\
\text { education }\end{array}$} & No education & 32.6 & 257 & 15.2 & 7 & 31.6 & 264 \\
\hline & Up to primary & 15.6 & 123 & 10.9 & 5 & 15.3 & 128 \\
\hline & Up to middle & 18.6 & 147 & 13.0 & 6 & 18.3 & 153 \\
\hline & Up to secondary & 19.0 & 150 & 10.9 & 5 & 18.6 & 155 \\
\hline & Secondary + & 13.7 & 108 & 50.0 & 23 & 15.7 & 131 \\
\hline & Don't know & 0.5 & 4 & & & 0.5 & 4 \\
\hline \multirow{2}{*}{$\begin{array}{l}\text { Husband's } \\
\text { literacy }\end{array}$} & Literate & 67.0 & 529 & 84.8 & 39 & 68.0 & 568 \\
\hline & Illiterate & 33.0 & 260 & 15.2 & 7 & 32.0 & 267 \\
\hline
\end{tabular}

Literacy rates among husbands is much higher when compared to women. Data presented in table 3.2 suggest that about two-thirds of the women interviewed indicated that their husbands are literate. The proportion of women who have literate husbands is much higher in urban areas ( 85 percent) than in rural areas (67 percent).

\section{Children Ever Born and Living}

Table 3.3 presents the distribution of married women by the number of children ever born (CEB). This table also shows the mean number of children ever born and the mean number of living children for each five-year age group. It is observed that overall in Upper Dir, the mean number of children ever born is 4.2 with 3.9 surviving children. When these results are compared with the 1998 Population Census results, a reduction of 0.9 children is observed in the number of children ever born.

Table 3.3 also shows the comparison of the mean number of children ever born and surviving children among women over 40 years of age. This reflects the extent and impact of mortality on the population. Married women of $45-49$ years on average have 7.8 children ever born, and 7.3 surviving children. 
Table 3.3: $\quad$ Percentage distribution of married women by number of children ever born, mean number of children ever born, living children and age group, compared to the 1998 Population census

\begin{tabular}{|c|c|c|c|c|c|c|c|c|c|c|}
\hline \multirow{3}{*}{$\begin{array}{l}\text { Age } \\
\text { Group }\end{array}$} & \multicolumn{5}{|c|}{ Number of Children Ever Born } & \multirow{3}{*}{$\begin{array}{l}\text { No. of } \\
\text { Women }\end{array}$} & \multicolumn{4}{|c|}{ Mean No. of Children } \\
\hline & 0 & $1-2$ & $3-4$ & 5 or & Total & & PAIMAN & aseline & 1998 Populat & n Census \\
\hline & & & & more & & & Ever born & Living & Ever born & Living \\
\hline $15-19$ & 67.6 & 31.0 & 1.4 & 0.0 & 100 & 71 & 0.4 & 0.4 & 1.6 & 0.9 \\
\hline $20-24$ & 22.2 & 55.7 & 20.9 & 1.3 & 100 & 158 & 1.6 & 1.5 & 2.6 & 1.8 \\
\hline $25-29$ & 6.5 & 35.5 & 37.9 & 20.1 & 100 & 169 & 2.9 & 2.8 & 4.3 & 3.3 \\
\hline $30-34$ & 0.7 & 11.8 & 36.1 & 51.4 & 100 & 144 & 4.7 & 4.4 & 5.6 & 4.4 \\
\hline $35-39$ & 3.1 & 4.6 & 17.7 & 74.6 & 100 & 130 & 6.0 & 5.5 & 6.9 & 5.8 \\
\hline $40-44$ & 1.2 & 2.3 & 4.7 & 91.9 & 100 & 86 & 7.7 & 7.3 & 8.3 & 6.4 \\
\hline $45-49$ & 0.0 & 1.3 & 7.8 & 90.9 & 100 & 77 & 7.8 & 7.3 & 8.1 & 6.7 \\
\hline Total & 12.0 & 23.5 & 21.9 & 42.6 & 100 & 835 & 4.2 & 3.9 & 5.1 & 4.0 \\
\hline
\end{tabular}

\section{Preceding Birth Interval}

The length of the preceding birth interval is very important, as it directly affects the health of both mother and child. A mother with repeated pregnancies, especially at short intervals, does not have sufficient time for recovery both physically and nutritionally and is therefore more likely to have pregnancy losses and babies of a lower birth weight. Table 3.4 shows that more than 18 percent of the women interviewed had their last birth after an interval of less than 18 months. More than 28 percent of women had their last child after a 36 months birth interval, while one-third 33.5 percent had their last birth after an interval of 25 to 36 months.

Table 3.4: $\quad$ Percentage distribution of married women by length of preceding birth interval

\begin{tabular}{lrr}
\hline Length of Preceding Birth Interval & Number & Percent \\
Less than 12 Months & 10 & 2.2 \\
\hline 13-18 Months & 79 & 17.6 \\
\hline 19-24 Months & 81 & 18.1 \\
\hline 25-36 Months & 150 & 33.5 \\
\hline More than 36 Months & 128 & 28.6 \\
Total & 448 & 100.0
\end{tabular}

\section{Access to Information}

In the baseline survey, respondents were asked several questions regarding access and exposure to television, radio and newspapers. One of the main objectives of the baseline survey was to determine the knowledge of married women on different maternal and newborn health issues and the source of that knowledge. This information is useful in determining which media channels should be employed in the dissemination of maternal and newborn health information to target audiences. Moreover, it is important to measure the likelihood of reaching target audiences, as well as to determine which media channels are most effective when it comes to reaching that target audience. 


\section{Access to Media (Television, Radio and Newspaper)}

Mass media is regularly used to campaign various issues, including those related to the health of mothers and newborns. In the past, radio was the most popular form of communication (Syed, 1979). In recent decades however, television seems to have become a more popular source of information.

\section{Television}

According to figure 3.2, only 10 percent of the respondents in Upper Dir watch television of which only 5 percent watch television on a daily basis. In other words, campaigning maternal and health issues through television will only reach about 5 percent of the target population in Upper Dir. Although 30 percent of the women interviewed in urban Upper Dir reportedly watch television daily, the proportion of urban population to total population in Upper Dir is less than 5 percent.

Figure 3.2: $\quad$ Percentage of women who watch TV or listen to the radio by place of residence

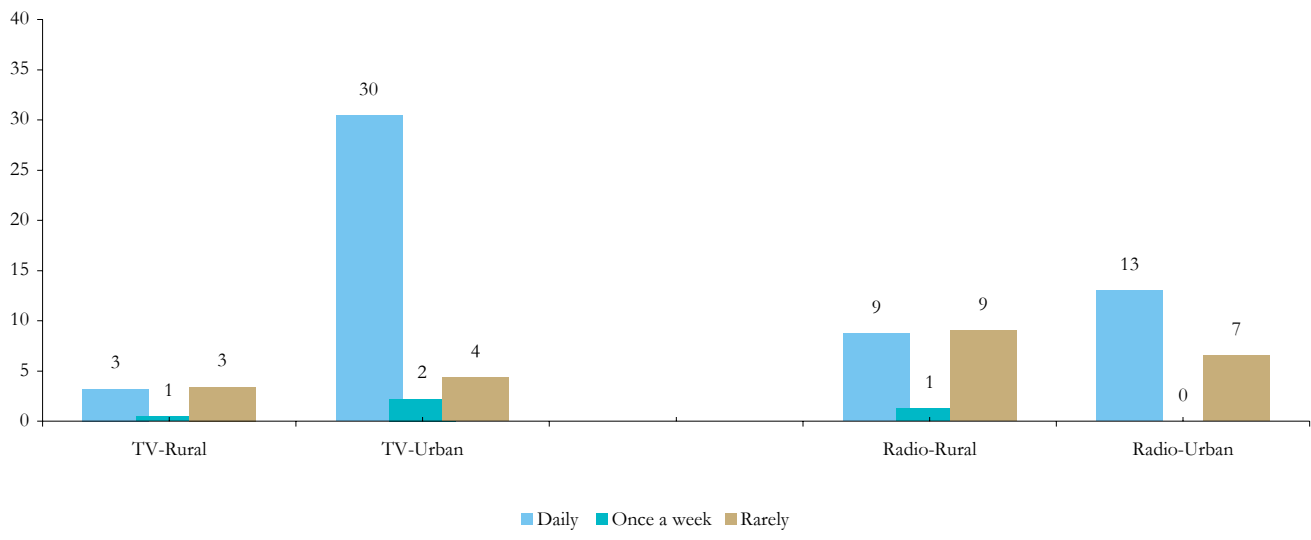

It is important to establish an overall picture of the decision-making structure or hierarchy within a household. Determining the person from whom the respondent must seek permission before watching television can help establish a clear understanding of the household hierarchy. Following that, a clearer picture of who makes decisions regarding the health of pregnant women and newborn children may be obtained.

Women who watch television were asked what they thought about the impact of television programs on the health behavior of women. According to figure 3.3, about 60 percent of those who watch television responded that television is very influential. 
Figure 3.3: $\quad$ Influence of TV programs on health behaviors of people

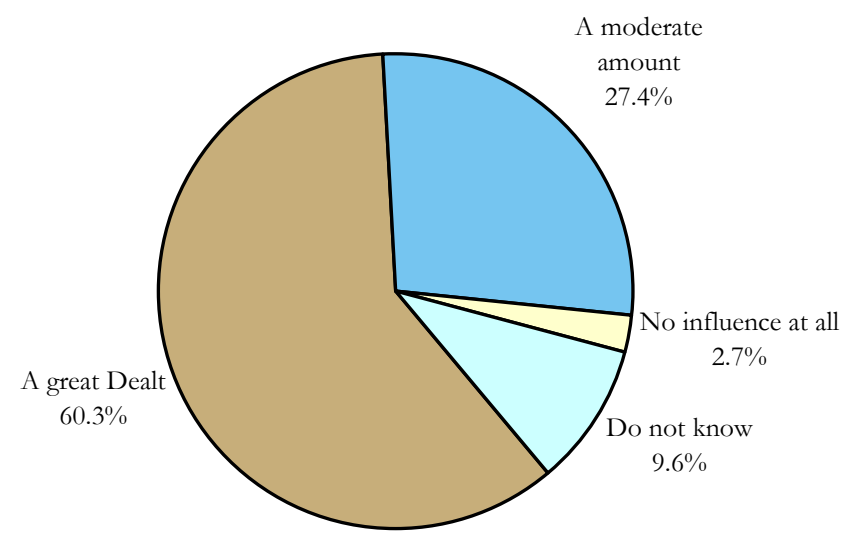

\section{Radio}

Much like television, radio is also a tool through which messages may be relayed to a relatively large audience. However, figure 3.2 appears to indicate that only 18 percent listen to the radio, out of which only 9 percent listen on a daily basis. It can therefore be determined that radio may not be an effective means of communication for the purpose of women's health and neonatal care as the audience available is very limited.

Figure 3.4 indicates the influence radio has on the health behaviors of people. About one-third of those who listen to the radio indicated that radio has a great deal of influence on the health behaviors of people, whereas another 37 percent indicated that it has a moderate influence. In Upper Dir, more than 9 percent of the mothers believe that radio has no influence on people's health behaviors.

Figure 3.4: $\quad$ Influence of radio on health behaviors of people

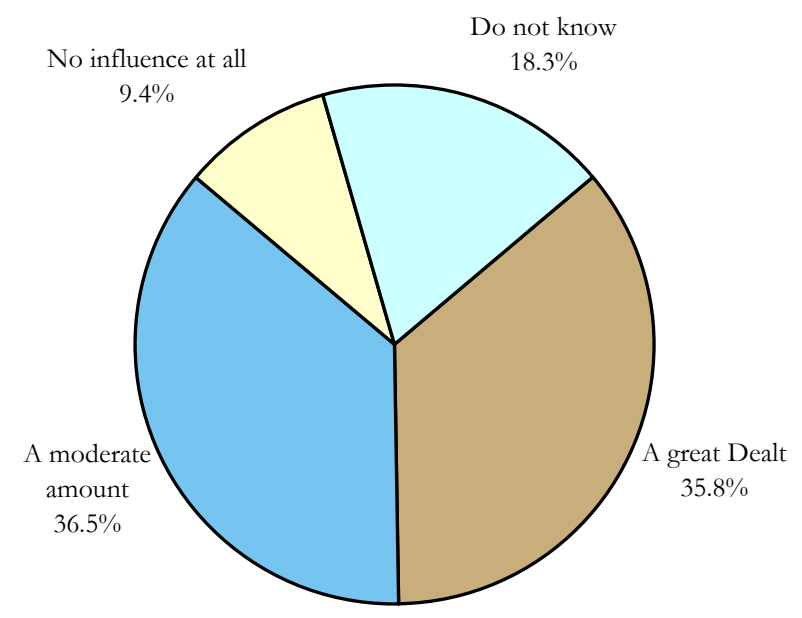




\section{Newspapers}

The results obtained for the percentage of people interviewed that read the newspaper on a daily basis are unexpectedly low. In Upper Dir, as outlined in figure 3.5, almost 91 percent of the respondents indicated that they never read the newspaper. Less than 2 percent indicated that they read the newspaper on a daily basis. Therefore, it can be said that newspaper or print media is not an effective means of communication either.

Figure 3.5: $\quad$ Frequency of reading newspaper

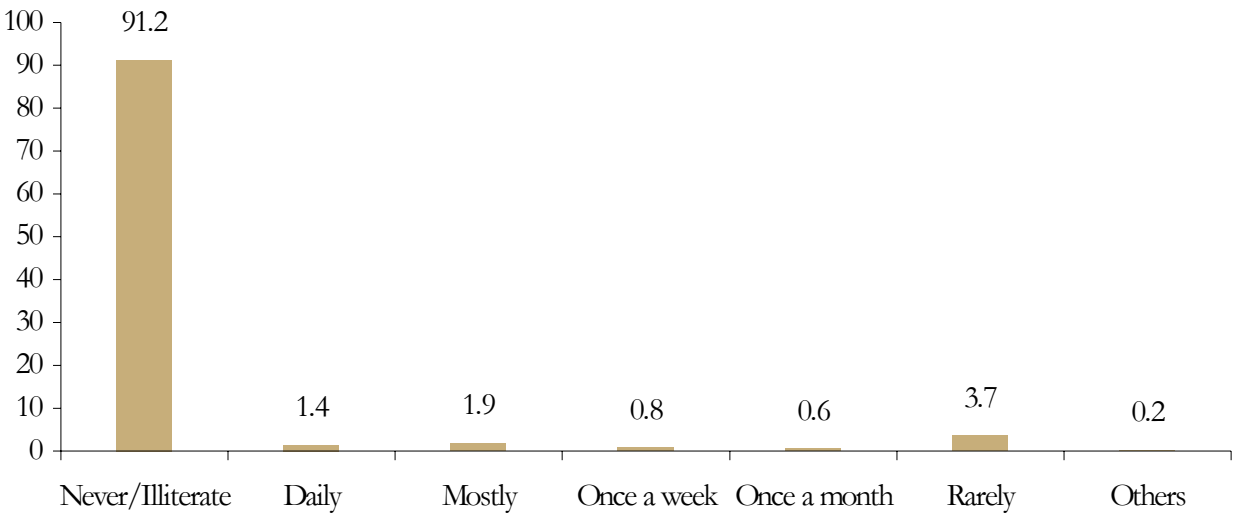

According to the figure 3.6, only 28 percent of the respondents in the district of Upper Dir have access to some sort of media; whether it is television, radio or newspapers. While it may seem possible to reach this small proportion of mothers through one of the three main media channels, there are some obstacles that stand in the way including the lack of decision-making power for women and the infrequency of access to the media. The remaining 72 percent of the population that does not have access to any sort of media must also be reached through other channels of communication. In order to do this, a more grassroots method must be adopted, which may include inter-personal communication through community workers, community gatherings, speeches and health education sessions.

Figure 3.6: $\quad$ Access to mass media (radio, TV or newspaper)

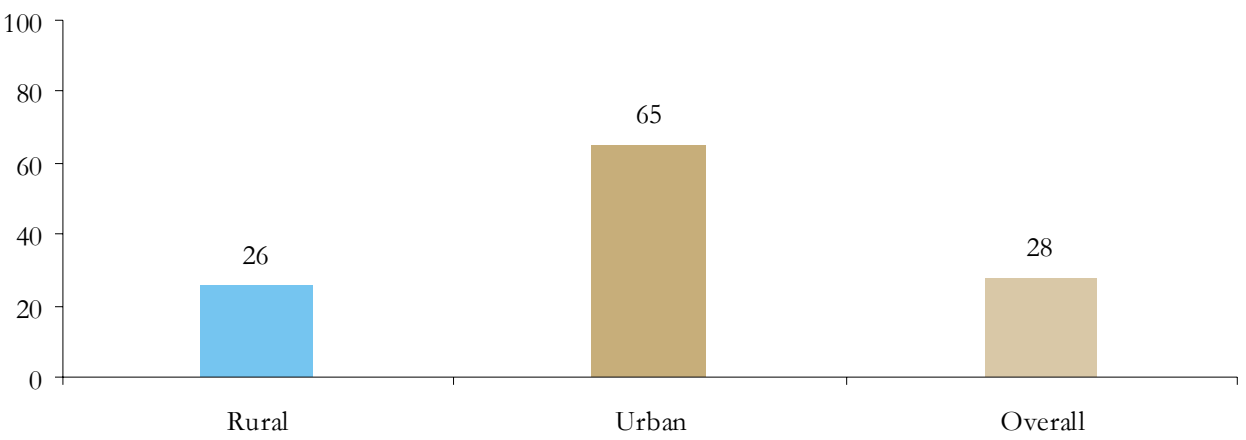




\section{Information/Education through Media}

Before moving on to questions regarding attitudes towards pregnancy, delivery and postpartum, respondents were asked to comment on whether or not they had heard or read anything about maternal and newborn mortality within the past three months. Figure 3.7 shows the responses given.

As seen above, a quarter of the married women had heard or read something regarding maternal health, while almost the same proportion had heard or read something regarding newborn health during the last three months prior to the baseline survey. However, it is clear that a very large portion of the population is not exposed to any messages regarding maternal and newborn health on a frequent basis.

Furthermore, respondents were asked if they had heard religious leaders and community/NGO workers speak about health care in the last three months. Less than 1 percent had ever heard anything regarding maternal and newborn health from community/NGO workers, while just over 1 percent of the population indicated that they had heard a religious leader speak about the topic.

It becomes evident from the data that the percentages of married women who had heard anything about maternal or newborn health are very low, indicating the absence of proactive education and awareness in many areas of Upper Dir. Hence, it would be a challenge for the PAIMAN team to reach these women and convey messages regarding maternal and newborn health.

Figure 3.7: $\quad$ Percentage of married women who had heard/ read about maternal and newborn messages during the last 3 months

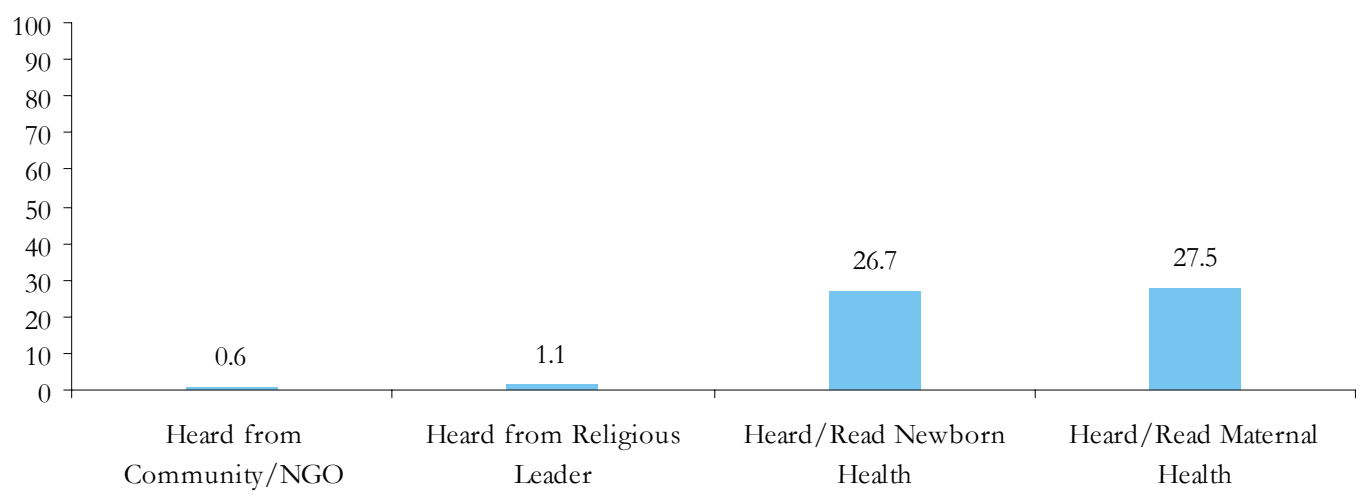




\section{Chapter 4}

\section{Knowledge of Safe Motherhood, Birth Preparedness and Community Resources}

This chapter explores the level of understanding women have of safe motherhood practices, birth preparedness and the use of community resources. It examines the level of health awareness women in the district possess, and thus provides an explanation for the maternal and newborn mortality rates. Respondents were asked questions regarding knowledge of complications during pregnancy, delivery, the postpartum period and newborn health. The findings of those responses are presented in this chapter.

\section{Knowledge of Danger Signs}

\section{Knowledge of Danger Signs during Pregnancy}

Figure 4.1 outlines the knowledge of married women regarding the various complications that may occur during pregnancy. Respondents were asked to indicate which complications they believe are dangerous and require medical attention.

Figure 4.1: $\quad$ Knowledge of danger signs during pregnancy, which require medical attention

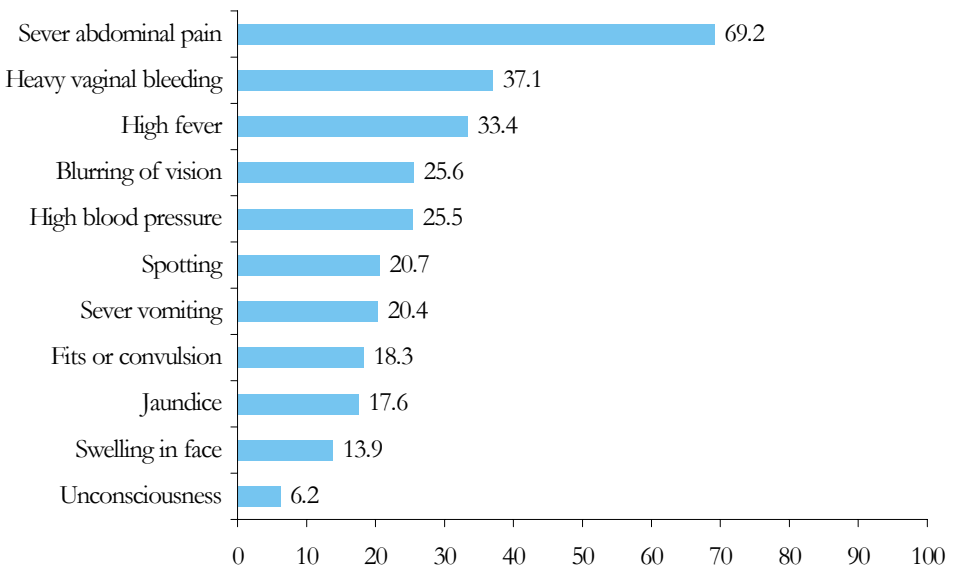

The most known complication among married women in Upper Dir is 'severe abdominal pain.' Approximately 69 percent of the women interviewed are aware of 'severe abdominal pain', while about 37 percent know 'heavy vaginal bleeding' is a complication, along with 33 percent that 
recognize 'high fever' during pregnancy as a sign of danger. A quarter of the women surveyed mentioned 'blurring of vision' and 'high blood pressure' during pregnancy as being danger signs. Few women know about 'fits or convulsions' and 'swelling in face' as danger signs.

Figure 4.2 shows that more than half (54 percent) of the women know at least three danger signs that may appear during pregnancy. Only about 13 percent of the women interviewed were unable to name even a single danger sign or complication during pregnancy. Therefore, it can be concluded that women's knowledge about danger signs during pregnancy is substantially high in the district of Upper Dir.

Figure 4.2: $\quad$ Percentage distribution of women by knowledge of the number of danger signs of pregnancy

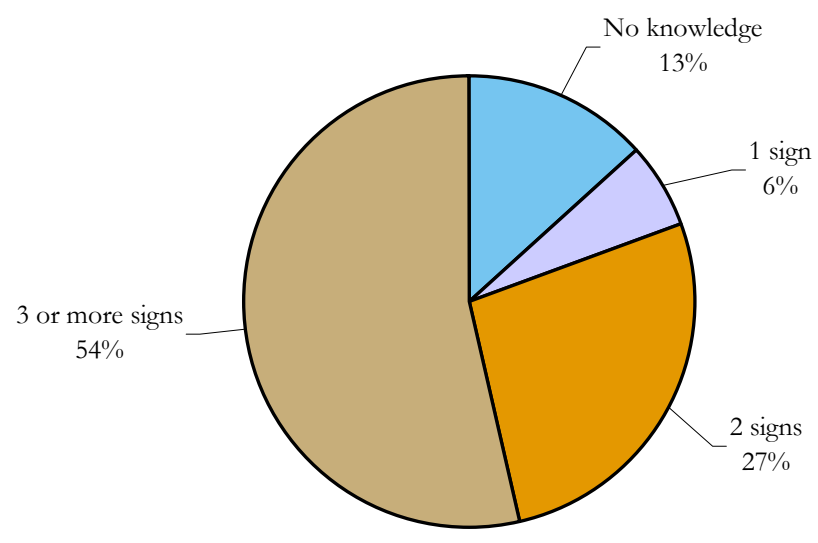

\section{Knowledge of Danger Signs during Childbirth/Delivery}

The fact is that most maternal deaths occur during delivery in developing countries. More than three quarters of the women surveyed failed to recognize the danger signs during delivery that may have severe consequences. Deliveries can only be made safe if married women are educated regarding the danger signs that may appear during delivery, so that they can decide when to seek treatment. Even under normal circumstances, about 15 percent of pregnant women require emergency obstetric care to avoid maternal and newborn deaths.

Figure 4.3 depicts the level of the respondents' understanding of complications during delivery. About half of the women (50 percent) know that immediate treatment is required if women experience 'prolonged or obstructed labor', while around 42 percent of the women mentioned that 'excessive vaginal bleeding' and 'mal-positioning of fetus' are signs of danger. Very few women (only 15 percent) mentioned 'premature rupture of membranes' as being a danger sign. 
Figure 4.3: $\quad$ Distribution of respondents who had knowledge about complications during delivery

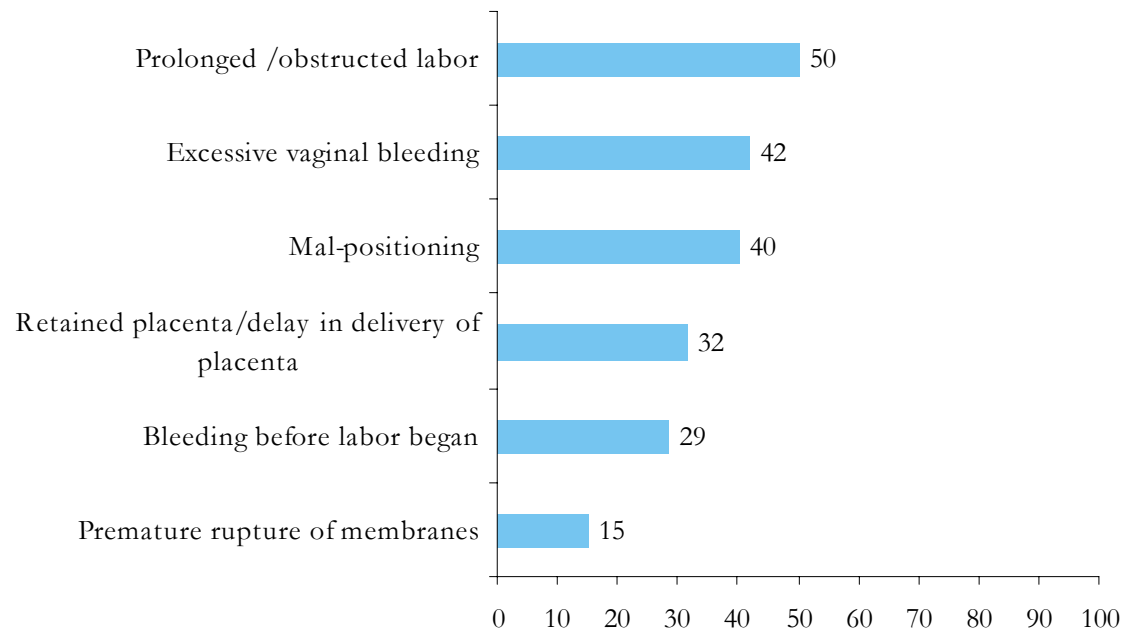

Figure 4.4 shows that 33 percent of the women know at least three danger signs of delivery, while 13 percent do not know about any of the danger signs of pregnancy. It is very difficult to save the life of a pregnant woman who is not able to recognize danger signs during delivery and is therefore unable to decide when to seek medical attention.

Figure 4.4: $\quad$ Percentage distribution of women by knowledge of number of danger signs of delivery

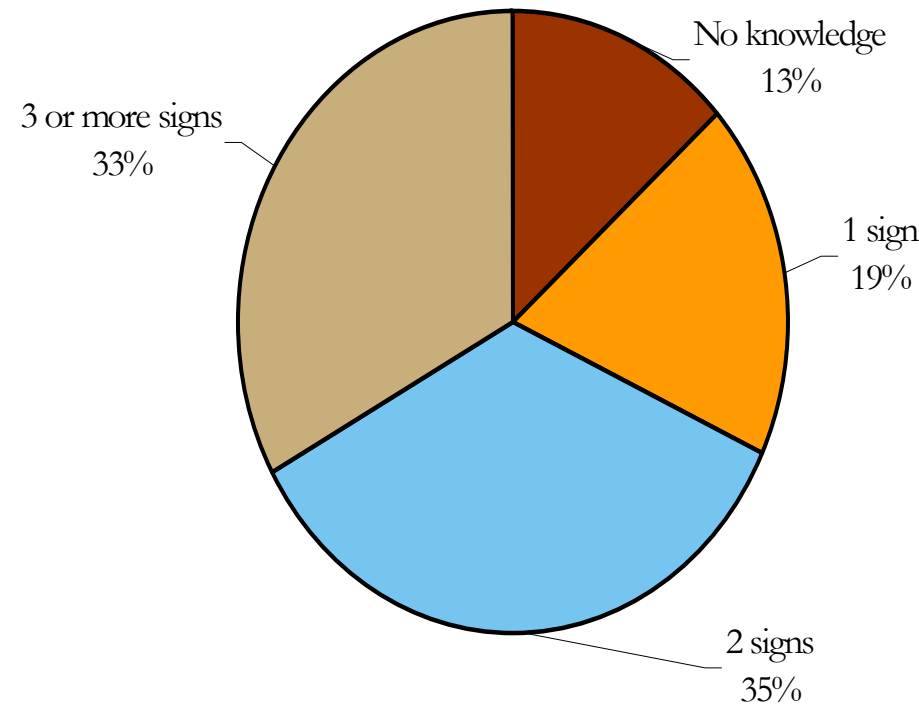




\section{Knowledge of Danger Signs during the Postpartum Period}

In the baseline survey, the postpartum period is defined as the 40 days after childbirth. Postpartum hemorrhage is another significant cause of maternal morality in developing countries.

The baseline survey findings indicate that 'excessive vaginal bleeding' is the most known danger sign (75 percent) during the postpartum period followed by 'high fever' (54 percent). High fever is a sign of infection (sepsis) and sepsis is one of the five leading causes of maternal deaths. About one fifth of the women mentioned 'prolapsed uterus' and 'fit or convulsions' as danger signs.

Figure 4.5: $\quad$ Percentage of married women who had knowledge about complications during postpartum period

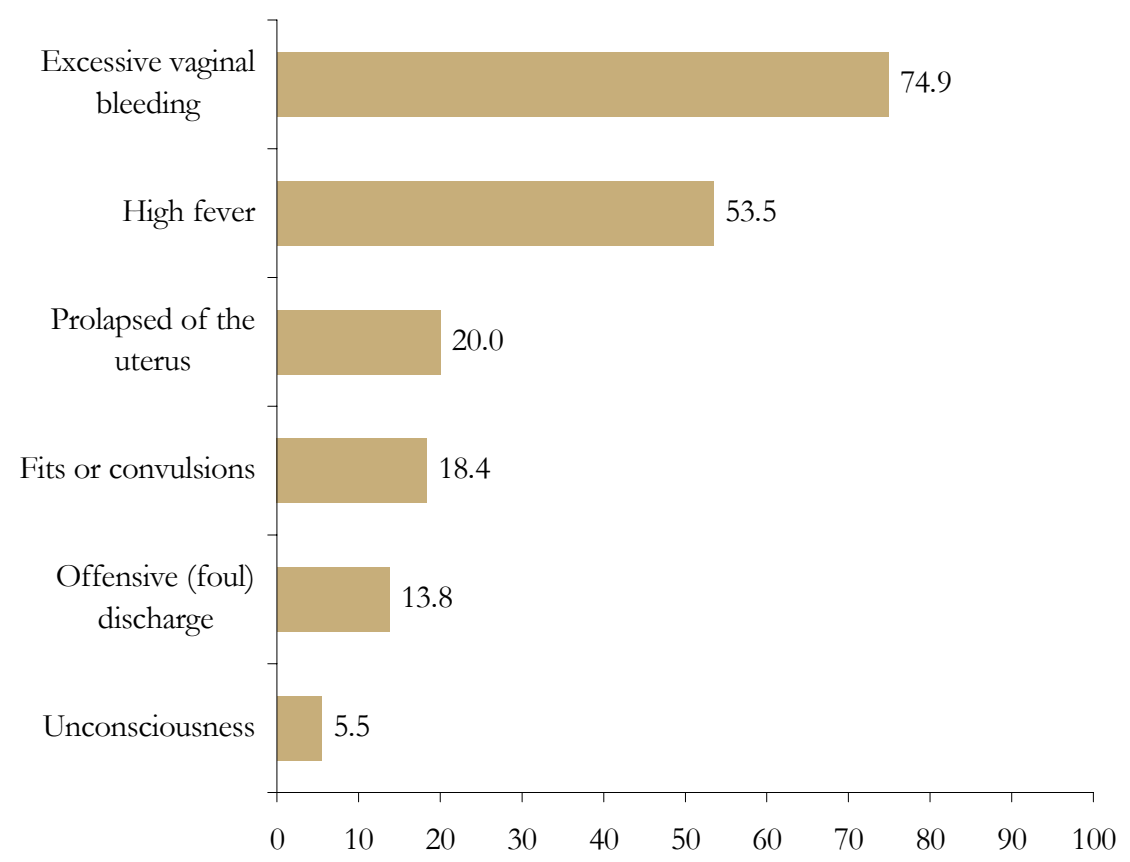

Figure 4.6 elicits that less than a quarter ( 24 percent) of the women surveyed were able to name at least three or more danger signs that may appear during the postpartum period, while about 45 percent were able to name two danger signs. However, 14 percent of the women did not know about any of the danger signs or complications which may appear during the postpartum period. 


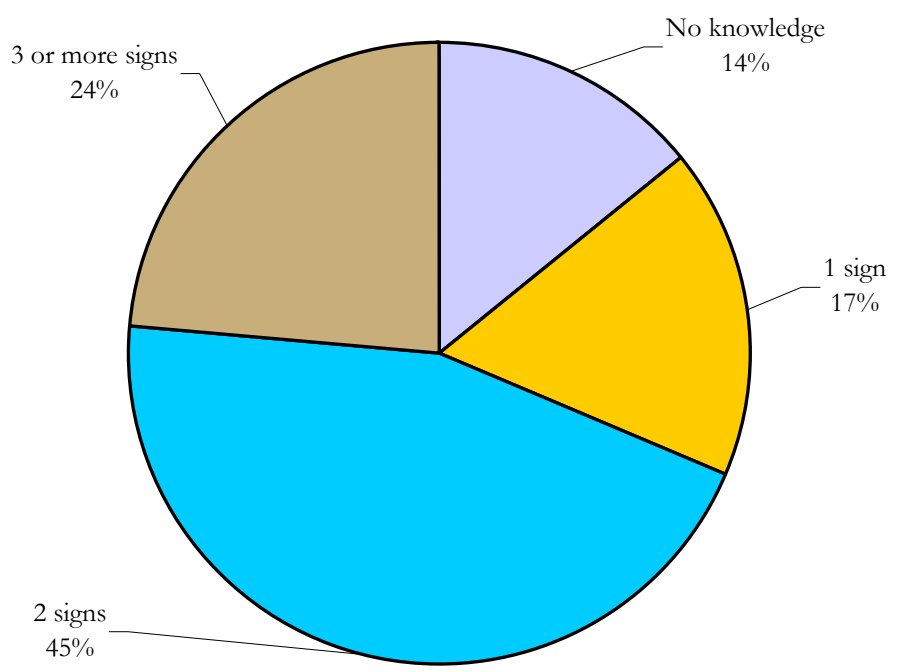

\section{Knowledge of Danger Signs in the Newborn}

Unfortunately, many women are also unaware of the danger signs that may appear in newborns, especially in the first seven days after childbirth. The newborn period is defined as the first four weeks after birth. While many women may not seek medical attention when it comes to their own health due to a lack of awareness, doing so with a newborn may be detrimental. Figure 4.7 depicts the percentage of respondents who believe that each complication listed requires medical attention. Three in every four women identified 'yellow skin' as being a danger sign, while 42 percent reported 'blue skin color' as a potential complication. Slightly more than a quarter of the women mentioned 'no/weak cry' as being a danger sign. About one fifth of the women mentioned 'no or poor suckling', 'blisters' 'fits' and 'difficulty breathing' as other danger signs which may appear among newborns. A very small proportion of women identified 'red swollen eyes' and 'fast breathing' as danger signs.

According to the data presented in figure 4.8, women's knowledge regarding danger signs in newborns is very high. Approximately 24 percent of the women know of two danger signs, whereas 57 percent know about three or more. Only 11 percent of the women are unaware of any of danger signs that may appear in newborns shortly after birth. 
Figure 4.7: $\quad$ Percentage distribution of respondents who had knowledge about danger signs in newborns

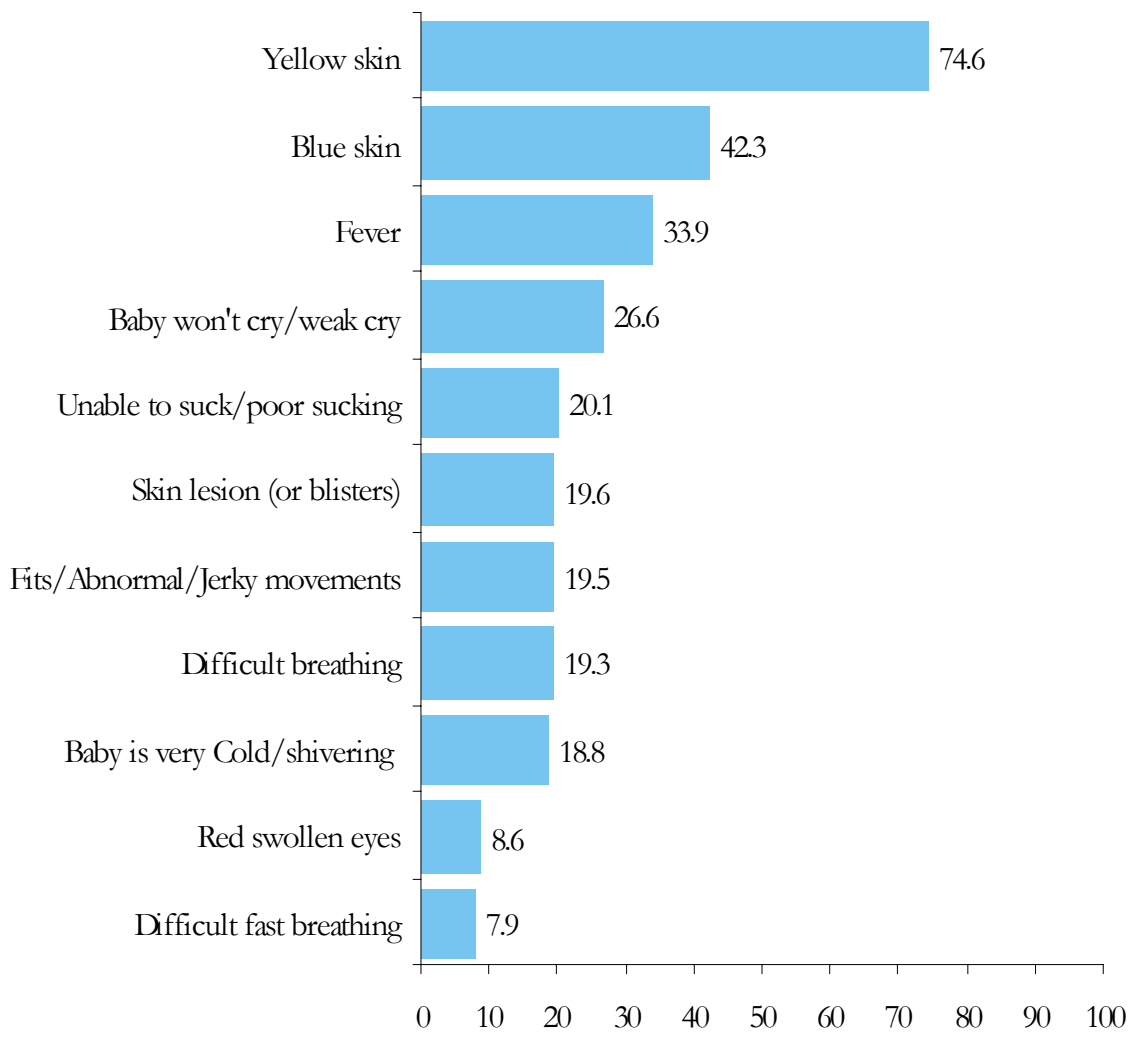

Figure 4.8: $\quad$ Percentage distribution of women by knowledge of number of danger signs among newborn at birth

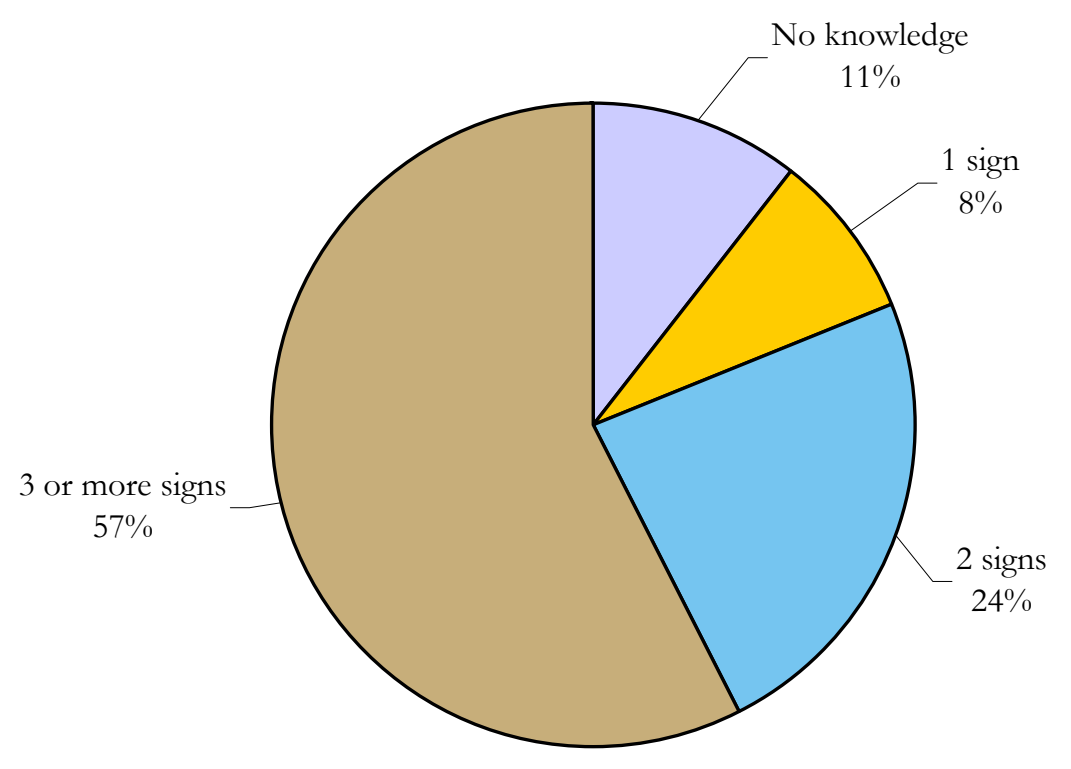




\section{Source of Information Regarding Danger Signs}

Respondents were asked to indicate where they received information regarding danger signs during pregnancy, delivery and the postpartum period. The main sources of information as identified by the women interviewed are 'district headquarter hospital' (56 percent), 'friends/relative' (35 percent), 'BHU/RHC' (23 percent) and 'private clinics/hospital' ( 24 percent).

Community-based care providers also provide information to a small section of women. Less than 10 percent of the women cited Lady Health Workers as a source of information and around 5 percent received information from Traditional Birth Attendants.

The fact that most respondents indicated that they obtained information about pregnancy through inlaws, family members and friends suggests that many women may not be getting accurate information, therefore leaving room for misconceptions. Furthermore, many women are not receiving reliable information regarding antenatal and postnatal health from a doctor's perspective.

Figure 4.9: $\quad$ Source of information of danger signs during pregnancy

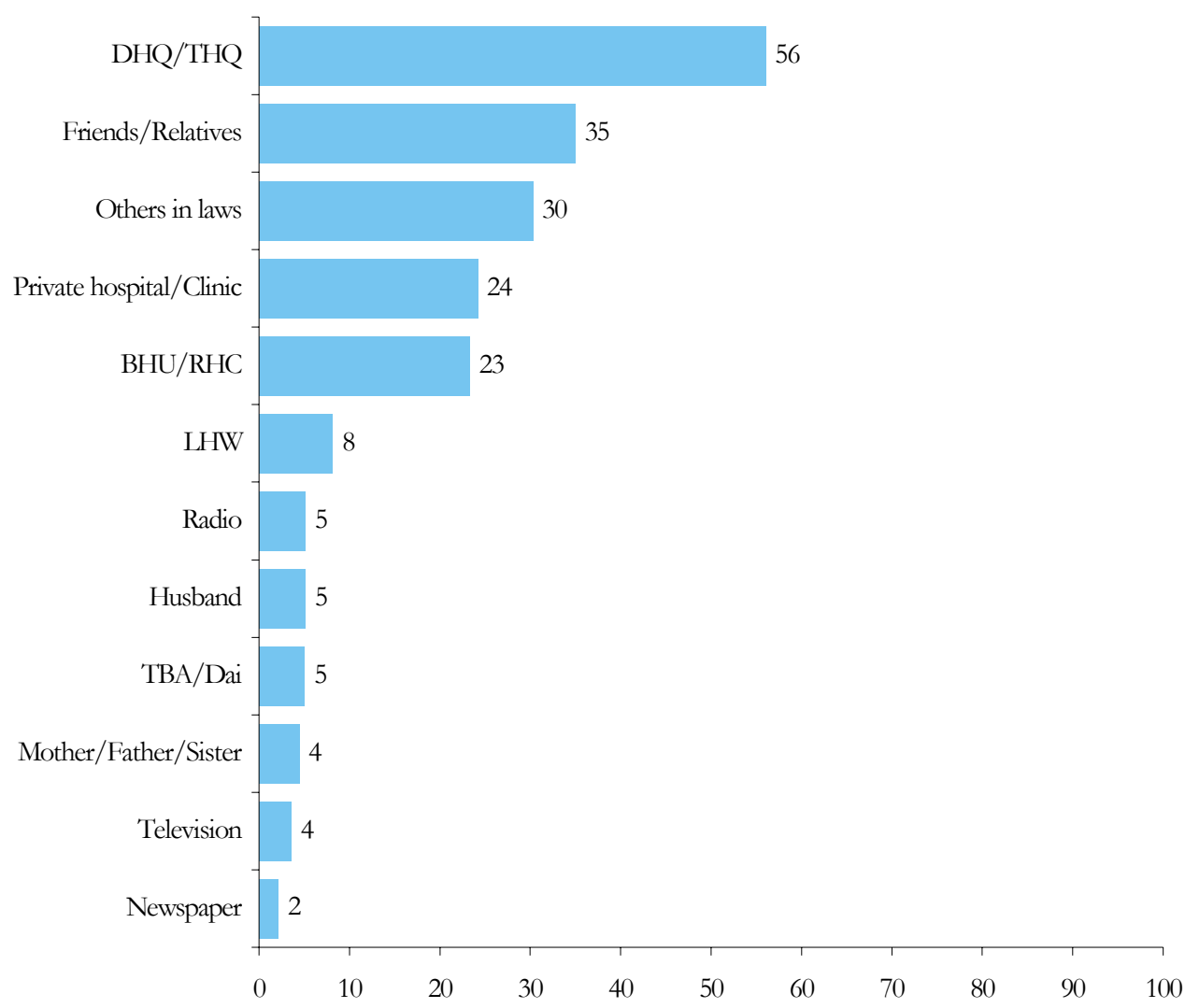




\section{Knowledge of Community Schemes for the Welfare of Women and Newborns}

In addition to asking questions regarding the knowledge of danger signs, married women were asked whether they were aware of any existing schemes in their respective communities that would guide women through a safe childbirth, while also teaching them to take care of newborns. The baseline focused on schemes pertaining to transportation, blood arrangements and funding, all services which help in ensuring that there are no delays during the delivery time. Arrangement of transport to a health facility is a major cause of delay and can often lead to maternal and newborn mortality, and therefore the arrangement ahead of time is necessary to eliminate such a delay. Unfortunately, many households are unable to do so due to a lack of transportation in their communities.

Table 4.1: $\quad$ Knowledge of existence and importance of transport, blood and finances by the community at the time of delivery

\begin{tabular}{lrr}
\multicolumn{1}{c}{ Committee Services } & \multicolumn{2}{c}{ Total } \\
& Percent & Number \\
\hline Existence of transport by the community at delivery & 1.0 & 8 \\
\hline Importance of community provided transport facility as perceived by respondents & 99.4 & 830 \\
\hline Existence of blood by the community at time of delivery & 0.6 & 5 \\
\hline Importance of community provided blood facility as perceived by respondents & 99.8 & 833 \\
\hline Existence of money by community at the time of delivery & 0.5 & 4 \\
\hline Importance of community provided money facility as perceived by respondents & 99.9 & 834 \\
\hline
\end{tabular}

Table 4.1 indicates that while more than 99 percent of the population believes in the importance of community arranged transport, blood and money facilities, very few respondents were actually aware of the existence of such facilities in thei respective communities. Almost none of the communities have any arrangement of transport, provision of blood and existence of finances for women at the time of delivery which is a major obstacle to safe birth practices. 


\section{Chapter}

\section{Attitudes Towards Pregnancy, Delivery and the Postpartum period}

This chapter explores the attitudes of married women towards pregnancy, delivery and the postpartum period. Determining these attitudes and beliefs is important for designing strategies that bring about a change in traditional thinking.

\section{Attitudes Toward Age at Marriage}

In response to the question of whether or not women should get married soon after puberty, 42 percent of women believe girls should get married soon after puberty, whereas half of the women believe they should not. A deeper look into this issue shows that many families do not value education, and choose marriage before providing girls and women with an education. As a result, women are married at an early age, and often completely forego the opportunity to obtain any education whatsoever. As well, there is a link between the amount of education obtained by women and the fertility rate of a country (Sathar, 1984). The younger the age at marriage, the greater the exposure to childbearing.

\section{Attitudes Towards Antenatal Care}

Women in Upper Dir were asked if they believe women need to have antenatal check-ups. An overwhelming majority ( 88 percent) believe it necessary for women to receive these check-ups, while only about 8 percent feel it unnecessary. Therefore, it becomes quite clear that while many women do want to receive antenatal check-ups, many are not able to access this service. Figure 5.1 outlines the percentage of respondents who feel that antenatal check-ups are either necessary or not.

About one third of the women that stressed the need to obtain antenatal care, said that women should have at least three antenatal check-ups from a qualified health care provider. However, about half of them are of the opinion that women should go for antenatal checkups only when required. Despite the fact that 88 percent of women believe in the importance of antenatal care, very few (one-third) know the recommended number of antenatal visits. 
Figure 5.1: $\quad$ Believe in necessity of antenatal check-ups/month of pregnancy when women should obtain antenatal care

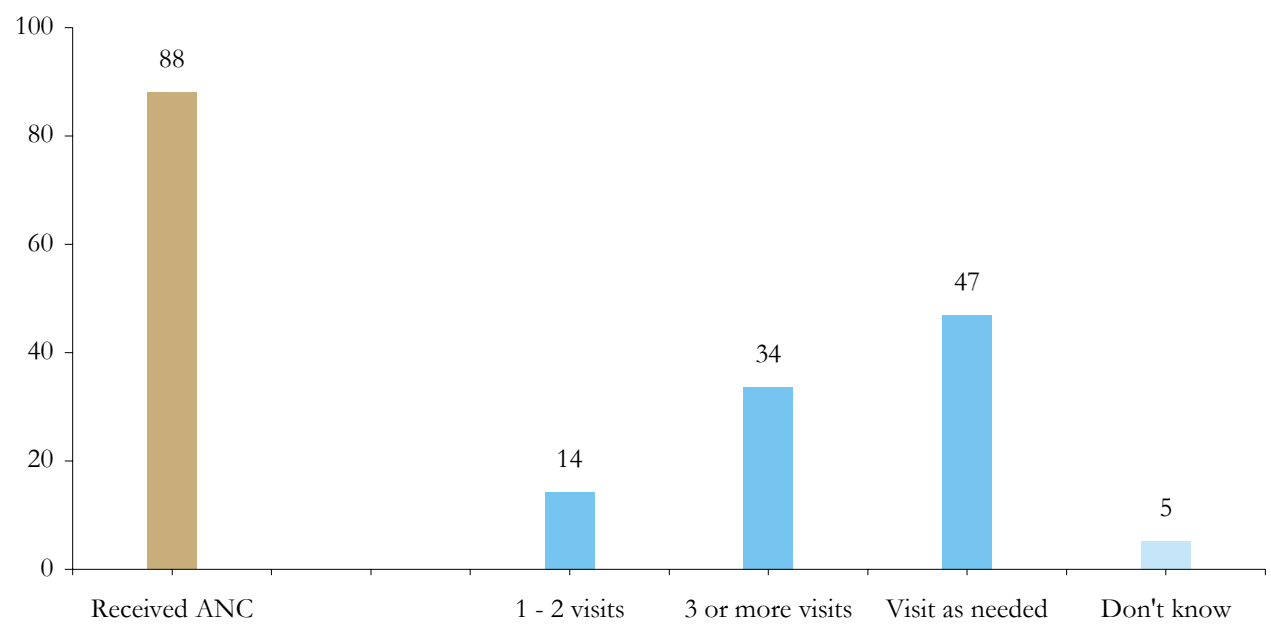

Antenatal care also encourages mothers to be more aware of their own health as well as the health of their newborn babies (Hollander, pp.45). When asked to state when a woman should receive antenatal care, the responses varied. About one third said that a pregnant woman should start receiving checkups during the first trimester, while one fifth believe antenatal care should be given during the second trimester. In addition, 29 percent of the women believe that women should go for antenatal checks only when check-ups are required (figure 5.2).

Figure 5.2: $\quad$ Month of pregnancy when antenatal care should be obtained

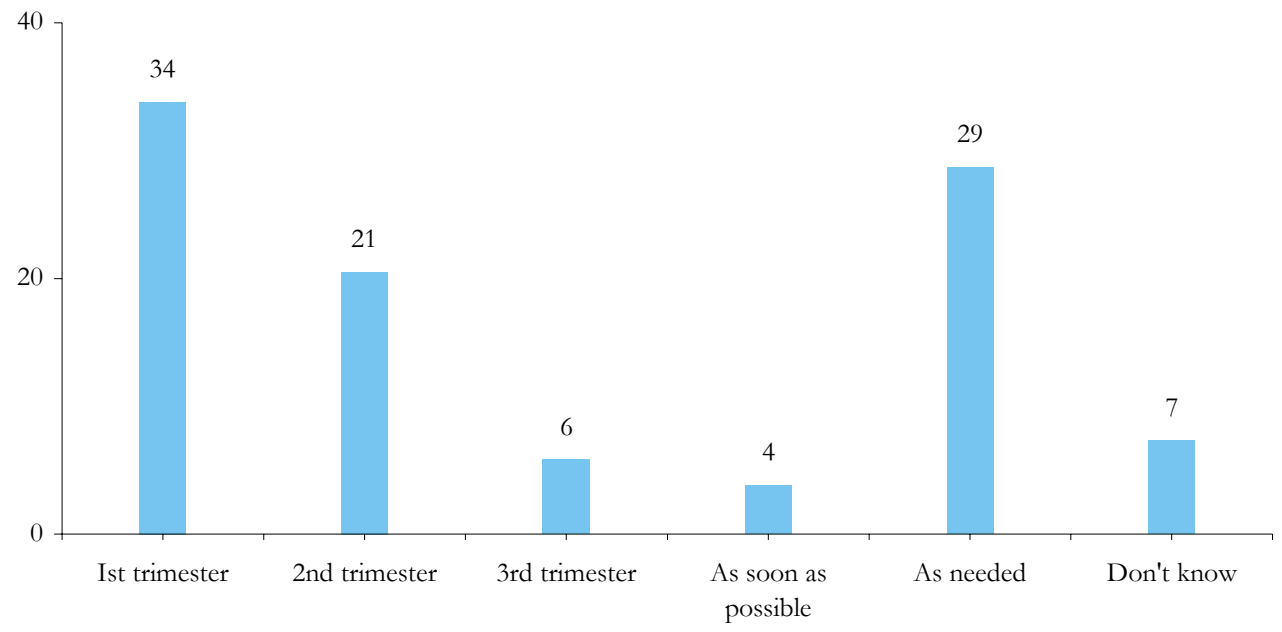

Respondents were asked to indicate where a woman should go for antenatal checkups. A large majority (71 percent) of the women cited the DHQ's as the source of their antenatal care, while 20 percent mentioned Basic Health Unit (BHU) or a Rural Health Center (RHC). About 38 percent of women mentioned private sector health facilities as their source of antenatal care (figure 5.3). 
Figure 5.3: $\quad$ Place considered suitable for antenatal checkups

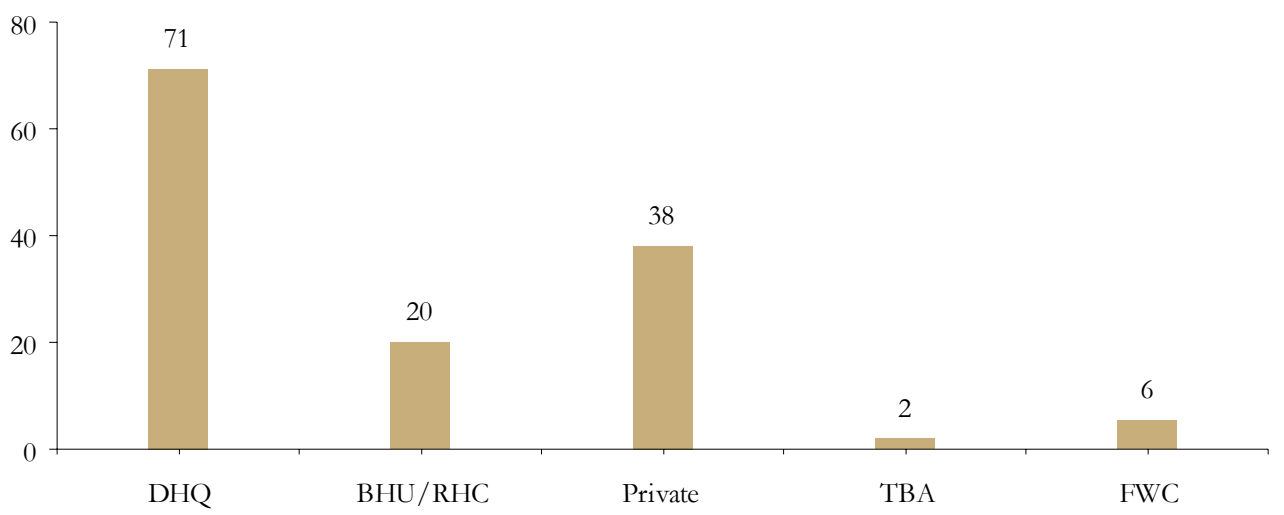

About 89 percent of the respondents indicated that women should get immunized against tetanus by receiving TT shots, while 70 stressed the necessity of iron/folate tablets during pregnancy (figure 5.4).

Figure 5.4: $\quad$ Percentage of married women who thought it necessary to receive TT shots and take iron/folate tablets during pregnancy

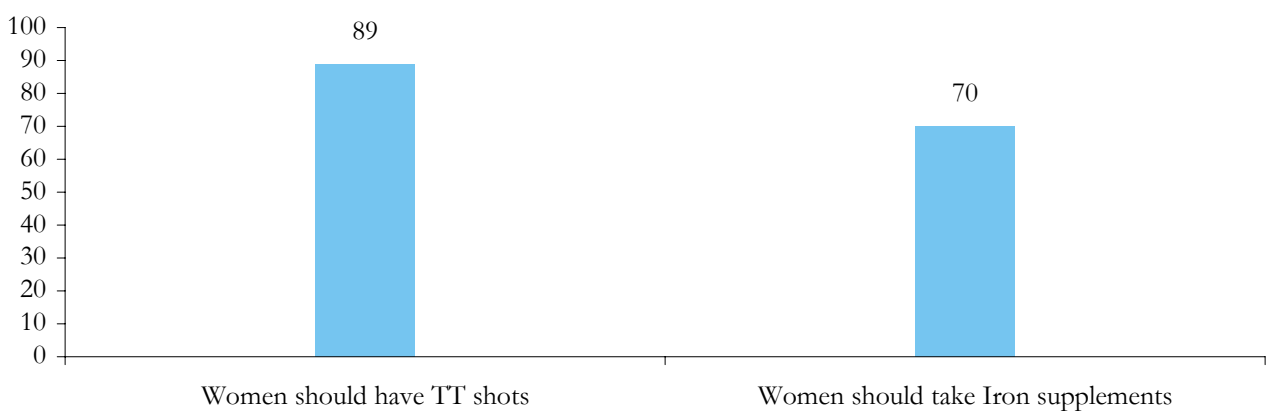

\section{Attitudes Towards Delivery}

Many families prefer the assistance of Traditional Birth Attendants (TBAs) or Dais to assist with deliveries. These TBAs/Dais have vast experience but no formal training, and therefore do not qualify as skilled birth attendants. However, many families do not realize the impact a lack of training can have on childbirth and chose to opt for TBAs over qualified health professionals.

In Upper Dir, about 90 percent of the women interviewed believe that women should obtain delivery services from a Skilled Birth Attendant (SBA) at the time of delivery. Women appear to recognize the fact that the assistance of skilled personnel could improve the outcome of pregnancy and reduce the chances of maternal and newborn morbidity and mortality. The main reasons for recommending skilled providers were: safety of mothers ( 52 percent); safety of newborns (42 percent); and the management of complications in a timely fashion (28 percent). Skilled birth attendants are better able to assess maternal and fetus health and are in a better position to identify the fetus' position. Skilled attendants are also able to refer pregnant mothers to well-equipped health facilities in the event that a 
complication should arise. However, 9 percent of the population still chose the assistance of TBAs over SBAs at the time of delivery. While the percentages for Upper Dir may not seem exceptionally high, it is important to keep in mind that traditional deliveries are still quite popular in Pakistan, though more so in some areas than in others.

When women were asked about the place where a delivery should take place, 45 percent of women stated that deliveries should take place at a hospital whereas 54 percent indicated that they should take place at home (table 5.1).

One possible reason why some women still want to deliver at home is that they are unable to make major decisions independently and must rely on their husbands or in-laws. Respondents were asked to indicate the person in their communities who should take charge of a pregnant woman and who should be responsible for making the important decisions regarding her health. According to figure 5.5 , only 5 percent of the women indicated that the woman herself should be given the freedom to take care of herself. More than a quarter of respondents believed that the woman's husband should be the person who takes charge in the event that a complication should arise, while two-thirds suggested that other family members should take charge.

Table 5.1: $\quad$ Respondents who believe that women should receive delivery services from health professional/ percentage of respondents who believe women in their community obtain delivery services from $S B A s$

\begin{tabular}{lrr}
\multicolumn{1}{c}{ Attitude } & \multicolumn{2}{c}{ Total } \\
& \multicolumn{1}{c}{ Percent } & Number \\
Women should have skilled birth attendant & 90.6 & 756 \\
\hline Reasons to have Skilled Birth Attendant & & \\
\hline To examine mother's and fetus health & 21.8 & 165 \\
\hline To know the Position of the Fetus & 13.5 & 102 \\
\hline For infection free delivery & 7.3 & 55 \\
\hline For safety of mother & 52.4 & 396 \\
\hline For safety of newborn & 42.2 & 319 \\
\hline Prompt treatment of complication (if arise) & 28.0 & 212 \\
\hline Others & 3.3 & 25 \\
\hline Hospital & & 377 \\
\hline Home & 45.2 & 449 \\
\hline Others & 53.8 & 2 \\
\hline Do not know & 0.2 & 6 \\
\hline & 0.7 & 834
\end{tabular}


Figure 5.5:

Person who should make decisions regarding the bealth of a pregnant women

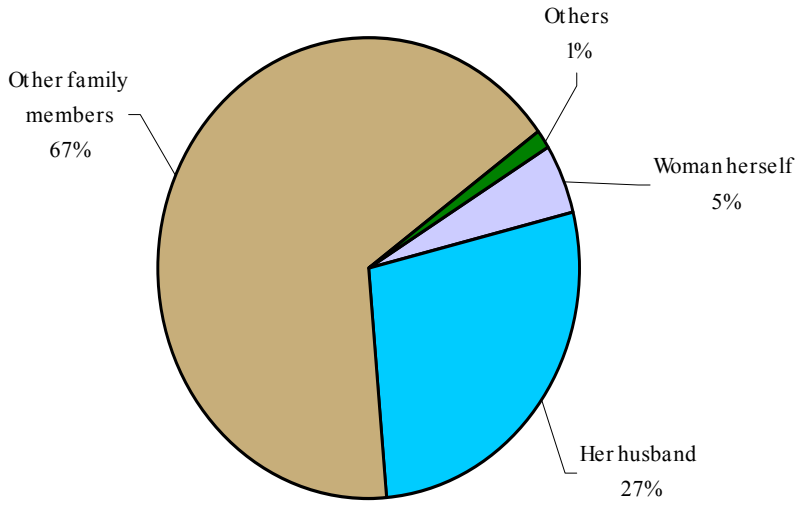

Finally, respondents were asked to indicate the mode of transportation they planned to use in order to reach a health facility at the time of delivery. Transportation to a health facility is a major delay in the delivery process, and may be very harmful to both the mother and the unborn baby. Many families often fail to arrange transport for pregnant women, thus having to rely on unreliable private transport.

Respondents were asked to indicate the mode of transportation they would use to reach a health facility. Only 6 percent had their own transportation, whereas 91 percent indicated that they would hire private transport.

Figure 5.6: $\quad$ Percentage of married women by mode of transport they would use to reach a health facility

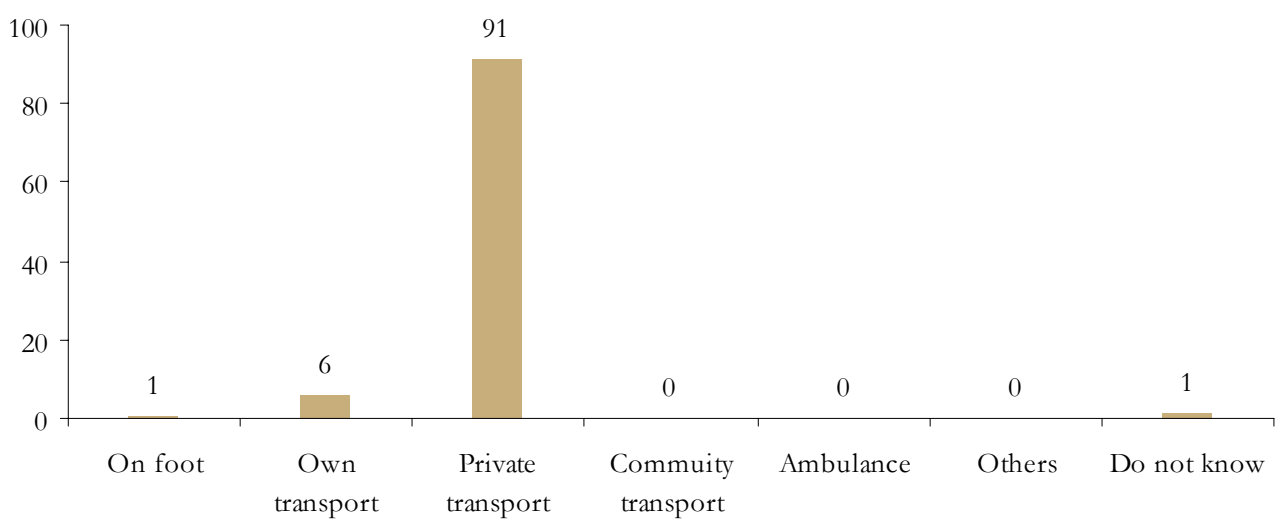

\section{Attitudes Towards Postpartum and Neonatal Care}

A large number of maternal deaths occur during the 48 hours after birth (JHPIEGO, 2004). "In spite of the high risk associated with the postpartum period, people seem to know very little about health practices during this period" (JHPIEGO, 2004). The importance of postnatal care is often undervalued. Postnatal care ensures that both mother and newborn are in good health, and monitors the recovery process of new mothers. However, when asked if women require postnatal care, 39 
percent of women indicated that postnatal care was unnecessary. Approximately 53 percent of the women interviewed in Upper Dir feel that postnatal care was unnecessary.

More than half of the respondents interviewed believe that some of the women in their community obtain postnatal care, whereas a quarter mentioned that none of the women in their community have visited any health care provider for postnatal checkups. Since about 15 percent of pregnant women require emergency obstetric care to prevent mortality, it is important to have regular postnatal checkups in order to monitor the recovery process. Lack of knowledge during the postpartum period may influence inappropriate or delayed care seeking, which may result in maternal morbidity or mortality.

Figure 5.7: $\quad$ Belief in necessity of postnatal care by place of residence

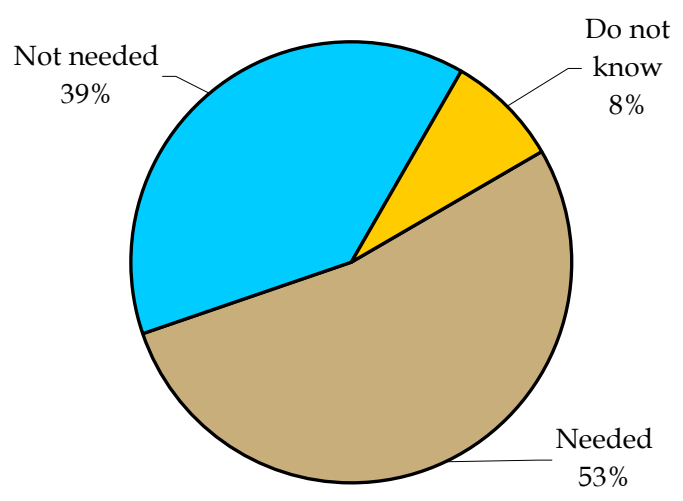

\section{Coverage of Lady Health Workers}

Women were asked if a Lady Health Worker (LHW) had been to their community. The data presented in figure 5.8 shows that less than half ( 45 percent) of the women were aware of the presence of an LHW in the community, while only a quarter (24 percent) of the women indicated that they had an LHW visit them within the past three months.

Figure 5.8: $\quad$ Presence of lady health worker in the community by place of residence

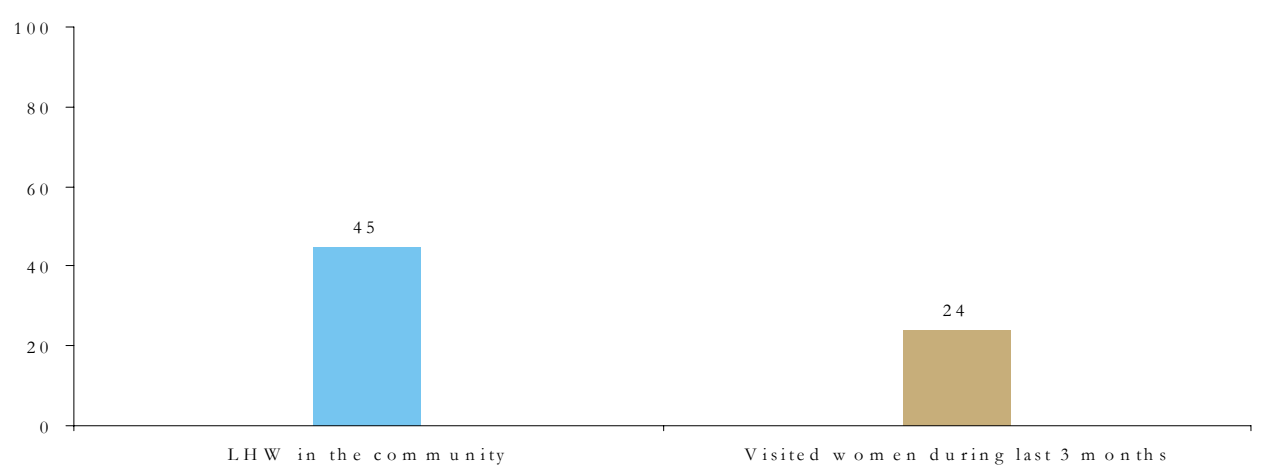




\section{Chapter}

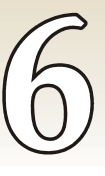

\section{Contraceptive Knowledge and Use}

Respondents were asked to name the ways in which a couple could delay or avoid a pregnancy. If the respondent did not spontaneously mention a particular method, the interviewer described different methods and asked the respondent to indicate if she recognized them. In the questionnaire, descriptions were included for six modern contraceptive methods and two traditional methods.

\section{Knowledge of Contraceptive Methods}

Many women are unaware of the different types of contraceptives that may be used to delay or prevent pregnancy. As women do not always have full control over the number of children they want to have, contraception is an important tool that helps give women that freedom of choice.

According to Figure 6.1, the most widely known methods in Upper Dir district are oral pills (90 percent), followed by injectables (86 percent). About 44 percent of women know about female sterilization and 29 percent know about IUD. About 20 percent of respondents know about condoms, 13 percent know about male sterilization and about 12 percent know about the withdrawal

method. Findings of the baseline survey suggest that women know more about female contraceptive methods than male methods.

\section{Ever Use of Contraception}

When asked if they had ever used any form of contraception, 37 percent of women answered in the affirmative. One-third of women indicated that they had used some form of modern contraceptives while 7 percent mentioned use of traditional methods. The most commonly used methods were temporary hormonal methods i.e. injectables ( 22 percent) and oral pills ( 21 percent). Ever use of male methods including condoms, male sterilization and withdrawal, long-term methods such as IUD and female sterilization were unexpectedly low as seen in figure 6.2. 
Figure 6.1: $\quad$ Percentage of married women by knowledge of specific contraceptive method

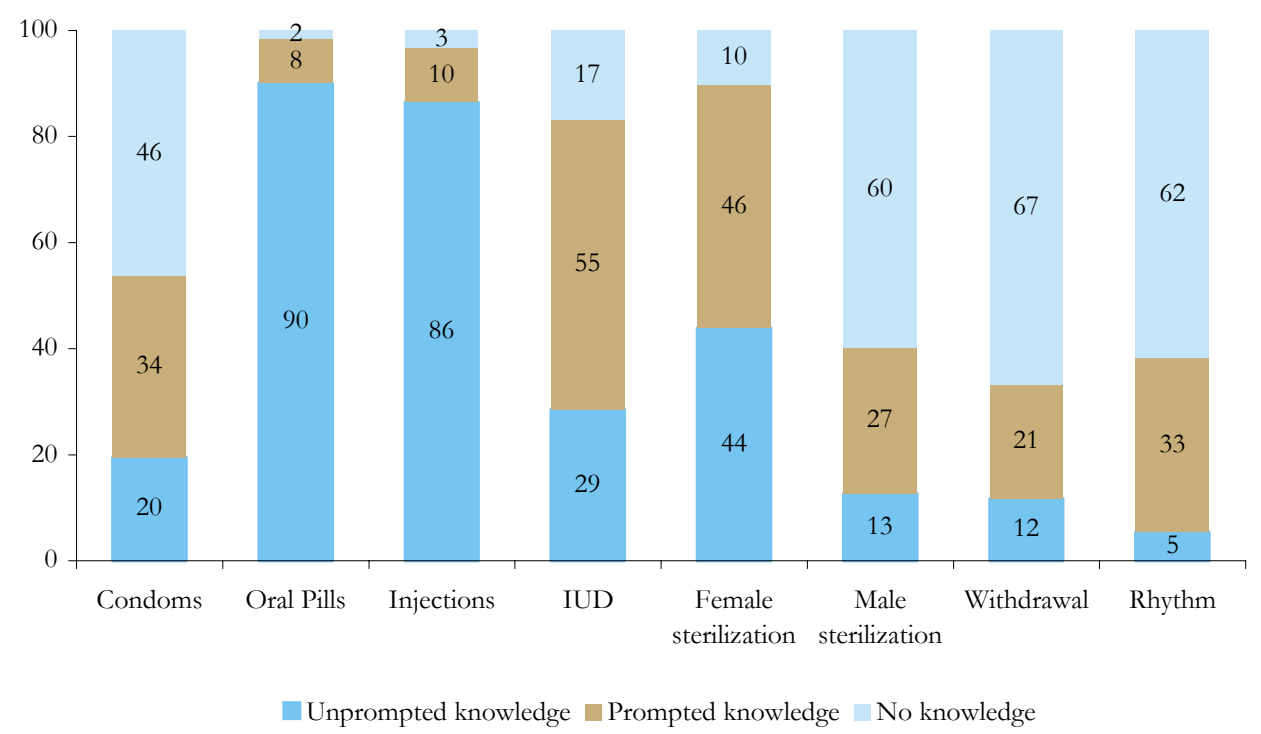

\section{Current use of Contraceptive methods}

Contraceptive prevalence rate is defined as the proportion of currently married women aged 15-49 years who were using some method of family planning at the time of the survey. Figure 6.2 shows the percent of married women who are currently using specific family planning methods. Contraceptive prevalence rate (CPR) in Upper Dir district is 16 percent. About 14 percent of the women are using modern contraceptive methods at the time of survey, whereas 2 percent are using traditional methods to avoid pregnancy.

Figure 6.2: $\quad$ Ever/current use of family planning method by contraceptive

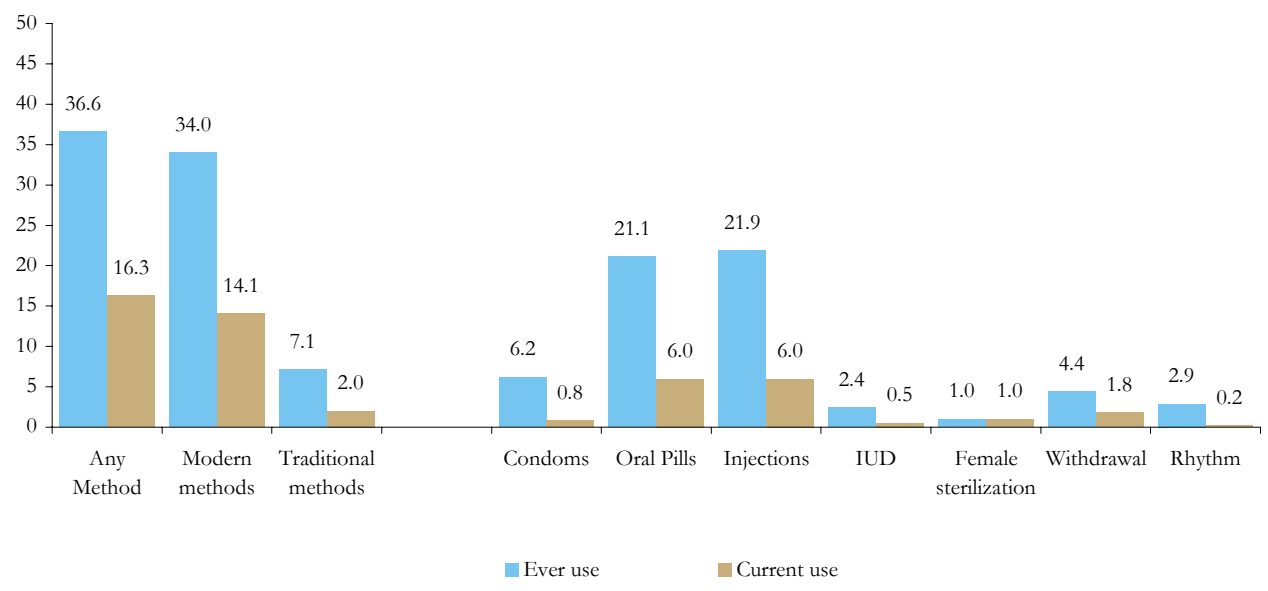


The most common methods being used in Upper Dir are injectables ( 6 percent) and oral pills (6 percent). Current use of condoms, IUD and female sterilization is less than 1 percent each. However, 2 percent of the women indicated use of the withdrawal method. Data presented in figure 6.2 suggests that current use of hormonal methods is high whereas current use of long term female methods (IUD, female sterilization) and male methods (condom and withdrawal) is negligible.

\section{Source of Contraceptive Supplies}

Current users of family planning methods were then questioned about the source from which they last obtained contraceptives. Figure 6.3 shows the percent distribution of current users of modern contraceptive methods by most recent source of supply. Findings show that contraceptive users are much more likely to rely on government sources than private medical sources (52 percent versus 42 percent).

In Upper Dir district, less than one-third of current users obtained their contraceptives from government hospitals (DHQ, RHC or BHU). About 13 percent of current users obtained their contraceptives from private hospitals/clinics, while another 29 percent bought contraceptives from medical or general stores.

LHWs are also an important source of contraception in Upper Dir, as they supply contraceptives to almost one fifth of the current users. Upper Dir has a predominantly rural population and LHWs seem very active in these areas. Though only 24 percent of women were visited by LHWs during the last three months prior to survey, it is encouraging to know that LHWs are supplying contraceptives to one-fifth of current users.

Figure 6.3: $\quad$ Distribution of current users of modern methods by source of supply

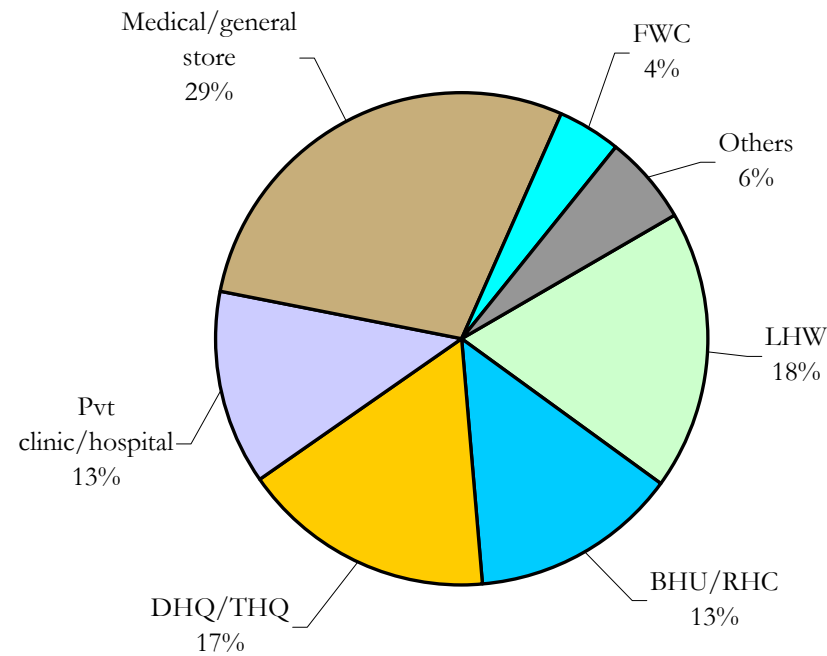




\section{Intentions of Future Use}

When the non-users of family planning methods were asked if they would like to use family planning methods in the future, the answers obtained were quite interesting. About 31 percent of the nonusers in Upper Dir said that they would like to use contraception in future. However, one-quarter of non-users do not intend to use any family planning methods in future, while 44 percent remain uncertain (figure 6.4).

Figure 6.4: $\quad$ Percentage of married women by future intention to use contraceptives

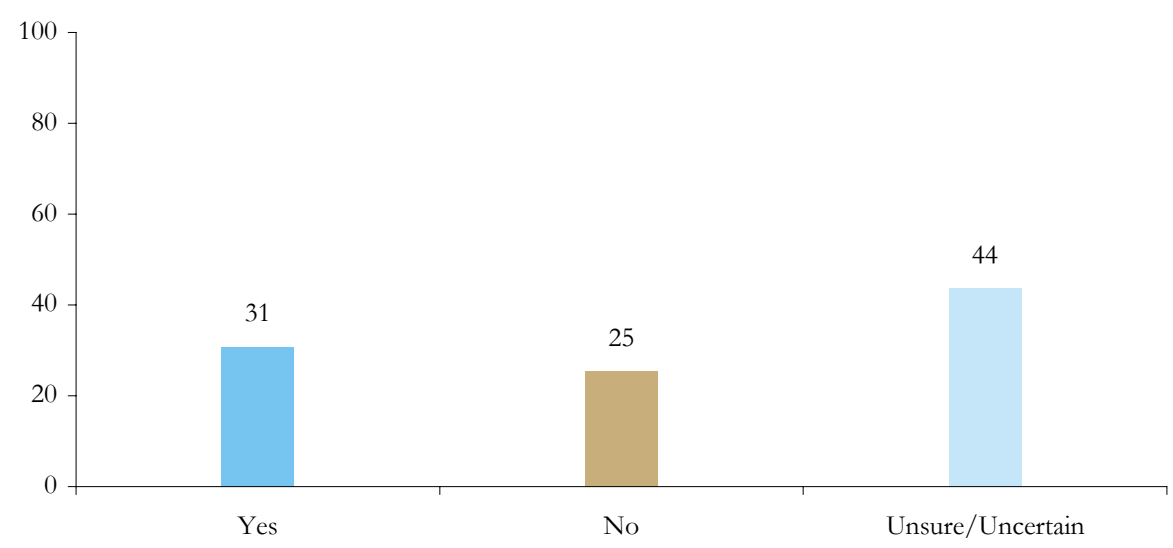




\section{Chapter}

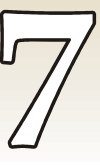

\section{Behavior Towards Maternal and Newborn Health}

Many of the women who were interviewed were pregnant at the time of the survey. However, some women, especially those early in the pregnancy, had not yet experienced the full range of events that take place over the nine-month gestational period. Women who had recently given birth were able to provide a full range of information on these events, and thus constitute an important part of the sample population in terms of understanding the attitudes and behavior concerning maternal and newborn health. This chapter pertains to the respondents' last pregnancy, given that it was within the past three years. Respondents were asked several questions regarding their experience during their last pregnancy including antenatal and delivery care, complications during pregnancy, delivery and postpartum period, postnatal care, and problems in accessing health care.

Information on antenatal, delivery and postnatal care is of immense value in identifying subgroups of women who do not utilize such services, and it is useful in planning for future improvements in the services. Delivery services are described according to the person assisting the delivery and the rate of caesarean section. Information on postnatal care was collected for women who did not give birth in a health facility, and it describes the time since delivery when care was received, as well as the person from whom it was received.

Information regarding complications during pregnancy, childbirth, and the postpartum period, as well as complications in the newborn was collected from these women. This information helps identify groups who are underserved. In total, there were 525 pregnancies in Upper Dir during the three years prior to the baseline survey. Out of these, 90 percent (473 pregnancies) resulted in live births, 3 percent (17 pregnancies) were stillbirths and 7 percent (35 pregnancies) ended in miscarriage. In the following sections, the data concerning 490 pregnancies that resulted in births (live or stillbirths) are analyzed.

\section{Antenatal Care}

In the survey, antenatal care was defined according to the type of provider, the number of visits made, and the stage of pregnancy at the time of the first visit, including whether or not tetanus toxoid injection and iron/folic tablets were received. The baseline survey also included questions regarding the antenatal care received by the respondent during their last pregnancy.

Figure 7.1 shows that 45 percent of the women interviewed never obtained antenatal care during their last pregnancy, while only about 26 percent had three or more antenatal check-ups. This would suggest that very few pregnant women had access to qualified health care providers in Upper Dir. 
Figure 7.1: $\quad$ Number of antenatal check-ups obtained

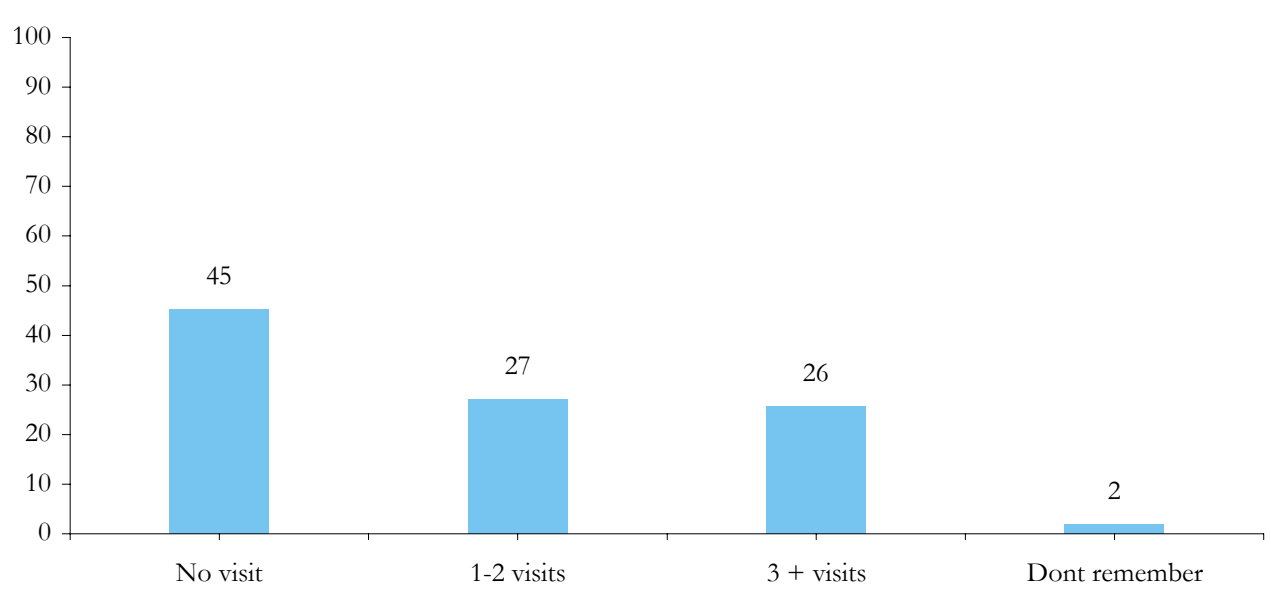

However, one-third of the pregnant women who had at least one antenatal checkup initiated it during their first trimester (figure 7.2). Almost the same proportion had their first antenatal visit in the second trimester. One quarter went to see a health provider during their last trimester of pregnancy.

Figure 7.2: $\quad$ Gestational age at first antenatal check-up

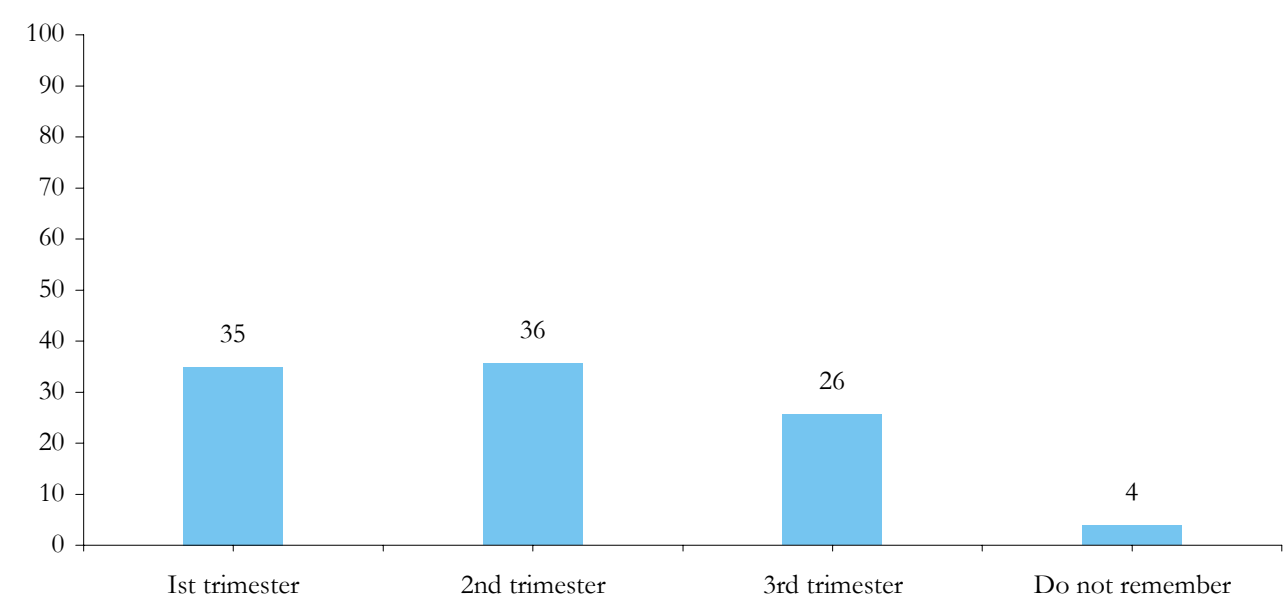

In Upper Dir, pregnant women went to government as well as private health facilities for their antenatal checkups. More than half (53 percent) of pregnant women who had at least one antenatal visit went to the district headquarter hospital, while less than one quarter visited basic health units (BHUs) or rural health centers (RHCs). More than one-third of pregnant women visited private health facilities for antenatal check-ups (figure 7.3). 
Figure 7.3: $\quad$ Place from which antenatal care was obtained

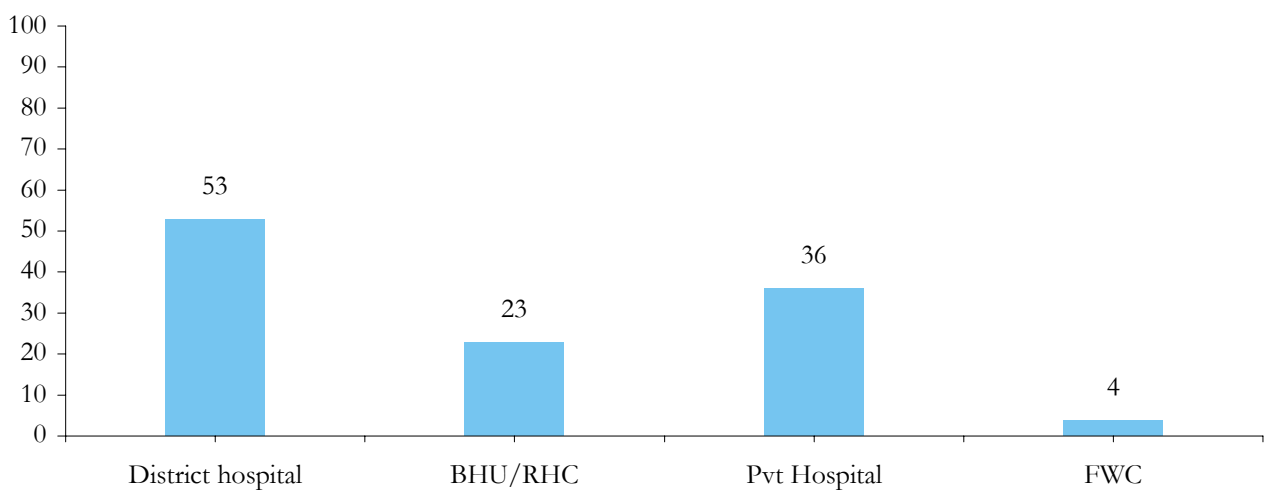

\section{Components of Antenatal care}

In Pakistan, it is recommended that every pregnant woman receive the following services during their antenatal visits to any health care provider; height and weight measurements, blood pressure measurement, iron tablets, immunization against tetanus, and abdominal examinations. In any antenatal visit, a woman should be informed of the danger signs of pregnancy, have her weight measured, and provide blood and urine samples for testing. Antenatal care can improve certain outcomes through the detection and management of possible complications. Antenatal care can also prevent, identify and treat iron deficiency and anemia in pregnant mothers, while improving the birth weight of the child.

Figure 7.4 shows the services provided to pregnant women during their antenatal checkups. Almost two thirds of those women who had at least one antenatal checkup got their blood pressure measured and were asked about their last menses period. More than half of the pregnant women got their urine and blood tested and about 45 percent got a referral for an ultrasound.

Figure 7.4: $\quad$ Services performed/questions asked during antenatal check-up

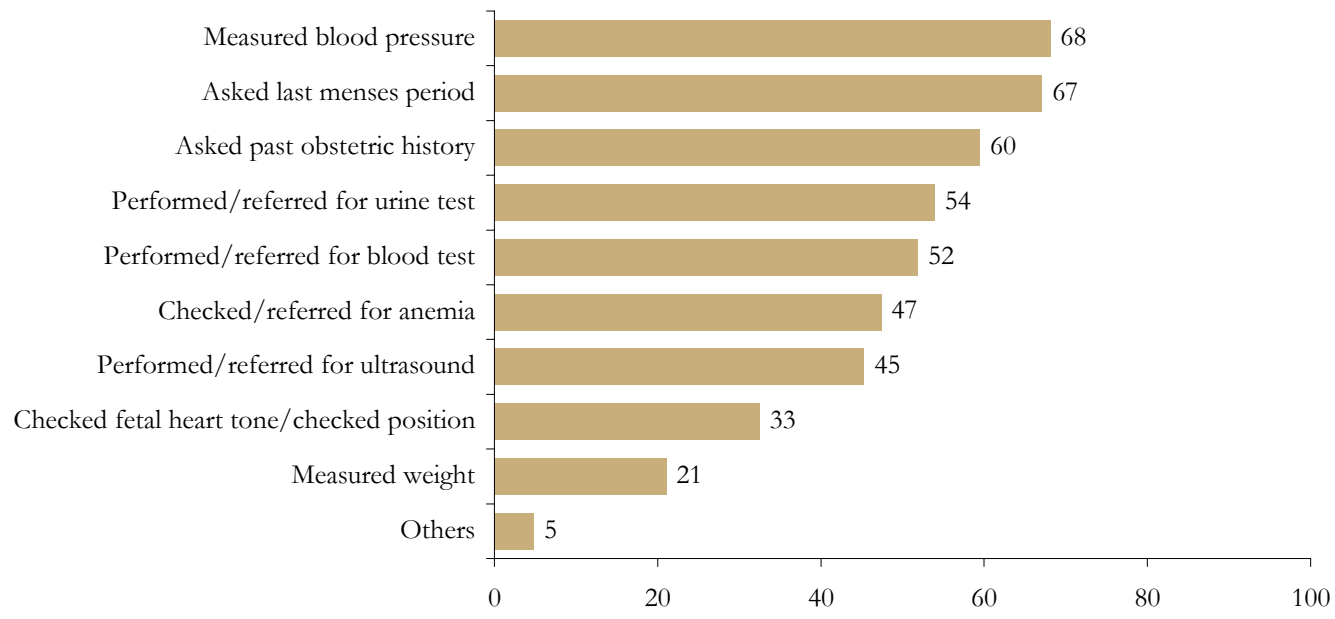


Advice was given on diet and nutrition to about 66 percent of the pregnant women, 55 percent received tetanus toxoid shots, and 28 percent were provided with information on breastfeeding. Only about a quarter of the pregnant women received information on danger signs (see figure 7.5).

Figure 7.5: $\quad$ Percentage of pregnant women by issues discussed during antenatal check-up

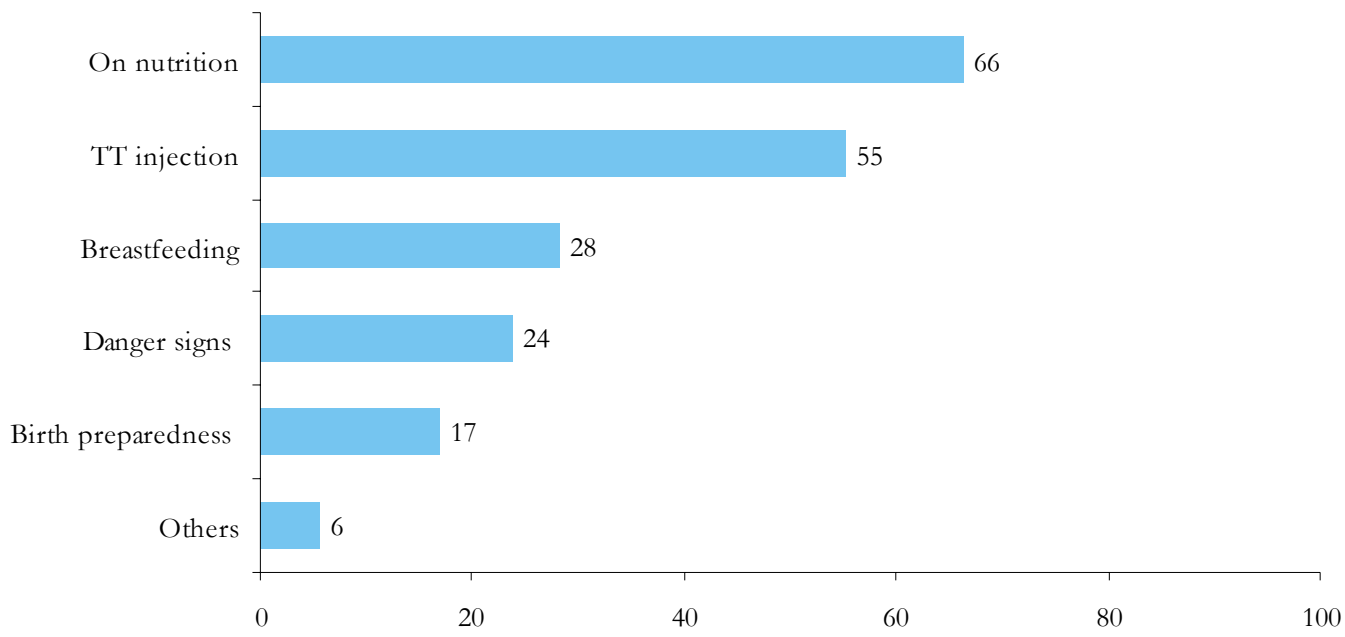

\section{TT Injections and Iron/Folate Tablets}

Respondents were also asked to state whether they took iron/folate supplements and received TT shots during their last pregnancy. In Pakistan, the immunization of pregnant women is enforced by a program coordinated by the Expanded Program on Immunization (EPI) and the Maternal and Child Health Care $(\mathrm{MCH})$ departments at the district level. The program recommends that women receive two tetanus toxoid (TT) injections during their first pregnancy. Booster injections are given once during each subsequent pregnancy to maintain full protection. In recent years, TT immunization has also been given to women before marriage, so that any pregnancy occurring within three years of their marriage would be protected against tetanus.

The data presented in figure 7.6 shows that 4 percent of the pregnant women got one T'T shot during their last pregnancy. However, about 50 percent of the women interviewed did not receive any TT shots, while 10 percent were not able to recall whether or not they received a shot. Only about 36 percent of the respondents received the recommended number of two TT shots. 
Figure 7.6: $\quad$ Percentage of married women by status of TT injections received during the last pregnancy

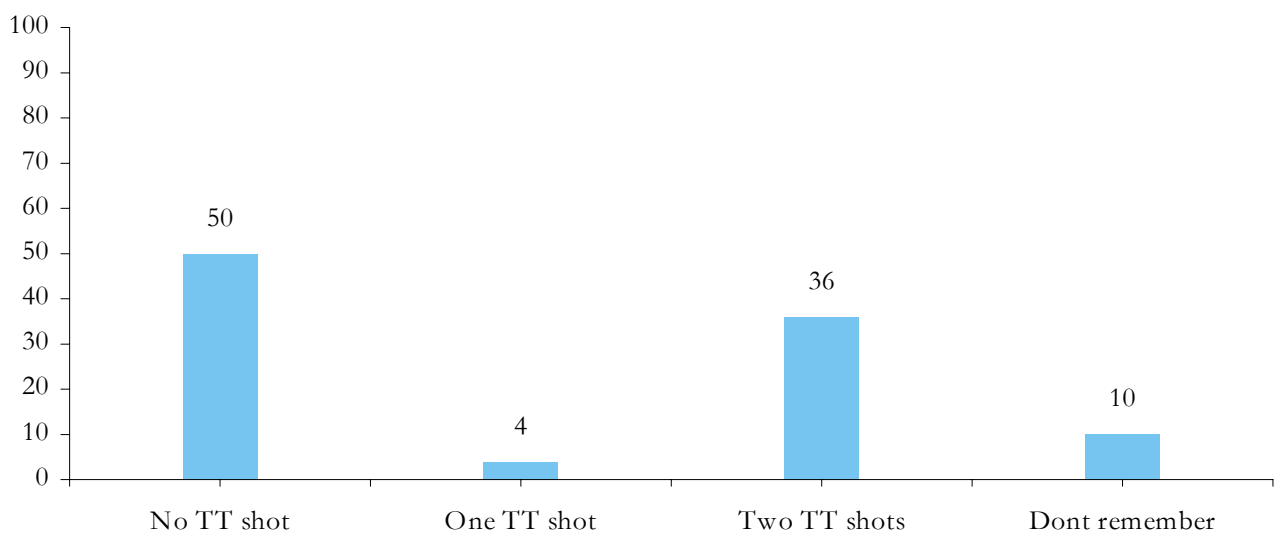

Of those pregnant women who received at least one TT shot, 92 percent received it from a government health facility, whereas about 4 percent received their TT vaccination from private hospitals/clinics (figure 7.7).

Figure 7.7: $\quad$ Place where TT shots were received

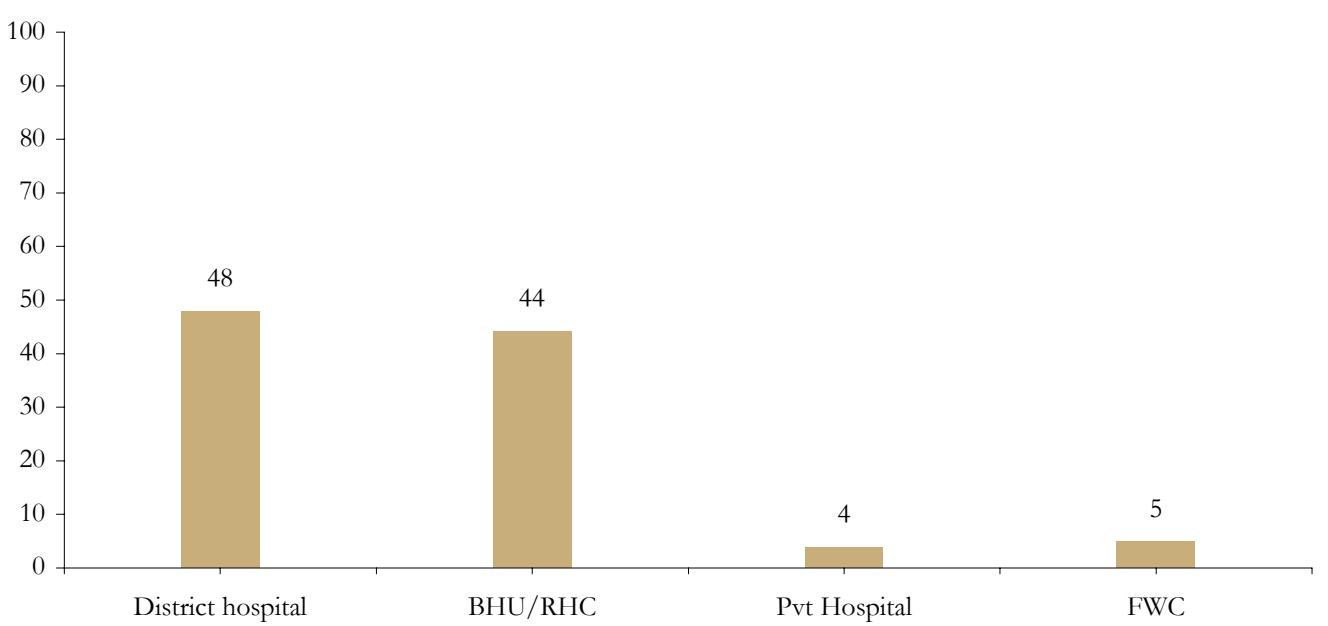

Furthermore, only 36 percent of the women interviewed said that they took iron/folate supplements during their last pregnancy (figure 7.8). 


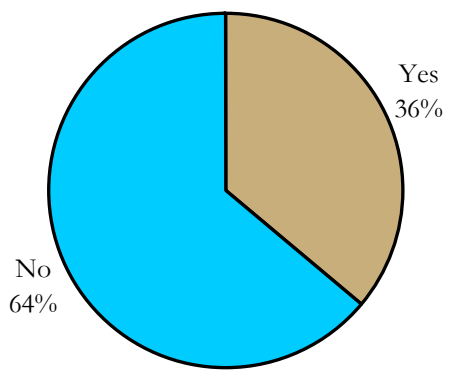

\section{Experience of Complications and Birth Preparedness}

\section{Complications during Pregnancy}

Respondents were asked to indicate if they had experienced any complications during their last pregnancy. Almost 73 percent of the respondents mentioned having experienced at least one of the danger signs during pregnancy.

The most common symptom as reported by 50 percent of the pregnant women was 'severe lower abdominal pain'. Other danger signs included 'severe headache' (30 percent), 'severe or prolonged vomiting' (23 percent) and 'fever' (22 percent). About 15 percent of the pregnant women mentioned 'blurring of vision' and 11 percent suffered from ' high blood pressure' (figure 7.9).

Figure 7.9: $\quad$ Percentage of married women who experienced complications during their last pregnancy.

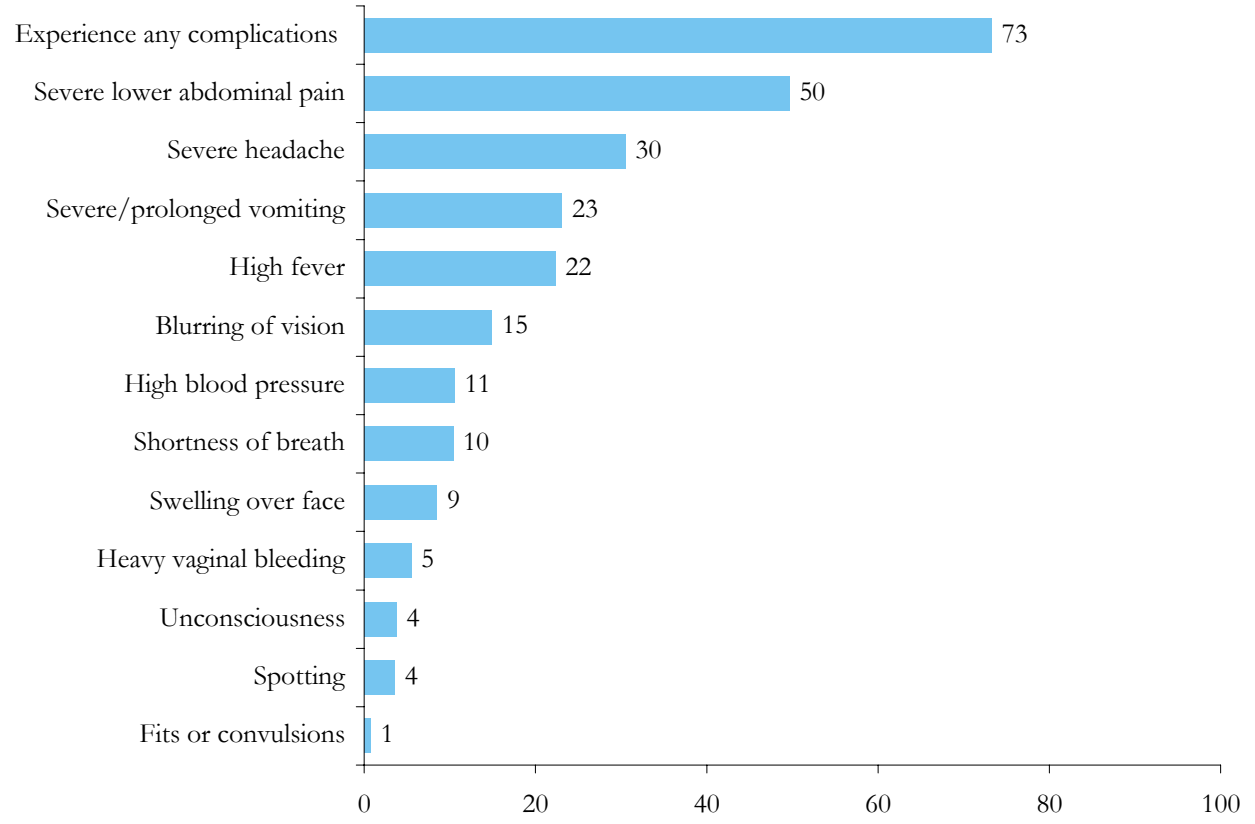




\section{Preparedness for Childbirth}

To ensure the safety of the mother and newborn at the time of delivery, certain preparations need to be made. These include deciding who is going to assist in the delivery, where the delivery is going to take place, how the woman is going to get to the place of delivery, and how much the delivery is going to cost. Delivery services, especially emergency obstetric care, are critical for pregnant women. Emergency care is important in the event that a woman experiences obstructed labor, pregnancyinduced hypertension and eclampsia. Obstructed or prolonged labor is one of the more serious complications that can cause maternal death. Obstetric care can also prevent or treat complications that affect the neonate, such as birth asphyxia.

The questions asked assessed the arrangements that were made for the time of delivery, as well as the removal of various delays, which may affect the health of both mother and baby. Respondents were asked if they had made the necessary arrangements regarding transport, money, blood, location and hours of operation of the nearest hospital, as well as clothes for the newborn baby. According to figure 7.10, more than 44 percent of mothers indicated that they had made most of these arrangements. About 56 percent of the women interviewed knew the location of hospital where the delivery could be conducted in case of an emergency. More than two fifths of married women reported having knowledge about delivery costs and had arranged money for both normal and emergency deliveries. A quarter had made arrangements for transport in case of an emergency, while about one fifth had spoken with a birth attendant.

Figure 7.10: $\quad$ Percentage of married women who made arrangements for their last delivery

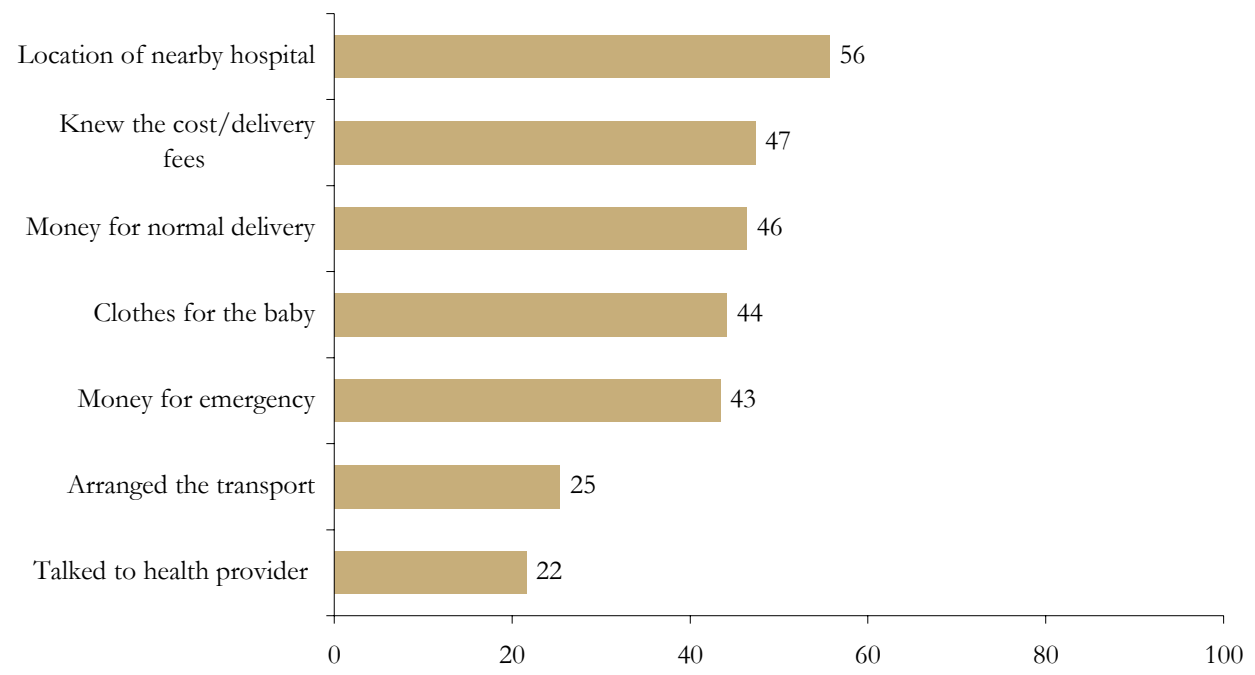




\section{Delivery Characteristics}

When asked about the status of their delivery, 89 percent of the women in Upper Dir indicated that they had a normal vaginal delivery, while about 2 percent each had assisted vaginal deliveries and caesarean sections. About 7 percent of the pregnancies resulted in either spontaneous or induced abortions.

As well, the outcome of each pregnancy was recorded, with live births making up 90 percent of all deliveries, and stillbirths and abortions making up about 3 percent and 7 percent of all pregnancies respectively.

Figure 7.11: $\quad$ Status of last delivery

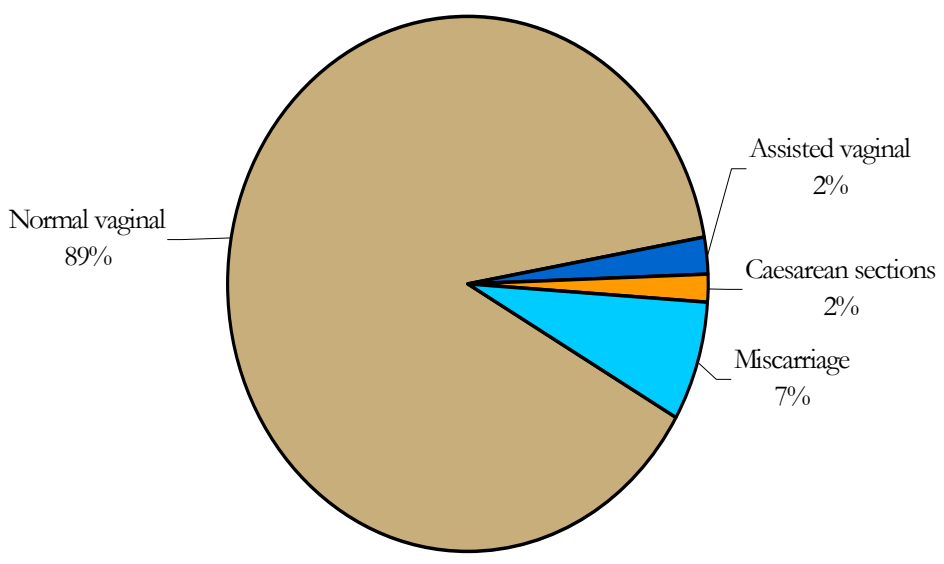

\section{Place of delivery}

Survey findings show that three quarters of all deliveries took place at home, while about 12 percent and 11 percent of the deliveries were conducted at government and private health facilities respectively. According to this data, both government and private health facilities have an equal share in providing institutional deliveries.

Figure 7.12: $\quad$ Place of last delivery

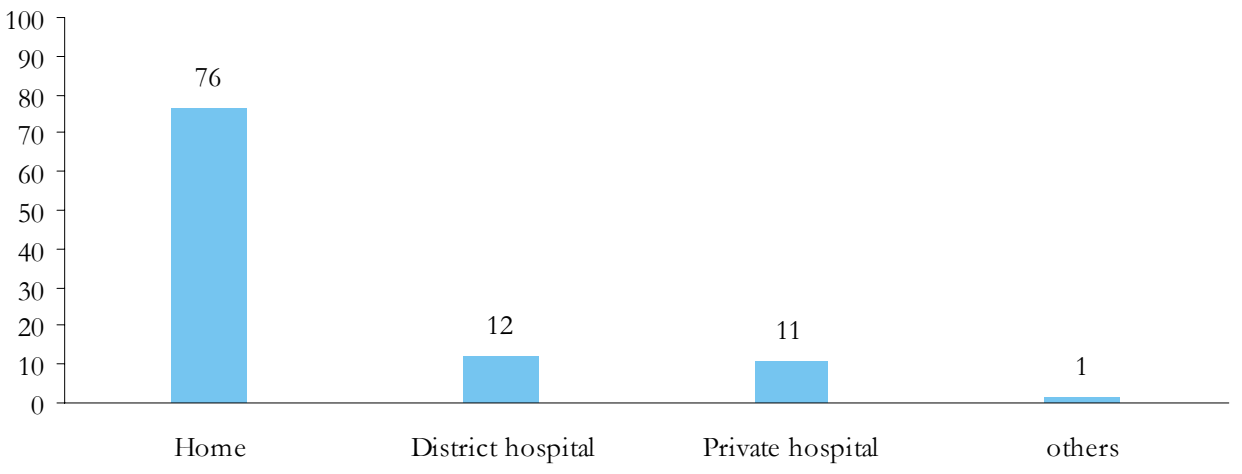




\section{Assistance during Delivery}

According to survey results, only 33 percent of all deliveries in Upper Dir were conducted by SBAs while the rest (approximately 66 percent) were conducted by unskilled birth attendants. Examples of unskilled attendants include TBAs who conducted approximately 22 percent of all deliveries, and female family members who conducted about 43 percent of the deliveries in Upper Dir. A challenge for the PAIMAN project will be convincing pregnant women to have their deliveries conducted by a person who is not a member of their family. On the other hand, it will be extremely difficult to train all relatives who usually conduct deliveries.

Figure 7.13: $\quad$ Distribution of births by type of attendant

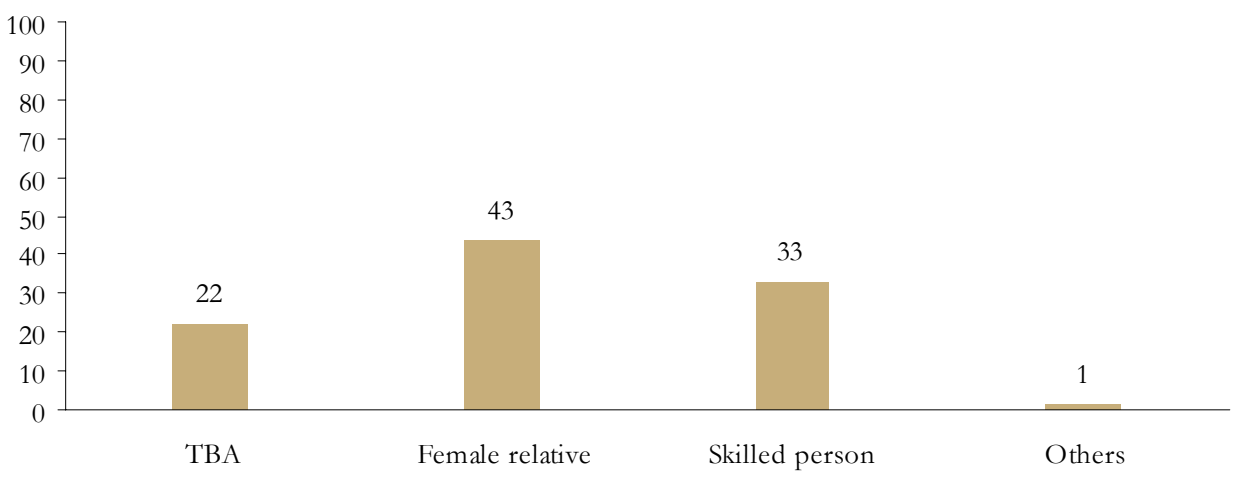

More than one-quarter of the women who used the services of a TBA said that family choice was the main reason for choosing the TBA over a health professional to assist with the delivery. Another quarter believed that TBAs are more knowledgeable than health professionals, while about 21 percent indicated earlier use of the TBA as the main reason for using her services again. Low cost and geographical proximity were the other reasons cited by 4 percent and 18 percent of the population respectively (Figure 7.14).

Figure 7.14: $\quad$ Main reason for using a $\quad$ TB $A$ / dai to assist with the last delivery

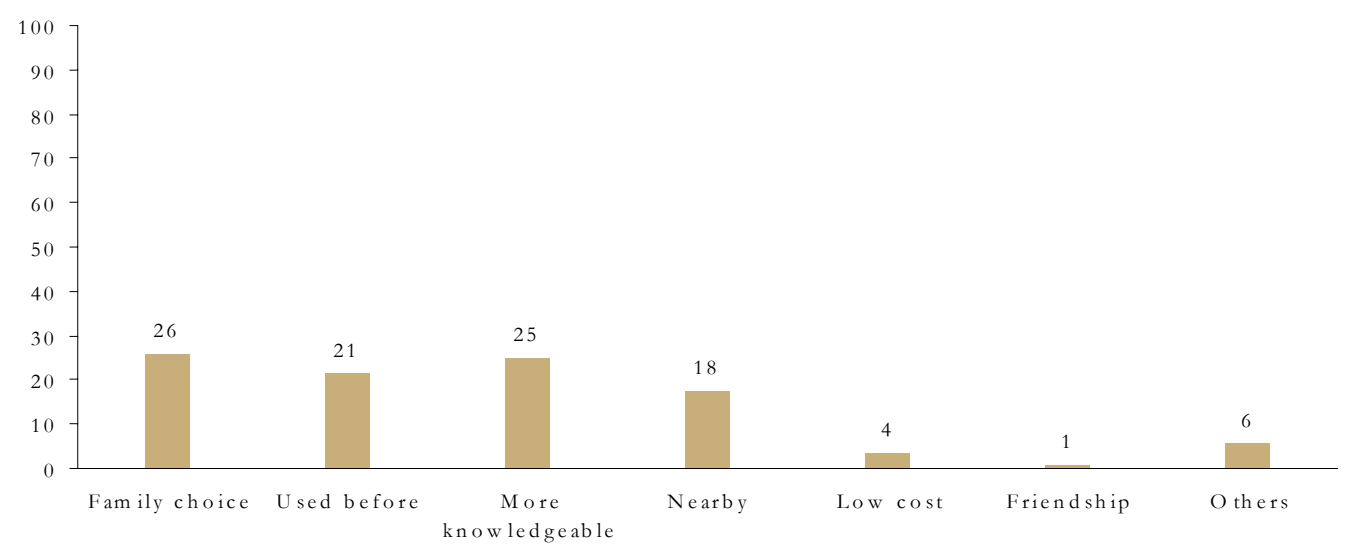




\section{Clean Delivery Practices}

Respondents were asked to state if their TBAs followed safe health practices such as washing their hands with soap prior to deliveries and using clean delivery kits. The data presented in figure 7.15 indicates that approximately 62 percent of the birth attendants washed their hands prior to delivery, whereas the remainder did not. One fourth of the women also reported that the TBA used new thread to tie the cord.

Figure 7.15: $\quad$ Percentage of delivery attendants who reportedly washed their hands before conducting the delivery/ type of thread used to tied the cord

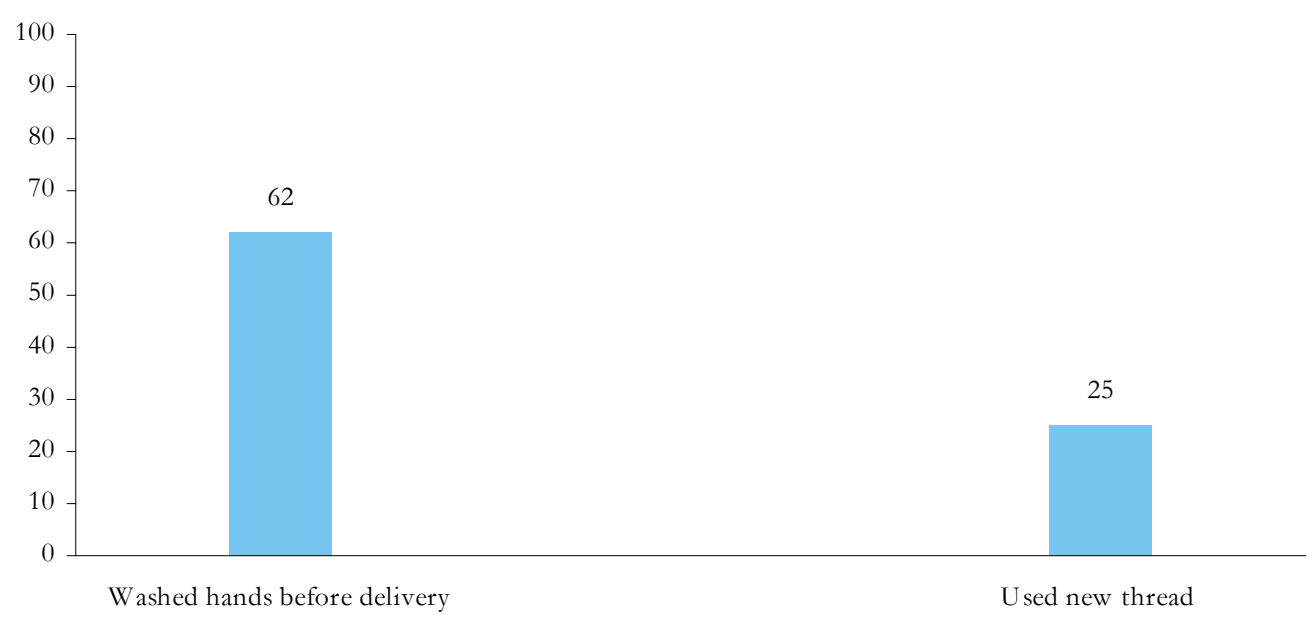

\section{Complications During Childbirth}

Respondents were asked to indicate the complications they may have experienced during childbirth. More than one third of the respondents mentioned that they experienced 'excruciatingly abnormal pain', 27 percent experienced 'prolonged or obstructed labor', 13 percent reported 'premature rapture of membranes' and 12 percent experienced bleeding before labor began (table 7.1).

Table 7.1: $\quad$ Type of complications experienced during the last delivery

\begin{tabular}{lrr} 
Complications & Percentage & Number \\
Prolonged/obstructed labor & 27.1 & 143 \\
\hline Bleeding before labor began & 11.9 & 63 \\
\hline Excruciating abnormal pain & 34.3 & 181 \\
\hline Premature rupture of membranes & 13.1 & 69 \\
\hline Delay in delivery of placenta/retained placenta & 6.8 & 36 \\
\hline Excessively postpartum bleeding. & 10.2 & 54 \\
\hline Tear in vagina, cervix or uterus & 8.0 & 42 \\
\hline Prolapsed of the uterus & 3.6 & 19 \\
\hline Fever & 15.5 & 82 \\
\hline Abnormal position fetus & 2.7 & 14 \\
\hline
\end{tabular}




\section{Decision-making within the family}

Delays in seeking care, in reaching adequate health facilities, and in receiving appropriate care at health facilities are recognized barriers to care for pregnant women, and these factors may be especially pronounced for young and older pregnant mothers. Timely and appropriate care provides an opportunity to prevent or manage the direct causes of maternal mortality such as hemorrhage, obstructed labor, infection and hypertensive disorders. It also reduces fetal and neonatal deaths related to obstetric complications. Table 7.2 shows that about 44 percent of the women surveyed indicated that their husbands were the ones who decided to seek treatment when faced with deliveryrelated complications. About 29 percent indicated that it was their mother-in-law who made the final decision, while only about 13 percent indicated that they themselves decided when to seek medical attention while experiencing complications.

Table 7.2: $\quad$ Person who made decision to seek health care/mode of transport used to reach health facility

\begin{tabular}{llrr} 
Measures taken & & Percent & \multicolumn{1}{c}{ Number } \\
& Self & 12.6 & 25 \\
\cline { 2 - 4 } & Husband & 43.9 & 87 \\
\cline { 2 - 4 } $\begin{array}{l}\text { Person who made decision to seek } \\
\text { health care }\end{array}$ & Mother in law & 28.8 & 57 \\
\cline { 2 - 4 } & Other family member & 12.6 & 25 \\
\cline { 2 - 4 } & TBA/Dai & 1.5 & 1 \\
\cline { 2 - 4 } & Others & 0.5 & 107 \\
\hline \multirow{3}{*}{$\begin{array}{l}\text { Mode of transport to reach health care } \\
\text { service }\end{array}$} & Service provider visited at home & 54.0 & 5 \\
\cline { 2 - 4 } & On foot & 2.5 & 68 \\
\cline { 2 - 4 } & Own transport & 7.1 & 4 \\
\cline { 2 - 4 } Total & Private transport & 34.3 & 198
\end{tabular}

\section{Availability of Transport}

The mode of transport used to reach a health facility was also an issue that was discussed during the survey. One-third of all women treated for delivery complications used private transport to reach a health facility. In more than half (54 percent) of the cases, service providers visited the respondents households to provide childbirth services.

Figure 7.16 shows the distribution of respondents by the time they took to reach a health facility. About one-fifth of the pregnant women were able to reach the facility within 30 minutes. More than one-quarter took 30 to 60 minutes to reach a health facility, while another quarter reached within one to two hours. 
Figure: 7.16: $\quad$ Time taken to reach the health facility for childbirth

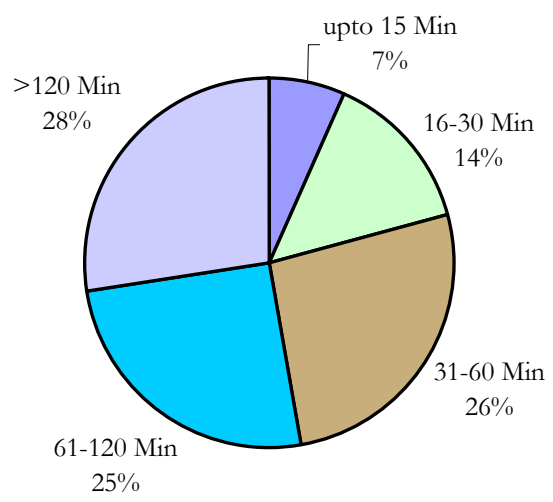

As seen in Figure 7.17, it took an average of one hour for respondents to secure transportation at the time of delivery, and another hour to reach a health facility. The average waiting time upon reaching a health facility was reportedly 15 minutes.

Figure 7.17: $\quad$ Average median time in minutes to get the transport, to reach the health facility and to obtain the treatment after reaching the facility

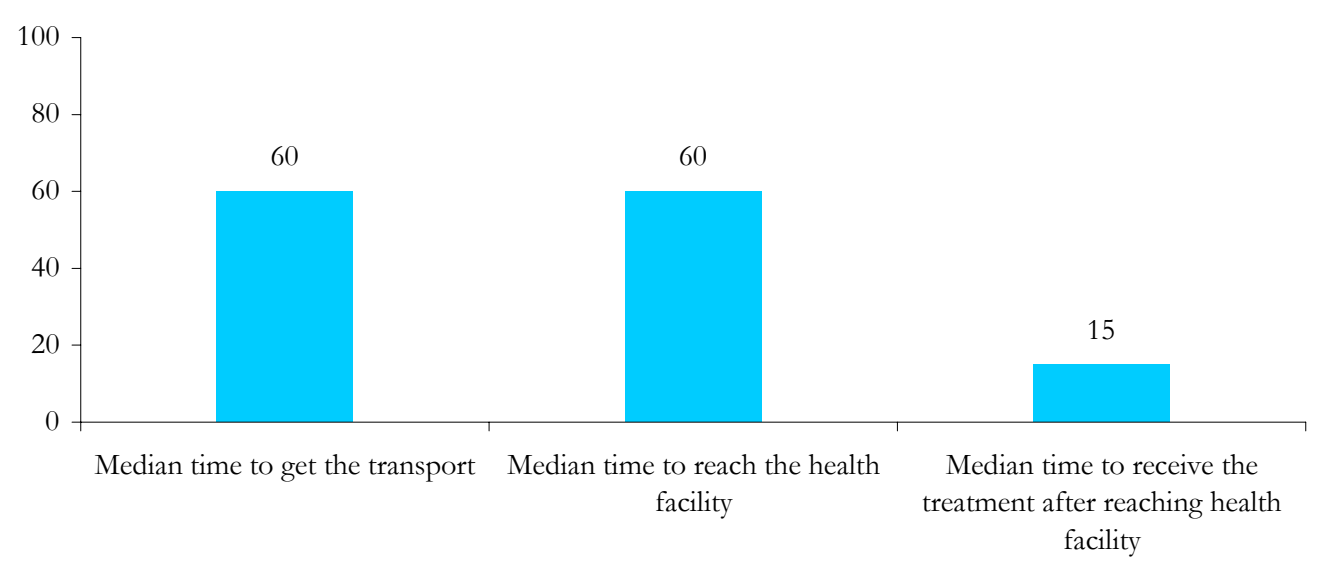

\section{Postpartum Care}

The postpartum period is a critical time for both the mother and the newborn. Respondents were asked about the quality and level of postpartum care they received after their last delivery. According to table 7.3 , a large portion (83 percent) of women did not receive any postnatal check-ups after their last pregnancy. Only about 14 percent of the women claimed to have had postnatal checkups. Among those who went for postnatal care, less than 1 percent had their first checkup on the same day as the delivery. According to table 7.3, 40 percent of the respondents reported complications during the postpartum period. 
Table 7.3:

History of postpartum care

\begin{tabular}{|c|c|c|c|}
\hline History & & Percent & Number \\
\hline \multirow{3}{*}{ Have a postnatal check-ups } & Yes & 13.9 & 68 \\
\hline & No & 82.8 & 405 \\
\hline & Delivered in hospital & 3.3 & 16 \\
\hline No. of days after delivery, have first check-up & Same day & 0.6 & 3 \\
\hline \multirow{2}{*}{ Experience complications during postpartum period } & Yes & 40.4 & 213 \\
\hline & No & 59.6 & 314 \\
\hline Total & & 100.0 & 527 \\
\hline
\end{tabular}

\section{Newborn/Infant Care}

The care provided to a newborn upon birth is crucial to the baby's health. Survey questions regarding initial infant and childcare help determine the cause of newborn morbidity and mortality.

\section{Child Care During Birth}

Respondents were asked where their child was placed immediately after delivery. While more than one-third (35 percent) of the mothers indicated that their newborns were placed with them immediately following delivery, a large percentage indicated that their newborns were placed on either a piece of cloth ( 25 percent) or on a mattress (15 percent). Almost 4 percent of the mothers indicated that their newborns were placed on the floor immediately after delivery. It is important to record the percentage of women subject to harmful or unhealthy procedures in order to understand the root causes of infant mortality.

Table 7.4:

History of newborn care

\begin{tabular}{|c|c|c|c|}
\hline History & & Percent & Number \\
\hline \multirow{6}{*}{ Placed child immediately after delivery } & On floor & 4.0 & 19 \\
\hline & On mattress & 15.2 & 72 \\
\hline & On a piece of cloth & 24.9 & 118 \\
\hline & Put with the mother & 34.5 & 163 \\
\hline & Others & 12.5 & 59 \\
\hline & Don't know & 8.9 & 42 \\
\hline Used new blade to cut the cord & Yes & 25 & 93 \\
\hline \multirow[b]{3}{*}{ New thread was used to tie the cord } & No & 67.7 & 252 \\
\hline & Do not know & 7.3 & 27 \\
\hline & & 87.6 & 326 \\
\hline \multirow{3}{*}{$\begin{array}{l}\text { Child dried up/cleaned before giving } \\
\text { bath }\end{array}$} & Yes & 84.8 & 401 \\
\hline & No & 5.9 & 28 \\
\hline & Don't know & 9.3 & 44 \\
\hline
\end{tabular}


When women were asked to name the instrument that was used to cut the cord, about a quarter of the mothers mentioned that a new blade was used; however, nearly 68 percent indicated that a new blade was not used at the time of delivery. A large majority ( 88 percent) of mothers mentioned that a new thread was used to tie the cord (Table 7.4).

It is not very common to weigh a newborn in a district where most of the births take place at home. For those women who did not weigh their newborns, a question was asked about the size of the baby at the time of birth. Figure 7.18 depicts the percentage distribution of babies by their size at birth. More than 82 percent of the mothers reported that the size of their babies at the time of birth was normal. About 16 percent reported that their baby was smaller than average, and only 1 percent reported that their baby was bigger than normal size.

Figure 7.18: $\quad$ Percentage of newborns according to their size (small, normal and big) at birth

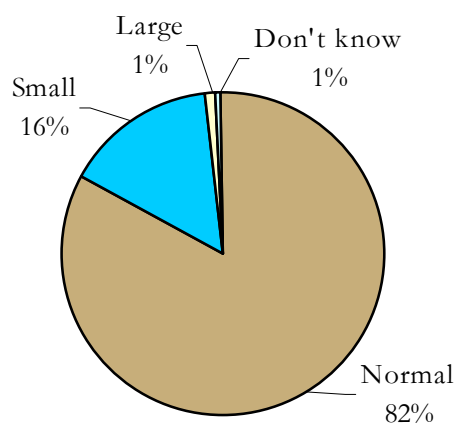

A question on the practice of bathing babies after the birth was also asked and figure 7.19 shows the responses. It shows that less than two-thirds of the babies were bathed within the first hour after their birth. Only a quarter of the newborns were bathed after 6 hours of their birth, which is the recommended practice.

Figure 7.19: $\quad$ Duration between the time of birth and the first bath given to a newborn

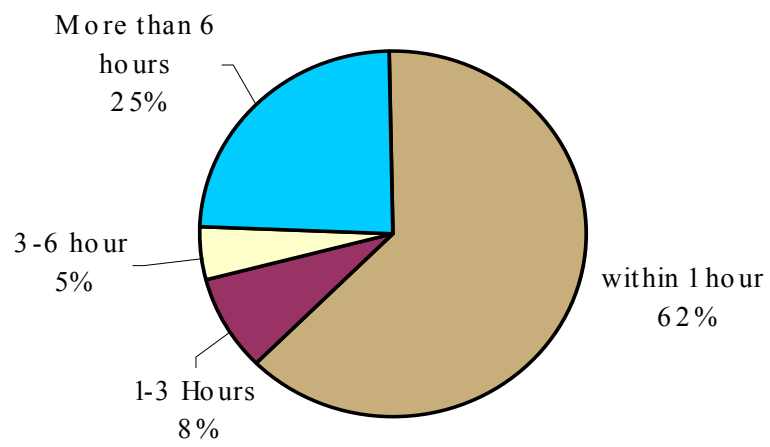




\section{Colostrum and Breastfeeding}

Respondents were also asked if they ever breastfed their infants. Over 97 percent of mothers indicated that they did in fact breastfeed their child. Colostrum is another very important aspect of newborn health, and respondents were asked if they gave colostrums to their newborn babies. In Upper Dir, 71 percent of mothers gave colostrums to their babies.

\section{Newborn Medical Check-ups}

Respondents were also asked if any physical and/or medical examinations were conducted on the newborn baby. Almost 62 percent of mothers mentioned that they had any medical or physical examinations conducted on their newborn babies. A lack of physical and medical examinations conducted after birth may potentially result in complications being left undetected, which in turn could be harmful to the health of a newborn. Respondents were asked to recall any complications or symptoms they noted in their newborn soon after delivery.

Figure 7.20: $\quad$ Newborn feeding and health indicators

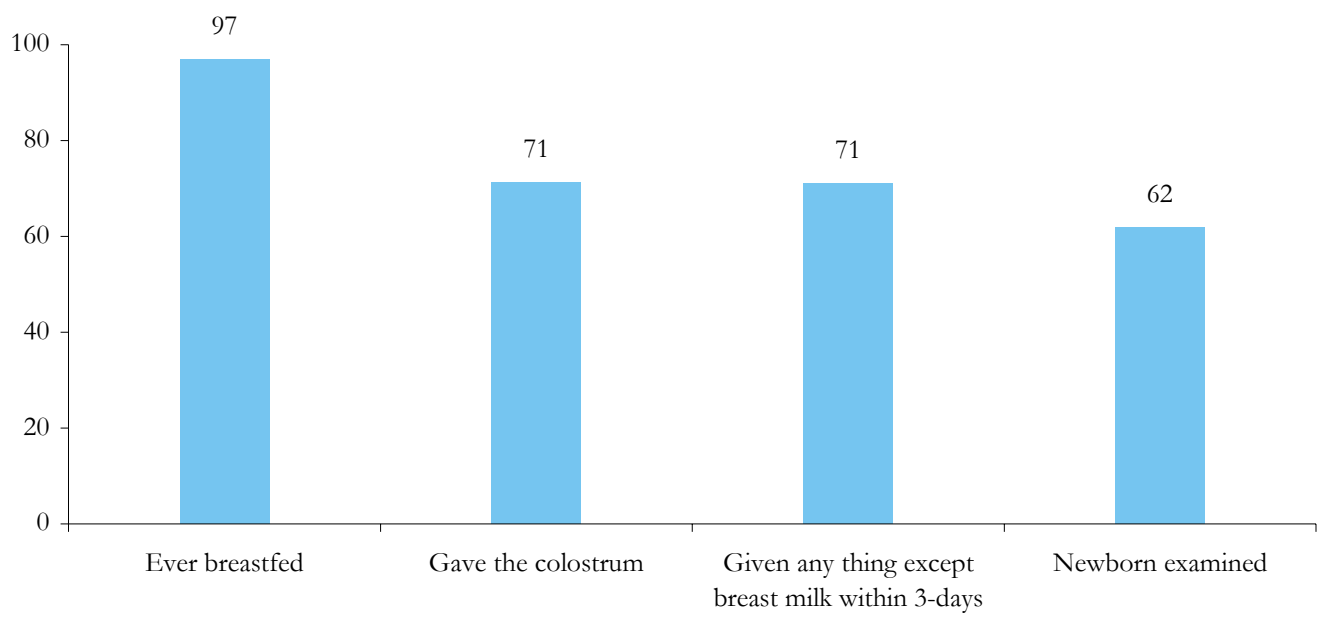

Discoloration of the skin (jaundice) and no or a weak cry were the most widely noted symptoms according to figure 7.20. Respondents were then asked if they noted any symptoms or complications within the first seven days after birth. Jaundice was the most commonly noted symptom in newborns within the first seven days of their birth. 
Figure 7.21: $\quad$ Percentage of newborns with danger signs/symptoms soon after deliver

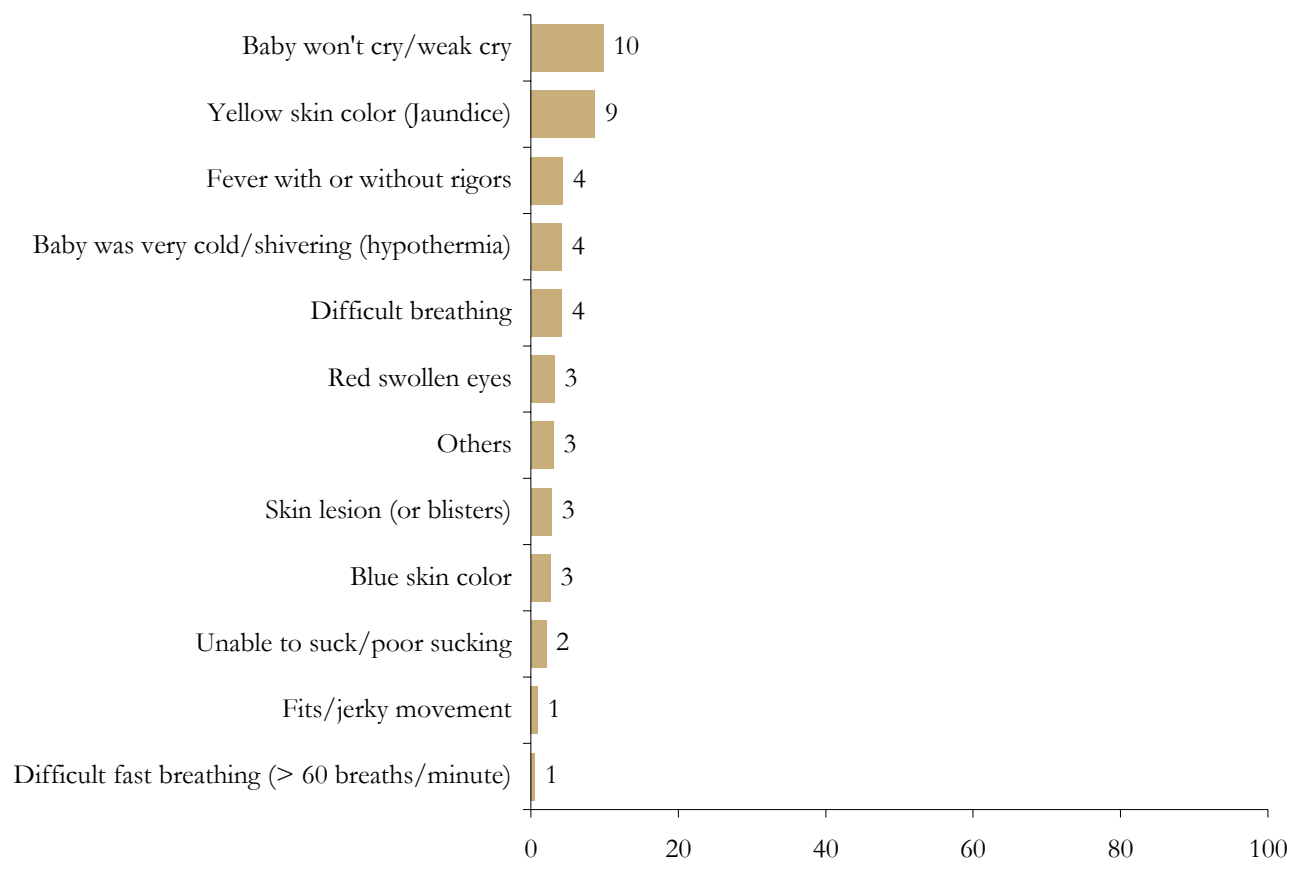

Figure 7.22 Percentage of newborns with danger signs within 7-days after delivery

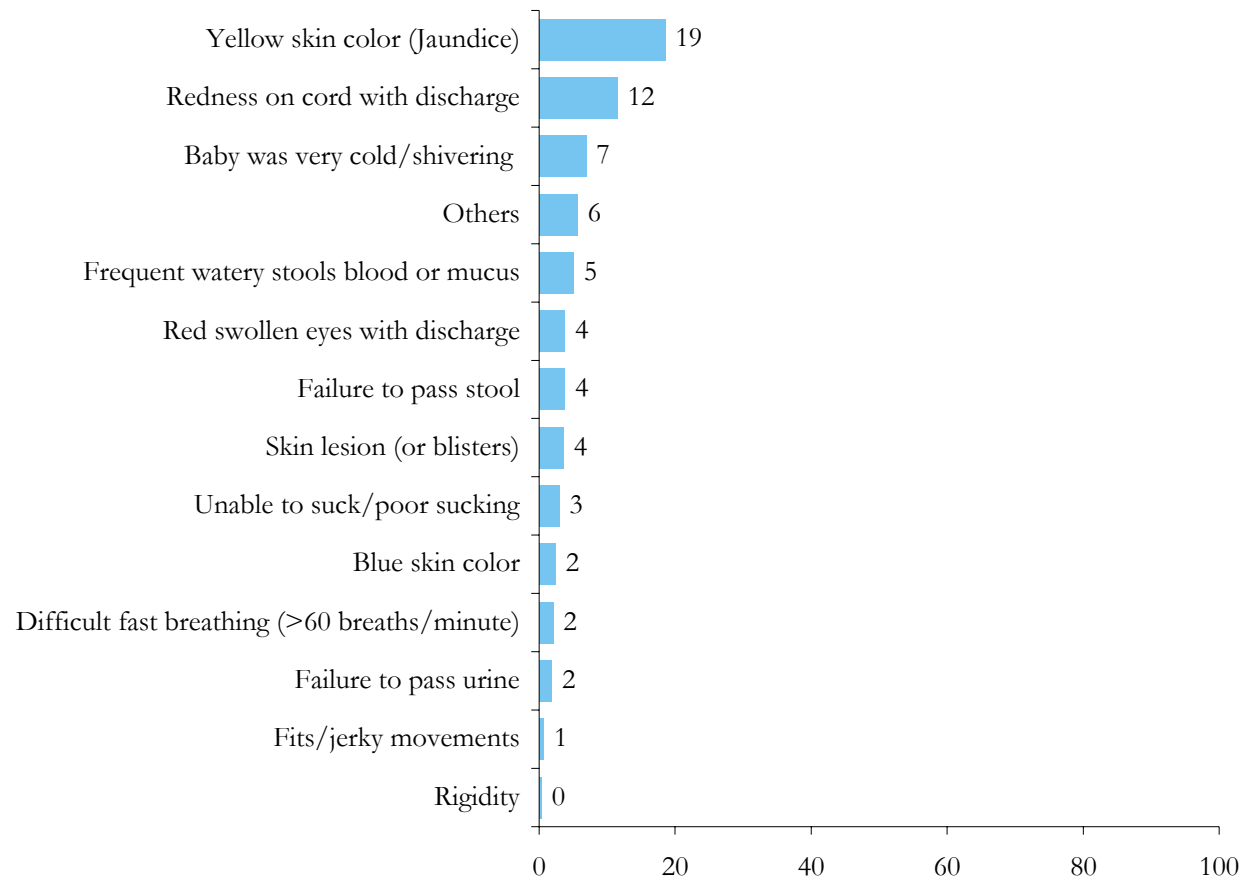


Finally, respondents were asked to indicate the measures they took to get their newborn treated once the symptoms mentioned above were noted. The highest percentage (44 percent) of mothers in Upper Dir indicated that they took their children to a public health facility and 28 percent to seek treatment at a private health facility. However, 17 percent of the women interviewed indicated that they did not seek any treatment (see figure 7.23).

Figure 7.23: $\quad$ Place where treatment was sought for newborn complications

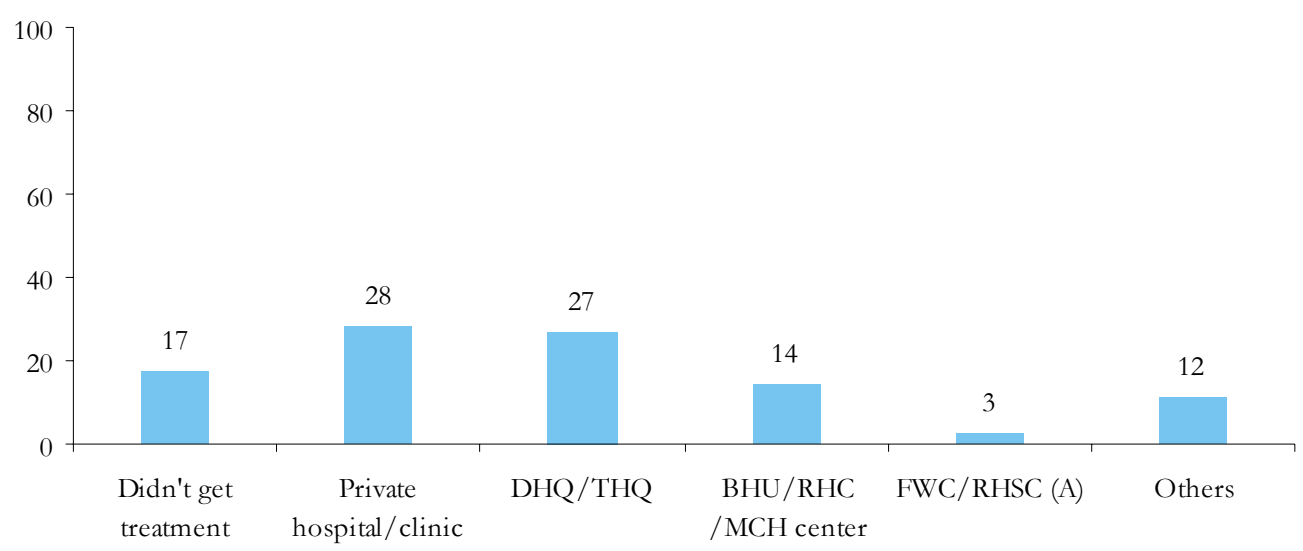

Respondents were asked to indicate the status of health of their last child. Over 97 percent of the children were still alive. Almost three-quarters of women in Upper Dir were still breastfeeding their children at the time of the survey.

A large percentage (70 percent) of the respondents indicated that their children had been healthy during the last two weeks and had not suffered from acute respiratory illnesses. However, almost 35 percent of the children under three years of age had had at least one episode of diarrhea during the last two weeks.

Figure 7.24: $\quad$ Status and bealth of last live birth

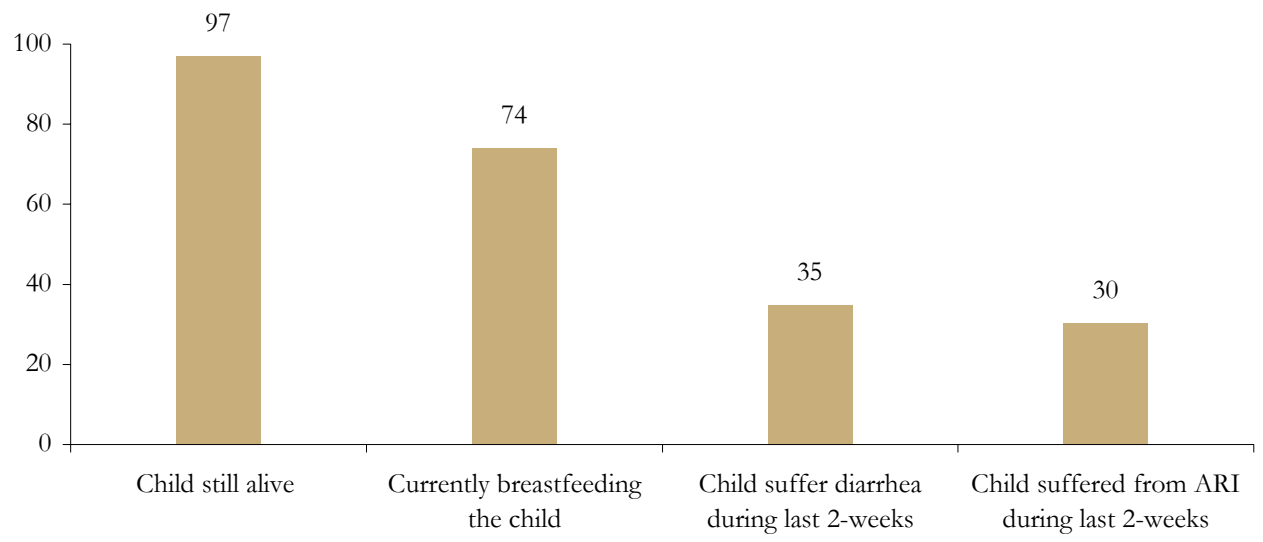





\section{Chapter (8)}

\section{Conclusions}

The baseline household survey conducted in Upper Dir is an essential tool in the process of understanding the different attitudes towards, and misconceptions regarding, pregnancy and neonatal care. Since PAIMAN is intended to improve the health of all pregnant women as well as their newborn children, it is important to understand the obstacles that stand in the way of good health. The baseline survey is based largely on the opinions and experiences of married women of reproductive age (MWRA), the very individuals who are to be the primary recipients of the work carried out through PAIMAN.

The overall age-sex distribution in Upper Dir shows a sex ratio of 95 males for every 100 females; whereas the ratio was 102 males to 100 females in the 1998 Population Census. This may be due to the improvement in the overall enumeration of the female population in individual households. Another sign of improvement is in marital status which clearly demonstrates a delay in age at marriage for females compared to the 1998 Population Census. However, women still tend to get married earlier than men. On average in Upper Dir, there are 4.2 children ever born and 3.2 living children.

Findings also show that approximately 28 percent of the population in the district of Upper Dir has access to some sort of media; whether it is television, radio or newspapers. While it may be easy to reach this portion of the population through one of the three main media channels, there are some obstacles that stand in the way including the lack of decision-making power for women and the infrequency of access to media. Also, the approximately 72 percent of the population that do not have access to any sort of media would need to be reached through other channels.

Regarding antenatal care, an overwhelming majority (88 percent) believe it necessary for women to receive antenatal check-ups. Therefore, it is quite clear that while many women do want to receive antenatal check-ups, and feel that it is a necessary part of neonatal care, many are not able to access this service. Findings show that all the major issues were discussed with a majority of the women during their antenatal visits.

Respondents were asked to indicate which complications during pregnancy they believe are dangerous and require medical attention. The findings show that about 70 percent of the women interviewed reported having experienced some complication during pregnancy.

The baseline findings show that over 40 percent of the pregnant women in Upper Dir did in fact receive TT shots during their last pregnancy. Furthermore, 36 percent of the women interviewed indicated that they took iron/folate supplements during their last pregnancy. 
While it seems that many women in Upper Dir do deliver through SBAs, many deliver their babies at home. This may happen when women are not able to make decisions independently, and must be dependant instead upon their husbands or in-laws. However, most of the respondents claimed that they had arranged for transport, money, and hospital fees etc. prior to the time of delivery, therefore eradicating any major delays.

About 50 percent of the respondents in Upper Dir indicated that they experienced 'severe lower abdominal pain' during their last pregnancy, while 'severe headaches' were reported by 30 percent of the population. Approximately 23 percent and 22 percent of the population reported severe/prolonged vomiting and fever respectively.

Married women in Upper Dir generally undervalue the importance of postnatal care. Almost 83 percent of the women in Upper Dir received no postnatal check-ups during their last pregnancy, whereas only about 14 percent claimed to have sought postnatal care. Although baseline survey findings indicate that excessive vaginal bleeding is the most known danger sign during the postpartum period, not all women were aware of this fact. Unfortunately, many women are unaware of danger signs that may appear in newborns, especially in the first seven days after delivery. The postpartum period is a critical time for mother and newborn. A very large portion of the married women did not receive any postnatal check-ups after their last pregnancy.

A very large percentage of the population indicated that they received their pregnancy-related information from their in-laws, family members and friends. Only 10 percent of the women in Upper Dir indicated that a Lady Health Worker was the source of their information.

The lack of transport to a health facility is a major cause of delay and can often lead to maternal and newborn mortality. It is very important to arrange transport ahead of time in order to eliminate that delay. Unfortunately, many households are unable to do so due to a lack of transportation in their communities. Most communities do not have any arrangements made for transport, provision of blood and finances for women at the time of need during delivery. This is a major obstacle to safe birth practices, as women are then forced to deliver at home, and may be exposed to infections and complications. Birth preparedness promotes the arrangement of such aspects.

Baseline results indicate that 16 percent of married women use contraception in Upper Dir. Furthermore, 14 percent of married women use modern methods and 2 percent use traditional methods.

The various sections of the survey allow for a comprehensive analysis of all areas concerned with maternal and infant health and well-being. The separation of rural and urban areas makes it easier to compare results, and analyze the reasons behind the differences. The indicators obtained will be used to monitor and evaluate the success of the project upon completion. 


\section{References}

Caldwell, J., Routes to Low Mortality in Poor Countries. Population and Development Review, Vol. 12, No. 2. (Jun., 1986), pp. 171-220.

Federal Bureau of Statistics, "Socio-Economic Indicators at District Level, Punjab," Statistics Division, Government of Pakistan, (2002).

Hollander, D., Antenatal Education Helps Turkish Women Adopt Health-Promoting Behaviour. International Family Planning Perspectives, Vol. 30, No. 1. (Mar., 2004), pp. 45-46.

JHPIEGO/Maternal and Neonatal Health Program, "Monitoring Birth Preparedness and Complication Readiness: Tools and Indicators for Maternal and Newborn Health," (2004).

Mahmood, Arshad, Determinants of Neonatal and Post-Neonatal Mortality in Pakistan. The Pakistan Development Review, Vol. 41, No. 4, Part II (Winter 2002), pp. 723-744.

Mahmood, Arshad, Socioeconomic Factors, Personal Illness Control and Infant and Child Mortality in Pakistan. Pakistan Population Review, Vol. 3, No. 1 (1992), pp. 67-86.

Martin, Linda G.; J. Trussell; Florentina Reyes Salvail; Nasra M. Shah, Co-variates of Child Mortality in the Philippines, Indonesia, and Pakistan: An Analysis Based on Hazard Models. Population Studies, Vol. 37, No. 3. (Nov., 1983), pp. 417-432.

Nawaz, Shuja, The Mass Media and Development in Pakistan. Asian Survey, Vol. 23, No. 8. (Aug., 1983), pp. 934-957.

Ringheim, Karin, When the Client is Male: Client-Provider Interaction from a Gender Perspective, International Family Planning Perspectives, Vol. 28, No. 3 (Sept., 2002), pp. 170-175.

Robbins, P.T., Global Approaches to Development. Sociology of Development, University of London, (2001), pp. 29-37.

Sathar, Zeba; Nigel Crook; Christine Callum; Shahnaz Kazi, Women's Status and Fertility Change in Pakistan. Population and Development Review, Vol. 14, No. 3. (Sep., 1988), pp. 415432.

Simmons, George B., Family Planning Programs or Development: How Persuasive is the New Wisdom? International Family Planning Perspectives, Vol. 5, No. 3. (Sep., 1979), pp. 101-110.

Syed, Sabiha H., Communications Channels and Family Planning in Pakistan. Studies in Family Planning, Vol. 10, No. 2. (Feb., 1979), pp. 53-60.

www.unesco.org 